
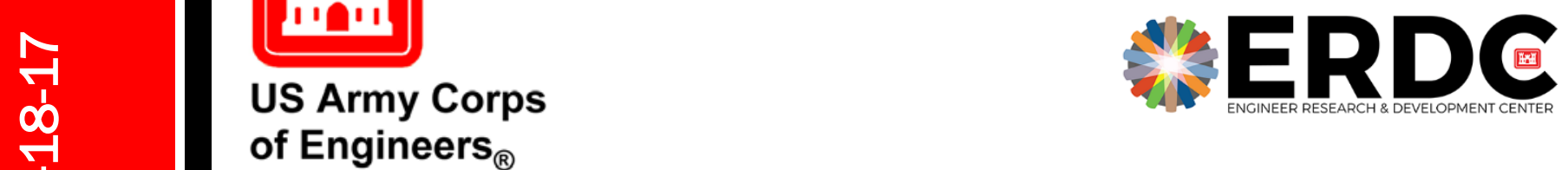

Engineer Research and

Development Center

Army 6.2 Applied Sciences Research Program

\title{
Snow Strategic Science Plan
}

Carrie M. Vuyovich, Elias J. Deeb, Christopher Polashenski,

September 2018

Zoe R. Courville, Christopher A. Hiemstra, Anna M. Wagner, John B. Eylander, and Robert E. Davis

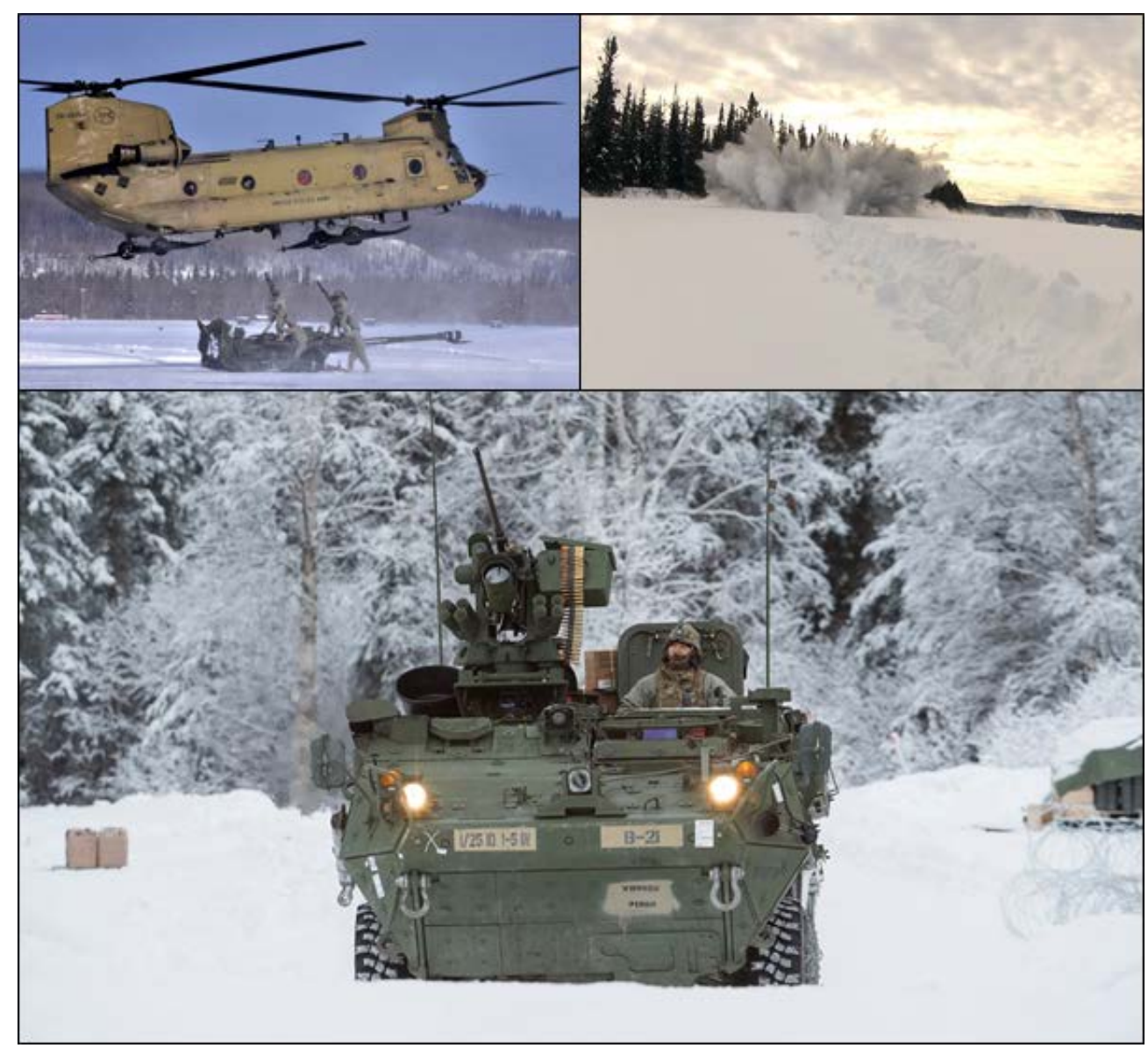

Approved for public release; distribution is unlimited. 
The U.S. Army Engineer Research and Development Center (ERDC) solves the nation's toughest engineering and environmental challenges. ERDC develops innovative solutions in civil and military engineering, geospatial sciences, water resources, and environmental sciences for the Army, the Department of Defense, civilian agencies, and our nation's public good. Find out more at www.erdc.usace.army.mil.

To search for other technical reports published by ERDC, visit the ERDC online library at http://acwc.sdp.sirsi.net/client/default.

Cover photos: Clockwise from upper right, (a) U.S. Soldiers hook up 155mm Howitzer to a $\mathrm{CH}-47$ Chinook helicopter (photo by John Pennell) ${ }^{1}$, (b) Explosive impacts in snow-covered terrain (photo uncredited) ${ }^{2}$, (c) U.S. Army Stryker Brigade Combat Team prepares for training aimed at Arctic operations (photo by Alejandro Pena). ${ }^{3}$

${ }^{1}$ https://www.dvidshub.net/image/4204597/arctic-artillery-goes-flying

2 http://www.jber.jb.mil/News/Photos/igphoto/2000071566/

${ }^{3}$ http://www.jber.jb.mil/News/Photos/igphoto/2001879711/ 


\section{Snow Strategic Science Plan}

Carrie M. Vuyovich, Elias J. Deeb, Christopher Polashenski, Zoe R. Courville,

Christopher A. Hiemstra, Anna M. Wagner, John B. Eylander, and Robert E. Davis

Cold Regions Research and Engineering Laboratory

U.S. Army Engineer Research and Development Center

72 Lyme Road

Hanover, NH 03755

Final report

Approved for public release; distribution is unlimited.

Prepared for U.S. Army Corps of Engineers

Washington, DC 20314-1000

Under Army Program Element 0603734A, “Military Engineering Advanced

Technology" 


\section{Abstract}

The U.S. Department of Defense (DoD) requires global terrestrial, atmospheric, and environmental awareness to support civil works and warfighting functions. Snow is a critical component of environmental awareness that can change rapidly and impacts DoD operations. Domestically, the U.S. Army Corps of Engineers (USACE), requires information on snow to develop accurate and timely hydrologic forecasts for water resource allocation, infrastructure design and construction, and flood forecasting. Abroad, DoD requires snow information for mission planning and operations.

The purpose of this document is to outline a plan for future research designed to improve snow characterization capabilities and meet identified data needs. A primary goal is to bring snow characterization efforts together in a system-based approach that will result in highly accurate global snow estimates.

The intent is to identify specific development pathways which can provide application-oriented information to take full advantage of the existing state of the science, and push the limits of research.

The technology gaps for snow operational support were placed into four broad categories for discussion. Short-through-long-term plans for improvement were identified and specific goals towards this plan were set.

DISCLAIMER: The contents of this report are not to be used for advertising, publication, or promotional purposes. Citation of trade names does not constitute an official endorsement or approval of the use of such commercial products. All product names and trademarks cited are the property of their respective owners. The findings of this report are not to be construed as an official Department of the Army position unless so designated by other authorized documents. 


\section{Contents}

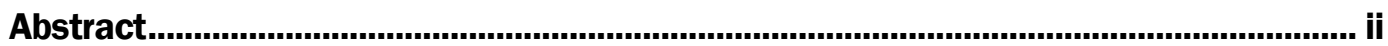

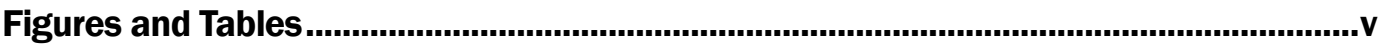

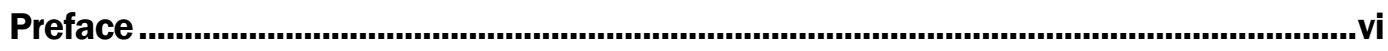

Unit Conversion Factors.................................................................................................vii

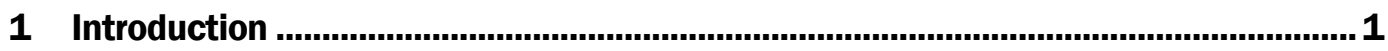

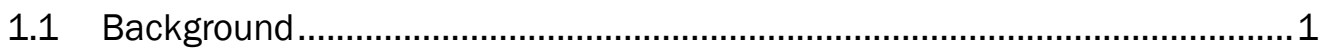

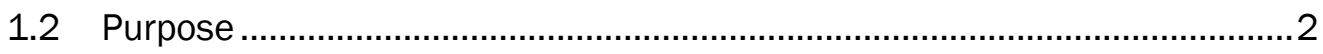

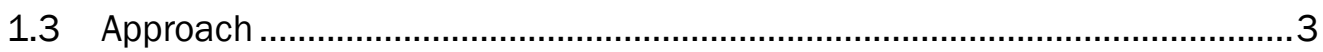

2 DoD Operational Requirements for Snow Characterization ...................................... 4

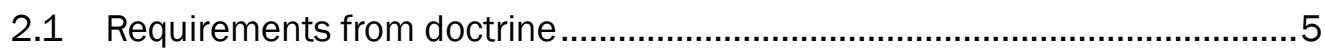

2.2 Requirements analysis........................................................................ 7

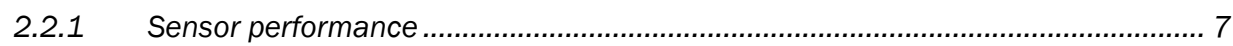

2.2.2 Mobility .............................................................................................. 10

2.2.3 Military infrastructure, civil works, and stability operations ................................. 12

3 Current State of Operational Snow Characterization ...........................................14

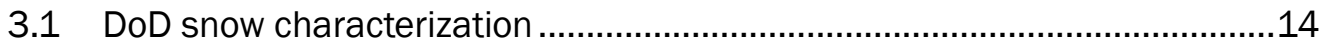

3.2 Other operational snow characterization systems .....................................17

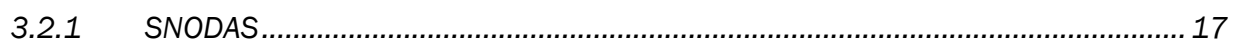

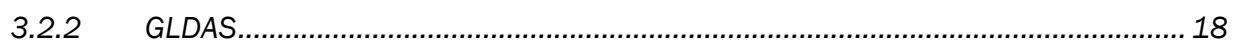

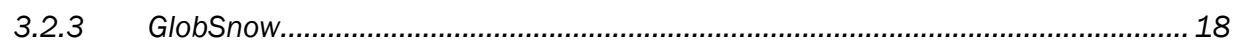

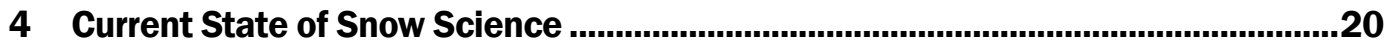

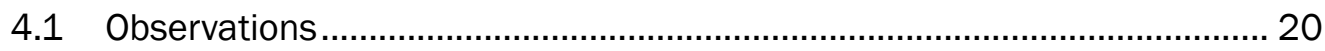

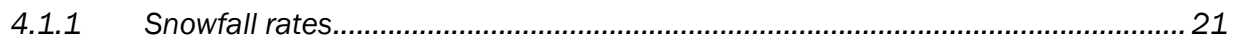

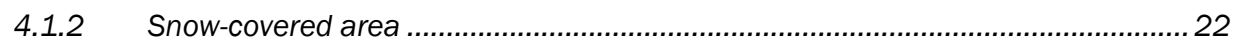

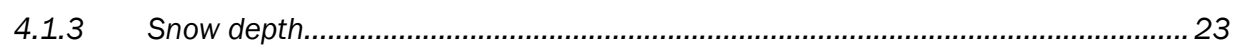

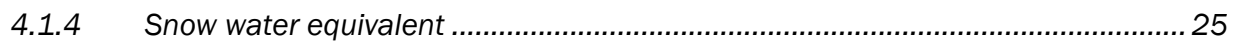

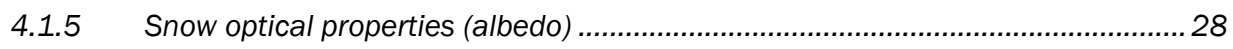

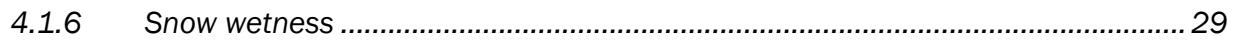

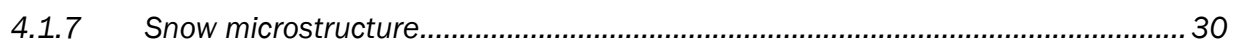

4.1.8 Snow strength and snow density ................................................................ 31

4.2 Snow spatial distribution and data merging .......................................... 32

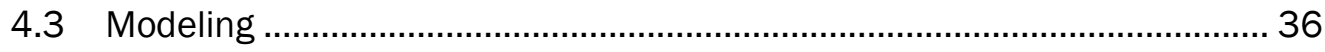

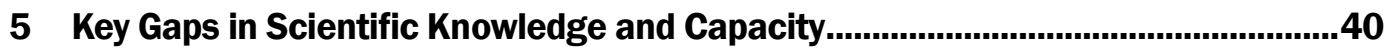

5.1 Remote sensing: signal processing and algorithm development............... 40

5.2 Ground observations: improved collection, sharing and archiving ............. 46

5.3 Data assimilation and spatial scaling .................................................. 48 
5.4 Process studies and model parameterization .......................................... 50

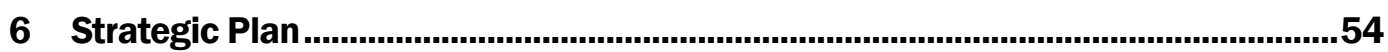

6.1 Improve current real-time snow characterization ( 1 - 3 years).................. 55

6.2 Advance data merging and assimilation capabilities (2 - 5 years) ............ 56

6.3 Operational snow characterization framework (more than 5 years)........... 58

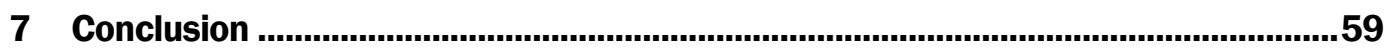

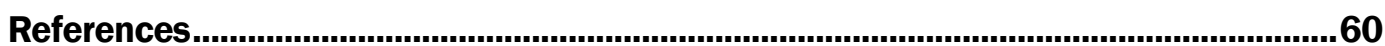

\section{Report Documentation Page}




\section{Figures and Tables}

\section{Figures}

Figure 1. The six warfighting functions: Mission Command, Movement and Maneuvers, Intelligence, Fires, Sustainment, and Protection. Linked by a common purpose. (U.S. Army 2012).

Figure 2. Modeled HMMWV (High Mobility Multipurpose Wheeled Vehicle) mobility for Afghanistan depicted maximum vehicle speed and taking into account average January snow estimates.

Figure 3. Northern hemisphere snow cover likelihood (October through May, 1995-2016) based on snow extents products from optical satellite remote sensing products.

Figure 4. Snow-covered area for the snow-impacted watersheds of Afghanistan estimated from the VIIRS instrument aboard the Suomi-NPP satellite.

Figure 5. Historical (1987 to present) passive microwave satellite assessment of snow water equivalent for the largest snow-impacted watershed in Afghanistan (Amu Darya). Chart shows the historical max/min, average, and standard deviation across the winter accumulation andspring ablation season. For perspective, the annual SWE trend for last season (2016-2017) is shown alongside the current year (2017-2018) as of 18 March 2018.

Figure 6. Simulated 1 March snow depth for Hubbard Brook Experimental Forest (New Hampshire, USA) for years 2000 to 2013.

Figure 7. Matrix of the spatial (snow class), temporal (seasonal), and wavelength dependence on the scientific knowledge and research gaps in the remote sensing of snow.

\section{Tables}

Table 1. Snow data requirements summarized by warfighting functional area.

Table 2. The relationship between primary mission planning variables and scientific snow metrics.

Table 3. Current snow science capabilities: ongoing applied research, TRL 3-5 (green); potential/basic research, TRL 2 (orange); identified research gap, TRL 1 (red), N/A (gray). 


\section{Preface}

This study was conducted for HQUSACE to support two work units: Army Terrestrial Environmental Modeling and Intelligence System (ARTEMIS) under the Army 6.2 Applied Sciences Research Program, and Snow Research to Support Mission Planning and Operations under U.S. Army Program Element 0603734A, Military Engineering Advanced Technology, to determine and establish the state of art in snow research from the perspective of Army requirements and applications, to develop techniques for obtaining snow/ice properties, to prepare a database on snow and environment conditions to support modeling and simulation, to develop and test current and emerging concepts of vehicle platforms, sensing systems and planning/decision aids, and to support collaborative work. The technical monitor for this project was Mr. David Finnegan, Director of the Remote Sensing and GIS Center of Expertise (RSGISCX), CRREL.

The work was led by the Remote Sensing and Geographic Information Systems Center of Expertise (CEERD-RS), U.S. Army Engineer Research and Development Center, Cold Regions Research and Engineering Laboratory (ERDC-CRREL). At the time of publication, Mr. David Finnegan was Chief, CEERD-RS. The Deputy Director of ERDC-CRREL was Mr. David B. Ringelberg, and the Director was Dr. Joseph L. Corriveau.

The authors would like to acknowledge the individuals who reviewed and provided significant input on this report, including Ms. Mary Jo Brodzik, NSIDC; Dr. Ned Bair, UCSB; Dr. Jennifer Jacobs, University of New Hampshire; Dr. Theodore Letcher, ERDC-CRREL; Dr. Glen Liston, Cooperative Institute for Research in the Atmosphere (CIRA), Colorado State University (CSU); Dr. Sujay Kumar, SAIC and NASA Goddard; Dr. Jerry Wegiel, SAIC and NASA Goddard; Mr. Nathan Wright, $16^{\text {th }}$ Weather Squadron (16WS/WXNC), 557 $7^{\text {th }}$ Weather Wing (557WW); Ms. Julie Parno, ERDC-CRREL; and Mr. Peter Gadomski, ERDC-CRREL.

COL Ivan P. Beckman was the Commander of ERDC, and Dr. David W. Pittman was the Director. 


\section{Unit Conversion Factors}

\begin{tabular}{|c|c|c|}
\hline Multiply & By & To Obtain \\
\hline degrees Fahrenheit & $(\mathrm{F}-32) / 1.8$ & degrees Celsius \\
\hline feet & 0.3048 & Meters \\
\hline inches & 0.0254 & meters \\
\hline knots & 0.5144444 & meters per second \\
\hline miles (U.S. statute) & $1,609.347$ & meters \\
\hline miles per hour & 0.44704 & meters per second \\
\hline ounces (mass) & 0.02834952 & kilograms \\
\hline ounces (U.S. fluid) & 2.957353 E-05 & cubic meters \\
\hline
\end{tabular}


This page intentionally blank. 


\section{Introduction}

\subsection{Background}

The U.S. Department of Defense (DoD) requires global terrestrial, atmospheric, and environmental awareness to support civil works and warfighting functions. Snow is a critical component of environmental awareness that can change rapidly and profoundly impact DoD operations. Domestically, the U.S. Army Corps of Engineers (USACE), under the auspices of the DoD, requires information on snow to develop accurate and timely hydrologic forecasts for water resource allocation, infrastructure design and construction, and flood forecasting. On 30 to 50\% of Earth's land area, runoff processes are dominated by snow in mountainous, temperate, boreal, and Arctic environments. Abroad, the Army requires snow information for mission planning and operations. Army warfighter functions are impacted by snow in ways ranging from hampered mobility to limited sensor performance. These impacts are highly dynamic because snow is a spatially variable and temporally evolving boundary condition. Accurate and timely snow condition information is critical to mitigating these impacts.

Providing the cold regions environmental awareness that DoD mission planners require is challenging because critical snow characteristics can be difficult to accurately observe or estimate. This characteristic is exacerbated by the fact that areas with the sparsest observations overlap where precipitation falls primarily as snow. Despite decades of research efforts, no single observational technique or modeling approach provides global snow data with the accuracy and resolution required to meet the DoD's terrestrial environmental awareness needs. An emerging consensus indicates the best way to meet those needs is likely a physics-based modeling framework that assimilates multi-scale in situ and remotely sensed observations. A synthesis of observational and modeling capabilities is necessary to meet DoD's increasingly sophisticated demands for environmental awareness.

In October 2017, the Army released a strategy to modernize the organization to meet the advanced challenges facing the nation. Six Army Modernization Priorities were identified to increase the Army's capabilities and 
readiness against emerging threats. These include Long Range Precision Fires; Next Generation of Combat Vehicles; Future Vertical Lift; Army Network, Control, Communication and Intelligence; Air and Missile Defense; and Soldier Lethality. Snow has the potential to impact five of these six priority areas (Air and Missile Defense is not impacted), underscoring the need for improved environmental awareness to inform rapid decision support and long-term planning.

\subsection{Purpose}

The purpose of this document is to outline a near- to medium-term plan for future research designed to improve DoD snow characterization capabilities and meet identified data needs. A primary goal is to bring DoD snow characterization efforts together in a system-based approach that will result in highly accurate global snow estimates. In support of this purpose, this document does the following:

1. Evaluates the operational requirements for snow characterization.

2. Describes the state of DoD snow characterization capabilities and compares them to existing requirements and identifies associated needs.

3. Describes the current state of scientific knowledge and identifies existing knowledge ready for transition from research to operational products.

4. Identifies gaps in fundamental and applied science that, if filled, could advance snow characterization.

5. Provides a near- to medium-term plan to fill knowledge gaps and transition existing knowledge into operational tools to meet current and future DoD needs.

This plan is intended to be an outline for basic and applied research conducted through partnerships between the U.S. Army Engineer Research and Development Center (ERDC), the Air Force 557 Weather Wing (557WW), other DoD organizations, the National Aeronautics Space Administration (NASA) and university partners. As the leader in cold regions expertise for the U.S. Army Corps of Engineers (USACE), ERDC's Cold Regions Research and Engineering Laboratory (CRREL) will coordinate snow research and transition improvements in snow science toward operational efforts led by federal partners. 


\subsection{Approach}

Research efforts to support global snow estimation will be organized around the goal of transitioning knowledge directly into a Land Information System (LIS), an advanced software framework that enables the integration of a wide range of datasets and model advancements available from the research community. These efforts will provide the groundwork for continued migration toward a mature LIS capable of providing snow characterization products optimally tuned to support battlefield-to-watershed scale requirements, as well as various Tactical Decision Aids (TDAs). This planning document addresses specific areas of interest to the DoD Community outlined in numerous requirements and planning documents. The intent is to identify specific development pathways which can (1) provide robust, realistic, and application-oriented information to take full advantage of the existing state of the science, and (2) push the limits of research to address the most stringent DoD requirements. 


\section{DoD Operational Requirements for Snow Characterization}

The direct impact of snow on critical warfighting tasks demands that relevant information be available and incorporated seamlessly into existing information networks and environmental planning tools. The data should be presented in a coherent environmental awareness platform with a focus on mission impacts. Variables presented must be those directly applicable to mission (e.g. visibility, vehicle accessibility), rather than snow science variables (e.g. suspended load, snow surface strength). A variety of timescales must be accessible. Near real-time observations and short-term forecasts are critical for interpreting intelligence, analyzing sensor data, and adaptive routing. Climatological data and long-term predictions are needed for infrastructure design and equipment investment decisions, as well as to provide historical context. Underlying an accurate system, however, must be scientific measures of snow variables that realistically interact with the rest of the forecast and environmental awareness system. The primary snow variables needed to feed into a robust environmental awareness tool include snow depth, snow water equivalent (SWE), snow-covered area (SCA), snowfall rates, snow microstructure, snow wetness, snow strength/ bonding, and snow optical properties (e.g. albedo), which are described in Section 4 .

In this section, DoD's requirements for snow information are analyzed, based on the Army's warfighting functional areas, which are defined by common tasks and systems to support specific mission objectives. There are six warfighting functions - Mission Command, Movement and Maneuvers, Intelligence, Fires, Sustainment, and Protection - that are linked by a common purpose (Figure 1). Snow can impact all warfighting functions within Army operations, from mission planning in cold regions to sustained support following operations. The purpose of this exercise is to detail the impacts of snow on operational tasks and to describe the information about snow conditions required for mission success. The alignment of warfighter needs with snow information enables us to prioritize DoD snow science needs, compare needs to the current state of the science, and recommend research directions. 
Figure 1. The six warfighting functions: Mission Command, Movement and Maneuvers, Intelligence, Fires, Sustainment, and Protection. Linked by a common purpose. (U.S. Army 2012)

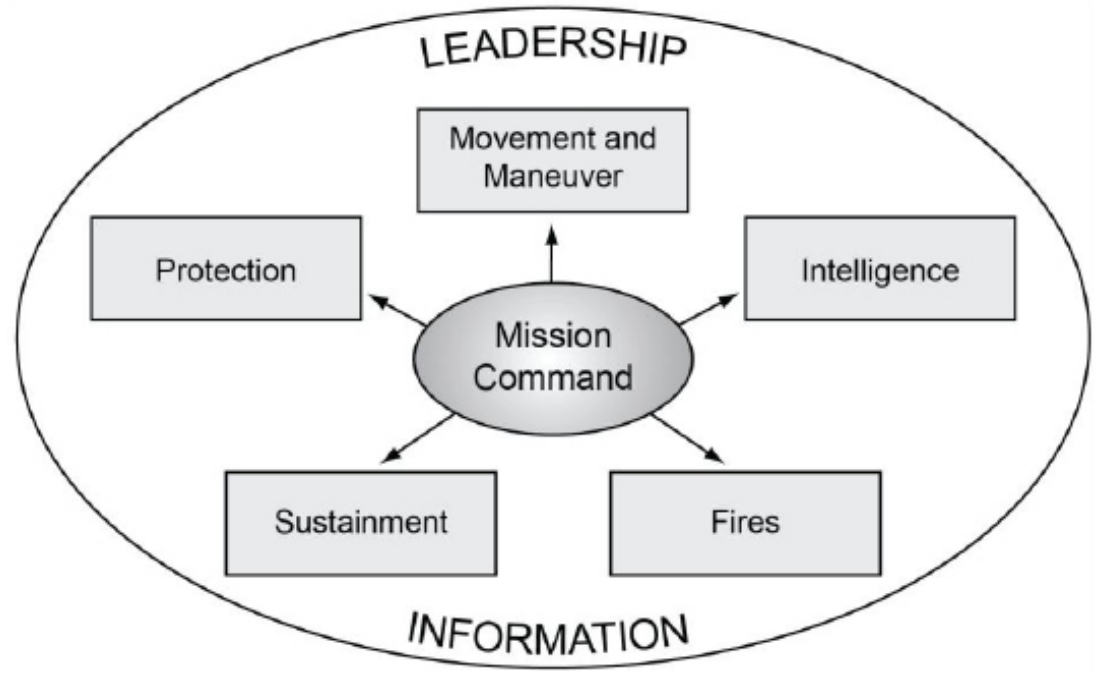

\subsection{Requirements from doctrine}

Several DoD documents which describe specific requirements to support and sustain missions in cold regions related to snow were reviewed in the development of the strategic plan (listed below). Each of the requirements evaluated demands information on snow conditions for operations in cold regions to be successful. An analysis of these documents as they pertain to the warfighting functional areas is presented in Table 1.

1. General Engineering, ATP 3-34.40, U.S. Army, February 2015

2. Combined Arms Countermobility Operations, ATP 3-90.8, U.S. Army, September 2014

3. Geospatial Engineering, ATP 3-34.80, U.S. Army, February 2017

4. Intelligence Preparation of the Battlefield/Battlespace, ATP 2-01.3, U.S. Army, November 2014

5. Brigade Combat Team Intelligence Techniques, ATP 2-19.4, U.S. Army, February 2015

6. Field Artillery Target Acquisition, ATP 3-09.12, U.S. Army, July 2015

7. DCGS-A (Distributed Common Ground System - Army) Increment 2, U.S. Army, March 2016

8. Army Weather Requirements:

9. Weather Support and Services for the US Army, AR 115-10, March 2017

10. Army Weather Functional Activities, AR 5-25, October 2016 
11. Prevention of Heat and Cold Casualties, TRADOC Regulation 350-29, U.S. Army, July 2016

12. Mountain Warfare and Cold Weather Operations, ATP 3-90.97, U.S. Army, April 2016

13. USACE Civil Works Strategic Plan (2014 - 2018), February 2015.

14. USACE Engineering Manual 1110-2-1406 Runoff from Snowmelt

15. USACE Engineering Manual 1110-2-1417 Flood-Runoff Analysis

16. USACE Campaign Plan FY18-22, June 2017

Table 1. Snow data requirements summarized by warfighting functional area.

\begin{tabular}{|c|c|c|c|c|}
\hline $\begin{array}{l}\text { Functional } \\
\text { Area }\end{array}$ & Operational Task & $\begin{array}{l}\text { Impact of snow on } \\
\text { Operations }\end{array}$ & $\begin{array}{c}\text { Snow Data } \\
\text { Requirements }\end{array}$ & $\begin{array}{l}\text { Supporting } \\
\text { Documents }\end{array}$ \\
\hline Protection & $\begin{array}{l}\text { Detection of adversary, } \\
\text { Mine/countermine } \\
\text { deployment, Concealment and } \\
\text { surveillance }\end{array}$ & $\begin{array}{l}\text { Sensor failure, Early or failed } \\
\text { mine detonation, Alternative } \\
\text { concealment, detection and } \\
\text { surveillance techniques } \\
\text { required }\end{array}$ & $\begin{array}{l}\text { Electromagnetic } \\
\text { signatures of snow at } \\
\text { various wavelengths, } \\
\text { Snow depth, Albedo, } \\
\text { Snowfall }\end{array}$ & $2,5,8,9$ \\
\hline $\begin{array}{l}\text { Movement } \\
\text { and Mobility }\end{array}$ & $\begin{array}{l}\text { Movement of vehicles and } \\
\text { equipment, Helicopter Landing } \\
\text { Zones (HLZ), Dismounted troop } \\
\text { movement }\end{array}$ & $\begin{array}{l}\text { Visibility, Ability to traverse } \\
\text { terrain, Mobility through deep } \\
\text { snow, Ability to land, Adverse } \\
\text { physical conditions, Travel } \\
\text { time, Water crossings } \\
\text { impacted by high water and } \\
\text { ice, Route blockage } \\
\text { Avalanche potential }\end{array}$ & $\begin{array}{l}\text { Climatology, Snow } \\
\text { distribution, Snow } \\
\text { strength, Snow depth, } \\
\text { Blowing snow }\end{array}$ & $2,3,5,8,10$ \\
\hline Fires & $\begin{array}{l}\text { Land-based and airborne fire } \\
\text { support, Deploy weapons } \\
\text { systems, Target acquisition }\end{array}$ & $\begin{array}{l}\text { Site access, Sensor } \\
\text { performance, Visibility }\end{array}$ & $\begin{array}{l}\text { Snow depth, Snow } \\
\text { strength, Signature } \\
\text { response of snow at } \\
\text { various wavelengths, } \\
\text { Snowfall }\end{array}$ & $5,6,10$ \\
\hline Intelligence & $\begin{array}{l}\text { Mission Planning, Terrain } \\
\text { analysis, Communications }\end{array}$ & $\begin{array}{l}\text { Sensor performance, Site } \\
\text { access, Travel times, Ability to } \\
\text { traverse terrain, Mobility } \\
\text { through deep snow }\end{array}$ & $\begin{array}{l}\text { Snow depth, } \\
\text { Snowfall, Signatures } \\
\text { of snow at various } \\
\text { wavelengths, Snow } \\
\text { distribution, Snow } \\
\text { strength }\end{array}$ & $4,5,7,10$ \\
\hline Sustainment & $\begin{array}{l}\text { Health and personnel services, } \\
\text { Construction and maintenance } \\
\text { of transportation systems, e.g. } \\
\text { airfields, road and railways, } \\
\text { Design and maintenance of } \\
\text { major facilities and base } \\
\text { camps. }\end{array}$ & $\begin{array}{l}\text { Adverse working conditions, } \\
\text { Additional equipment } \\
\text { required for snow removal, } \\
\text { Increased work time } \\
\text { estimates, Snowmelt } \\
\text { drainage, Snow loads, Drifting } \\
\text { snow }\end{array}$ & $\begin{array}{l}\text { Snow climatology, } \\
\text { Snow distribution, } \\
\text { Snow depth, SWE, } \\
\text { Snow melt, Blowing } \\
\text { snow }\end{array}$ & 1,9 \\
\hline
\end{tabular}




\subsection{Requirements analysis}

The impacts of snow on warfighting functions are summarized in terms of three task groupings that crosscut warfighting functions: Sensor Performance, Mobility, and Military Infrastructure. Each of these task groupings requires a specific set of snow property information to mitigate impacts on operations, which are discussed in more detail below. Mission command requires tools that integrate snow information seamlessly into the planning process to maximize success across all functions. Snow information needed for domestic civil works and stability operations is similar to that required by Sustainment, and is therefore grouped with Military Infrastructure. The relationship between primary mission planning variables and scientific snow metrics are listed in Table 2.

\subsubsection{Sensor performance}

Snow impacts sensor performance, affecting Fires, Intelligence, and Protection warfighter functions by altering the electromagnetic, radar, thermal, and acoustic signatures of the battlefield environment. These impacts map to the Army Modernization Priorities in the areas of Long Range Precision Fires, Army Network, Control, Communication and Intelligence, and Soldier Lethality. Alterations in these signals directly hamper the ability to acquire targets with radar and electro-optical means, gather intelligence (e.g. due to snow concealment and communications attenuation), and detect surface and subsurface features (e.g. mines). In situ sensor performance, most generally related to Protection, may be impacted when snow accumulation obscures apertures of acoustic monitors and surveillance cameras, or triggers intrusion sensors or mines. However, snow may also create opportunities to discriminate targets in alternate spectra and conceal force activities. The primary snow properties that affect signature spectra are snow microstructure, albedo, density, depth, layering, and wetness. This section is organized by signature frequency to describe how snow impacts specific sensor types. 
Table 2. The relationship between primary mission planning variables and scientific snow metrics.

\begin{tabular}{|c|c|c|c|c|c|c|c|c|c|c|c|c|}
\hline \multirow[b]{3}{*}{ Task } & \multirow[b]{3}{*}{$\begin{array}{l}\text { Decision Support } \\
\text { Variable }\end{array}$} & \multirow[b]{3}{*}{$\begin{array}{l}\text { Real- } \\
\text { time }\end{array}$} & \multirow{2}{*}{\multicolumn{2}{|c|}{ Timescale }} & \multicolumn{8}{|c|}{ Snow Variables } \\
\hline & & & & & \multirow{2}{*}{\begin{tabular}{|l} 
Flux \\
\\
Snowfall \\
Rates
\end{tabular}} & \multicolumn{3}{|l|}{ Amount } & \multicolumn{4}{|c|}{ Physical Properties } \\
\hline & & & Forecast & Climatology & & $\begin{array}{l}\text { Snow } \\
\text { Covered } \\
\text { Area } \\
\text { (SCA) }\end{array}$ & $\begin{array}{l}\text { Snow } \\
\text { Depth }\end{array}$ & SWE & $\begin{array}{c}\text { Optical } \\
\text { Properties }\end{array}$ & Wetness & $\begin{array}{c}\text { Micro- } \\
\text { structure }\end{array}$ & Strength \\
\hline \multicolumn{13}{|l|}{ Sensor Performance } \\
\hline Target/Adversary Detection & $\begin{array}{l}\text { Sensor efficacy, radar, electro- } \\
\text { optical signatures }\end{array}$ & $x$ & $x$ & & $x$ & & $x$ & $\mathrm{x}$ & $x$ & $x$ & $x$ & \\
\hline Force Concealment & $\begin{array}{l}\text { Camouflage efficacy, } \\
\text { background electromagnetic } \\
\text { signatures, acoustic } \\
\text { attenuation }\end{array}$ & $\mathrm{x}$ & $x$ & $x$ & $\mathrm{x}$ & & $\mathrm{x}$ & $\mathrm{x}$ & $x$ & $\mathrm{x}$ & $\mathrm{x}$ & \\
\hline Terrain Analysis & $\begin{array}{l}\text { Ground state, terrain/ } \\
\text { vegetation discrimination }\end{array}$ & $\mathrm{x}$ & $x$ & $x$ & $\mathrm{x}$ & $\mathrm{x}$ & $\mathrm{x}$ & & $x$ & $x$ & $\mathrm{x}$ & \\
\hline Buried Threat Detection & $\begin{array}{l}\text { Thermal and radar signal } \\
\text { attenuation }\end{array}$ & $\mathrm{x}$ & & & $x$ & & $\mathrm{x}$ & $x$ & & $x$ & $x$ & $x$ \\
\hline Surveillance Sensors/Mine performance & Burial, tripwire function & $\mathrm{x}$ & $\mathrm{x}$ & & & & $\mathrm{x}$ & & & & & \\
\hline Communications & Signal attenuation & $x$ & & & $x$ & & $x$ & $x$ & & $\mathrm{x}$ & $x$ & \\
\hline \multicolumn{13}{|l|}{ Mobility } \\
\hline \multicolumn{13}{|l|}{ Austere Entry } \\
\hline Over Snow Travel & $\begin{array}{l}\text { Snow load bearing capacity, } \\
\text { traction, depth }\end{array}$ & $\mathrm{x}$ & $x$ & $x$ & $x$ & $x$ & $x$ & & & $x$ & $x$ & $x$ \\
\hline Avalanche Hazards & Snowpack Stability & $x$ & $x$ & & $x$ & $\mathrm{x}$ & $x$ & & & $x$ & $x$ & $x$ \\
\hline Helicopter Landing Zones & $\begin{array}{l}\text { Rotorwash/visibility, snow } \\
\text { load bearing capacity }\end{array}$ & $\mathrm{x}$ & $x$ & & $x$ & $\mathrm{x}$ & $x$ & & & & $x$ & $x$ \\
\hline \multicolumn{13}{|l|}{ Travel on Improved Surfaces } \\
\hline Surface Movements & $\begin{array}{l}\text { Trafficability, Snow Removal } \\
\text { needs, Visibility }\end{array}$ & $\mathrm{x}$ & $\mathrm{x}$ & & $\mathrm{x}$ & & $x$ & & & & & $x$ \\
\hline Aircraft Landings & Visibility, Snow depth & $x$ & $x$ & & $x$ & & $x$ & & & & & $x$ \\
\hline Vehicle Design & Traction, Rolling Resistance & & & $\mathrm{x}$ & & $\mathrm{x}$ & $x$ & & & & $\mathrm{x}$ & $\mathrm{x}$ \\
\hline \multicolumn{13}{|c|}{ Military Infrastructure/Civil Works/Stability Operations } \\
\hline Emergency/Flooding Management & $\begin{array}{l}\text { Melt discharge/river flow } \\
\text { rates }\end{array}$ & $\mathrm{x}$ & $x$ & $x$ & & & & $x$ & & $\mathrm{x}$ & & \\
\hline Structure Design & Snow Load, Drainage needs & $\mathrm{x}$ & $\mathrm{x}$ & $\mathrm{x}$ & & & $x$ & $\mathrm{x}$ & & & & \\
\hline Irrigation/Hydropower Management & $\begin{array}{l}\text { Melt discharge/river flow } \\
\text { rates }\end{array}$ & $\mathrm{x}$ & $x$ & $x$ & & & & $\mathrm{x}$ & & $\mathrm{x}$ & & \\
\hline Road Construction and Maintenance & Snow timing and depth & $\mathrm{x}$ & $\mathrm{x}$ & $\mathrm{x}$ & $\mathrm{x}$ & $\mathrm{x}$ & $\mathrm{x}$ & & & & & \\
\hline
\end{tabular}




\subsubsection{Electro-optical (EO)}

The optical properties of snow dramatically alter the EO signature of the battlespace over short periods of time. Snow has high reflectivity in shortwave (UV-Visible) spectra, due to effective internal scattering, with much lower reflectivity in near infrared wavelengths. Due to scattering, absorption, variability due to grain size, density, and liquid water, theory suggest that snow is optically thick at depths generally no more than 10 $20 \mathrm{~cm}$ (Warren, 1982), restricting access to surface signatures. On the ground, snow's impact on camouflage effectiveness influences both force protection and target acquisition. During snowfall and blowing snow events, visibility is severely hampered, impacting adversary detection. Optical signatures of snow vary depending on its microstructure, impurity concentration, and wetness. Subtle changes in these properties that can occur over short time periods (e.g., diurnal cycles) may be exploited to improve target discernment and camouflage effectiveness.

\subsubsection{Radar}

Scattering properties of snow across radar and microwave wavelengths are extremely dependent on snow wetness, layering, and snow microstructure. Radar signals, used for communication and by locating systems, such as weapons locating radar (WLR), are generally attenuated in the presence of snow. Dramatic changes in the radar and microwave signatures can occur when snow begins to melt, or when moisture in soil beneath the snow changes state. Both present challenges and opportunities for discriminating targets, terrain analysis, and identifying buried threats, which can most effectively be mitigated or exploited with detailed information about the response of snow to these changes.

\subsubsection{Thermal}

Snow's low temperature may be expected to make differentiating thermal signatures easier; however snow's high emissivity creates opportunities for masking warm objects with low emissivity coatings. Furthermore, snow's very high thermal resistance restricts differentiation of buried objects.

\subsubsection{Acoustic}

Sound travel is dampened by the presence of snow, the snow's density, and, particularly, by its retention in forest canopy. The acoustic damping 
qualities may impact adversary detection, helicopter sound-shed modeling, and incoming fire-source detection. Snow's acoustic properties may also be used in order to discern other snow physical properties, allowing multi-sensor systems to improve signal discrimination.

\subsubsection{Mobility}

The movement of troops and equipment through cold regions is highly susceptible to snow properties (e.g. snowfall rates, SCA, depth, distribution, strength, wetness, and microstructure). Movement and Maneuver warfighter function such as Fires and Intelligence and Sustainment are limited by snow site conditions. Example Army priority areas impacted by snow are: Next Generation Combat Vehicles, Future Vertical List, and Soldier Lethality. Figure 2 depicts an example of modeling mobility in Afghanistan using average snow estimates.

Figure 2. Modeled HMMWV (High Mobility Multipurpose Wheeled Vehicle) mobility for Afghanistan depicted maximum vehicle speed and taking into account average January snow estimates.

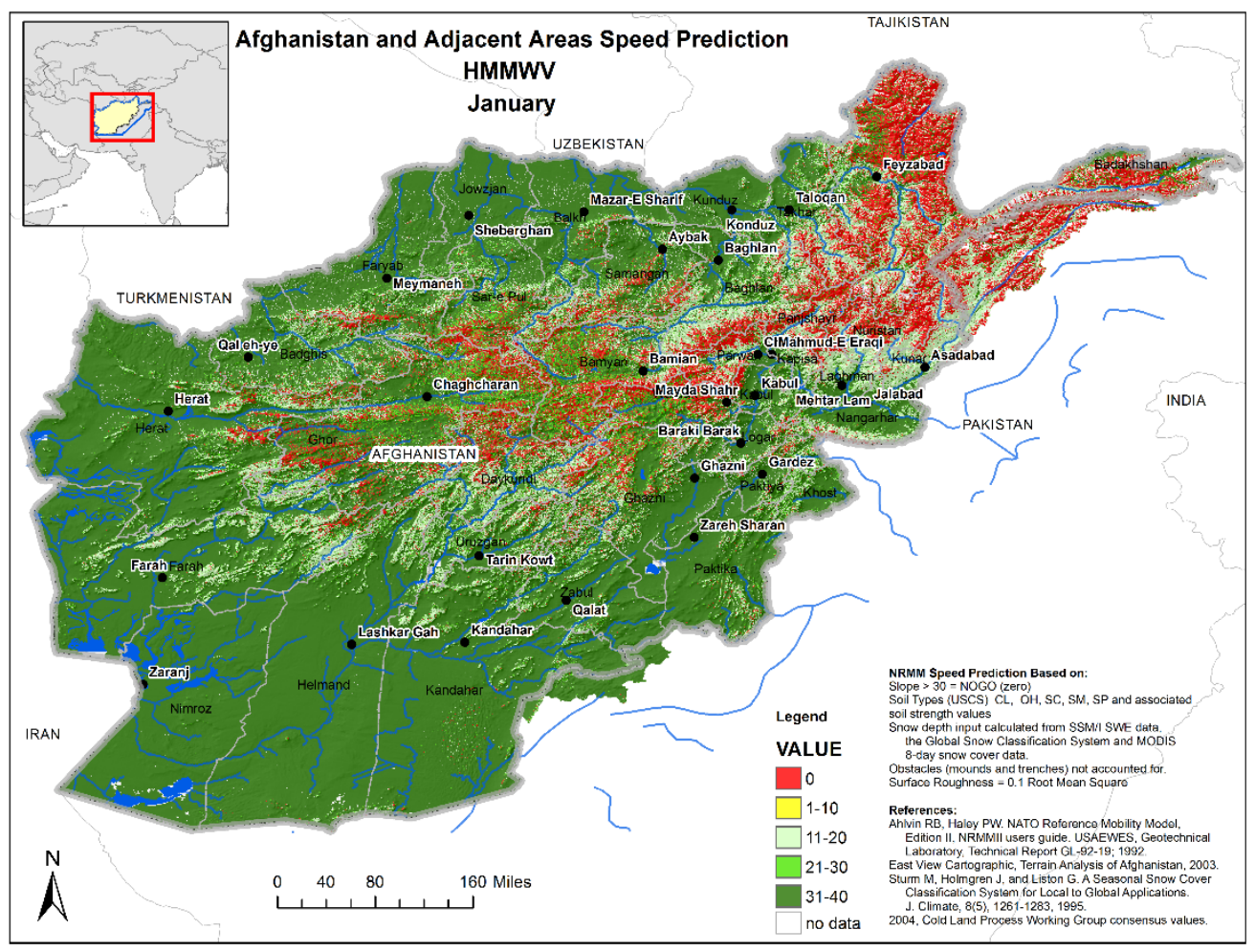




\subsubsection{Mounted and dismounted austere entry}

Austere entry is impacted by the depth and structural properties of snow including stratigraphy and snow wetness. Snow load bearing capacity controls the ability to perform over-snow maneuvers. Deep snow combined with steep slopes increases the danger due to avalanches. Both snow strength and avalanche danger estimation require detailed information on snow macro- and microstructure and grain bonding. The mobility of vehicles with ground loads in excess of snow's load bearing capacity is severely limited when snow depths exceed vehicle ground clearance, making snow depth a critical parameter. Snow's high insulating property prevents heat loss from soils delaying soil frost penetration, and during snow melt periods can increase soil moisture. These impacts on the soil thermal regime and moisture content have direct implications for vehicle mobility and ground stability. Travel times and speeds can vary by orders of magnitude with small changes in snow conditions, and variability in these conditions may cross key thresholds of equipment performance. Therefore, information about snow depth and structural properties must address landscape and soil heterogeneity.

\subsubsection{Mobility on improved surfaces}

Snow accumulation on improved surfaces, such as roads and airfields, can greatly reduce mobility. Rolling resistance is increased by snow in the vehicle path, particularly when depths exceed a significant fraction of tire height. Traction of vehicles is reduced, and controlled, by the strength, bonding properties, degree of compaction, and coefficient of friction of the snow - all of which vary with snow age and temperature. Estimates of these properties are required for optimal performance of mobility models, such as the North Atlantic Treaty Organization (NATO) Reference Mobility Model (NRMM), as well as in tire and track design. Force sustainment operations must include capabilities for removing snow from improved travel surfaces and from around stored supplies. Anticipating and meeting these needs requires snow climatology information and forecasting capabilities.

\subsubsection{Aircraft landings}

Landings on snow surfaces and snow-covered surfaces are impacted by the bonding properties and depth of snow, which in turn are greatly impacted by meteorological conditions including temperature, insolation, and wind 
conditions. Taxiing aircraft are subject to the same mobility concerns discussed above for improved surfaces. In addition, snow creates acute visibility impacts on aviation. Loosely bonded snow can be entrained in wind, leading to low visibility in moderate to high winds. Blowing snow commonly requires implementation of instrument flight rules (IFR) due to conditions near the surface in otherwise clear weather. Rotorwash during helicopter landing can also create hazardous whiteout conditions during landing. The degree to which wind and rotorwash mobilize snow particles is highly dependent on snow bonding strength and microstructure, with the threshold wind velocity for mobilization of snow particles varying from $\sim 4 \mathrm{~m} / \mathrm{s}$ for recent snow to more than $14 \mathrm{~m} / \mathrm{s}$ for wet snowpacks ( $\mathrm{Li}$ and Pomeroy 1997).

\subsubsection{Military infrastructure, civil works, and stability operations}

Snow strongly impacts tasks related to designing, building, and operating in cold regions, and affects infrastructure such as networks, roads, and buildings. Snow impacts the Modernization Priority of Army Network, Control, Communication and Intelligence by affecting communications, network design and long-term planning. Snow can also provide a significant source of streamflow which must be considered when managing for flooding, hydropower, and irrigation. These tasks form a critical component of the Sustainment function and domestic civil works operations. Snowfall, snow water equivalent (SWE), and snowmelt (i.e. snow wetness and subsequent runoff) are important variables to consider.

\subsubsection{Infrastructure}

In terms of Sustainment, infrastructure operations impacted by snow include maintenance for airfields, roadways, and railroads, construction timing, and resupply. These all rely on accurate snowfall and snow accumulation forecasts. On a longer timescale, issues related to snow removal, snow loads, snow drifting, and snowmelt drainage can be mitigated or avoided with relevant snow information. Design-level decisions in construction, equipment acquisition, and planning of operations must be guided by expected snow conditions (e.g., roof loads, water drainage rates). These estimates rely on accurate climatological estimates of snow conditions including snow depth and distribution, snow water equivalent, and snow melt rates. 


\subsubsection{Water resources}

Snowpack storage is a critical component of water resources management for both domestic uses and stability and counterinsurgency operations. The DoD requires accurate and timely SWE and melt forecasts to support realtime operations both domestically and abroad, including water flow forecasting and reservoir management. These operations ensure sustainability of water resources used in hydropower and irrigation. Emergency management efforts in response to floods and drought require real-time SWE and melt-rate data to improve predictions. SWE and melt-rate data over decadal timescales are necessary for engineering design and construction of dams, levees, and other riverine structures, with particular focus on quantification of extreme event magnitude and frequency. 


\section{Current State of Operational Snow Characterization}

There is currently no source of operational snow data that meets the DoD requirements in terms of spatial coverage (global), accuracy $( \pm 10 \mathrm{~cm})$, and resolution. These requirements are not explicitly stated but inferred from requests for snow products throughout the DoD. The spatial resolution requirements vary by application from $30 \mathrm{~m}$ for targeted mobility assessments to $1 \mathrm{~km}$ for global snow estimation. The temporal resolution requirements vary from hourly for weather simulations to monthly or seasonal for longer-term analyses. Additionally, estimates of most snow variables identified as critical components of environmental awareness in our requirements analysis above are not estimated or provided as output. The current DoD snow characterization capabilities are described below, as well as recent efforts to move towards a modeling and data assimilation system. Other large-scale, operational snow characterization systems are also described for comparison.

\subsection{DoD snow characterization}

Current DoD capabilities address only SCA and snow depth, leaving out SWE, strength, albedo, microstructure, and snow wetness, and snowfall rates, as well as any estimate of uncertainty. These omissions impact warfighting functions and civil works activities through decreased environmental awareness of conditions that affect sensor performance, mobility, infrastructure, and streamflow estimation. In addition, the current state of snow depth and snow-covered area estimation, the two variables with operational products, also have significant limitations. In this section we evaluate the current state of DoD snow estimation capabilities.

The U.S. Air Force 557th Weather Wing (557WW) is the primary DoD agency responsible for predictive battlespace awareness for the U.S. Air Force, Army and Intelligence community warfighter forces. Currently, the $557 \mathrm{WW}$ uses a combination of in situ and remotely sensed data sources to estimate snow depth on land and sea ice to support DoD missions through their Snow Depth Model (SNODEP, Kopp and Keiss 1996; Hall 1986). SNODEP assimilates in situ and remote observations to create a global- 
coverage map of snow cover and depth. It is one of the only sources of operational snow depth data available daily on a global scale. SNODEP's output is used by the DoD, U.S. Government, and other worldwide meteorological agencies to provide valuable snow depth and snow cover estimates for decision systems. The National Center for Environmental Prediction (NCEP) uses the SNODEP in conjunction with their higher resolution satellite-based snow coverage product as an input to the Global Forecast System (GFS). SNODEP snow cover estimates are also used by Air Force forecasters in the global cloud analysis system and in DoD Tactical Decision Aids (TDAs).

Despite the widespread adoption of the convenient, high temporal resolution, global snow product, the SNODEP model has several major shortcomings. First, SNODEP provides only snow depth and includes no mechanism for estimating aspects needed for operational planning, such as SWE (critical for hydrology) or snow strength (key to mobility). Second, the SNODEP model has a relatively low physical basis compared to the current state of science. Critical processes and properties of snow, such as metamorphism, surface and snowpack energy balance, thermal conductivity, and wind redistribution are not included. Third, SNODEP occasionally uses a snow climatology to extrapolate between available data. The climatology is based on spatially incomplete observations collected prior to the mid-1950s and the model's own output since that time rather than more current conditions that may be affected by a warming climate. In addition, snowpack properties and distributions are the result of the current winter's weather conditions, which may be completely unrelated to climatological snow information. As a result of these shortcomings, the resolution and accuracy of SNODEP's analysis make it inadequate for robust tactical decision support and hydrologic forecasting.

The SNODEP model is also limited by the availability and quality of observations that it assimilates. SNODEP currently collects in situ observations of snow depth from meteorological reporting observations (METAR) and synoptic surface observations through the Joint Meteorology and Oceanography (METOC) Observation Data Segment (JMOBS). Many of these observational sites do not record snow depth explicitly, and consequently the World Meteorological Organization (WMO) uses an indirect method for extracting the snow depth observations which are integrated into the model. In the U.S. only, SNODEP includes more non-traditional observa- 
tions such as from NWS Cooperative stations, the Community Collaborative Rain, Hail \& Snow Network (CoCoRaHS), and National Resource Conservation Service (NRCS) Snow Telemetry (SNOTEL) sites.

SNODEP also ingests remote sensing snow observations. Major updates to the model have enabled assimilation of data from passive microwave sensors aboard the Defense Meteorological Satellite Program (DMSP) satellites (starting in 1996). Currently the Special Sensor Microwave Imager/Sounder (SSMIS) sensor data is employed to estimate snow depth using a 2-channel empirical algorithm (Markus et al. 2006). Operational assimilation of remotely sensed snow depth into SNODEP has been hampered by discontinuity of satellite missions and changing product availability (e.g. the 2011 AMSR-E failure). Initial efforts have been made to incorporate observed snow into SNODEP estimated SCA based on the Moderate Resolution Imaging Spectroradiometer (MODIS)/Meteorological Operational satellite Program (MetOp) observed snow mask at 1/4 degree resolution; however, improvements that increase the resolution of these SCA products to 500m resolution using the Visible Infrared Imaging Radiometer Suite (VIIRS) aboard the National Aeronautics and Space Administration (NASA)/National Oceanic and Atmospheric Administration (NOAA) Suomi-NPP (National polar-orbiting Partnership) are currently underway through the joint efforts of CRREL and the 557WW.

Recognizing the need for improved quality environmental awareness information, the 557WW implemented the Land Information System (LIS) to advance operational land surface characterization capabilities and to provide offline reanalysis products that can inform tactical decision systems (Eylander 2013). LIS is an advanced software framework, developed through collaboration between NASA and the $557 \mathrm{WW}$, which merges atmospheric analyses and land surface models (Kumar et al. 2006; PetersLidard et al. 2007). The framework enables integration of multiple land surface models and provides data assimilation capability for a variety of operational assets (Kumar et al. 2008). LIS provides surface layer characterization of soil temperature, moisture profiles, and energy fluxes at varying resolution both regionally and globally. LIS also has the ability to integrate alternate snow modeling capabilities and output additional snow characteristics including SWE and albedo. Land surface models (LSMs) currently in LIS which simulate snow includes the Noah LSM (versions 2.7.1 to 3.6), Noah-MP (Ek et al. 2003), the Joint UK Land Environment 
Simulator (JULES) (Best et al. 2011), the Australian Community Atmosphere Biosphere Land Exchange (CABLE) model (Kowalcyk et al. 2013), Catchment (Koster et al. 2000), Mosaic (Koster and Saurez 1996), and the Community Land Model (CLM) (Oleson et al. 2010) which represents a major step forward in model sophistication. Currently only Noah 3.6 is available in the 557WW's LIS implementation, with JULES and Noah-MP expected to be added in 2018-19.

Additionally, the LIS framework provides an opportunity to investigate techniques likely to improve the characterization of snow to meet the DoD's snow data requirements. Within the LIS framework there is capacity to increase data assimilation, quantify uncertainty, incorporate more sophisticated methods for interpreting remotely sensed data, and employ sophisticated model structures to address battlefield-scale information needs. The shared use of LIS in the research and operational communities presents a viable transition pathway for a more comprehensive DoD utilization of updated physically-based model algorithms, satellite-based data assimilation techniques, and higher resolution analyses. The capability to utilize, interpret, and develop both stand-alone historical and real-time snow products that incorporate remotely sensed and in situ measurements may also benefit DoD operations.

\subsection{Other operational snow characterization systems}

\subsubsection{SNODAS}

The Snow Data Assimilation System (SNODAS) is a modeling and data assimilation system developed by NOAA National Weather Service's National Operational Hydrologic Remote Sensing Center (NOHRSC) that provides estimates of SWE, snow depth and other snowpack properties in support of hydrologic modeling and analysis for the contiguous United States (including lower portions of Canada). SNODAS simulates snow cover using a physically based, spatially-distributed energy- and mass-balance snow model with downscaled output from the Numerical Weather Prediction (NWP) models as forcing data (Carroll et al. 2001). SNODAS also assimilates satellite-derived observations of snow covered area, and airborne, and ground-based observations of snow depth and SWE. Outputs produced by SNODAS are snow depth, snow melt, SWE, and snow temperature. The spatial resolution of the model is $1 \mathrm{~km}$, and the temporal resolution is 24 hours. This product represents one of the best operational snow products available in terms of accuracy and resolution, though the 
accuracy of the estimates deteriorates with limited temporal and spatial observations. The geographical coverage of this product is also limiting for analysis and forecasting abroad.

\subsubsection{GLDAS}

The Global Land Data Assimilation System (GLDAS) is a collaborative effort between NASA/GSFC, and NOAA's National Centers for Environmental Prediction (NCEP), which incorporates satellite- and ground-based observational data products using land surface modeling and data assimilation techniques to generate global land surface states and fluxes (Rodell et al. 2004). Observation-based precipitation and downward radiation products and analyses from atmospheric data assimilation systems are employed to force the models. Satellite and ground-based hydrological observations, including snow cover and water equivalent (from MODIS and SNODEP), soil moisture, and surface temperature, are used to help constrain model states and inform spatial distribution. The system produces global model output at a 3 -hour timestep at a $1 / 4^{\text {th }}$-degree resolution. Snow water equivalent and snow depth are estimated using the NOAH land surface model, version 2.7.1. While this product is available globally, the resolution is too coarse for many DoD requirements, there is an approximately 3-day lag in the data availability, and the snow model accuracy is insufficient (Slater et al. 2007; Niu et al. 2011; Wrzesien et al. 2017).

\subsubsection{GlobSnow}

The Finnish Meteorological Institute (FMI) was funded by The European Space Agency (ESA) to produce long-term datasets of SWE (33 year dataset) and SCA (17 year dataset). The GlobSnow-2 SCA product incorporates high resolution Advanced Very High Resolution Radiometer (AVHRR) and Suomi-NPP VIIRS data with the lower resolution SWE product. The SCA product was produced for the time frame 1995-present as daily estimates in areas of seasonal snow cover (excluding perennial snow cover and glaciers) generated at approximately $1 \mathrm{~km}$ spatial resolution. GlobSnow-2 SWE products cover the time frame 1978-present using a combination of satellite microwave radiometer and ground-based weather station data. The main satellite data sources for the SWE product are Nimbus-7 SMMR, DMSP SSM/I and SSMIs for 1987 - present, and Terra AMSR-E for 2002-2010. Satellite and ground-based observations are assimilated into a coupled snow-microwave emission modeling system 
to produce near real-time daily estimates in non-mountainous Northern Hemisphere regions at $25 \mathrm{~km}$ spatial resolution. The coarse resolution and the lack of data in mountainous regions limit this products usefulness for DoD applications. 


\section{Current State of Snow Science}

Substantial scientific efforts have been made to understand, observe, and predict snow characteristics, including all of the identified properties required for DoD decision support. The maturity of these efforts varies widely, with some properties still requiring fundamental basic research for advancement and others ready for rapid transition into improved DoD environmental awareness systems. The current state of scientific knowledge on snow is not fully implemented in existing models, and advances in basic understanding could push the state of knowledge further to meet the operational needs identified in Section 3. In Section 4.1 we describe each of the critical snow variables and the current state of observational capability. Section 4.2 describes recent work evaluating snow spatial patterns and the potential application to snow estimation. In Section 4.3, we discuss ongoing research efforts to simulate the evolution of snow and their readiness for incorporation into operational models. The current state of snow science related to operational needs from observational (ground-based and remote sensing) and modeling perspectives is presented in Table 3 in terms of the parameters identified and the general technical readiness level (TRL), where TRL 1 represents a knowledge or technology gap, TRL 2 is basic research, and TRL 3-5 represents applied research.

\subsection{Observations}

Observation of snowfall and snow characteristics can be conducted using ground-based measurements and remote sensing methods. Ground measurements are typically labor intensive and/or require a great deal of infrastructure. Large spatial coverage through ground measurements is difficult and expensive. Data quality can be excellent, but only if substantial care is taken in data collection. Remote sensing techniques provide better spatial coverage, but do not directly measure many of the most desired variables and often require further refinement to achieve sufficient accuracy for DoD applications. Below we address each of the critical snow metrics identified, the observing tools available, and type of datasets existing at this time. From a northern hemisphere perspective, Figure 3 provides an example of snow cover likelihood using FMI's historical GlobSnow snow extent product. 
Figure 3. Northern hemisphere snow cover likelihood (October through May, 19952016) based on snow extents products from optical satellite remote sensing products.

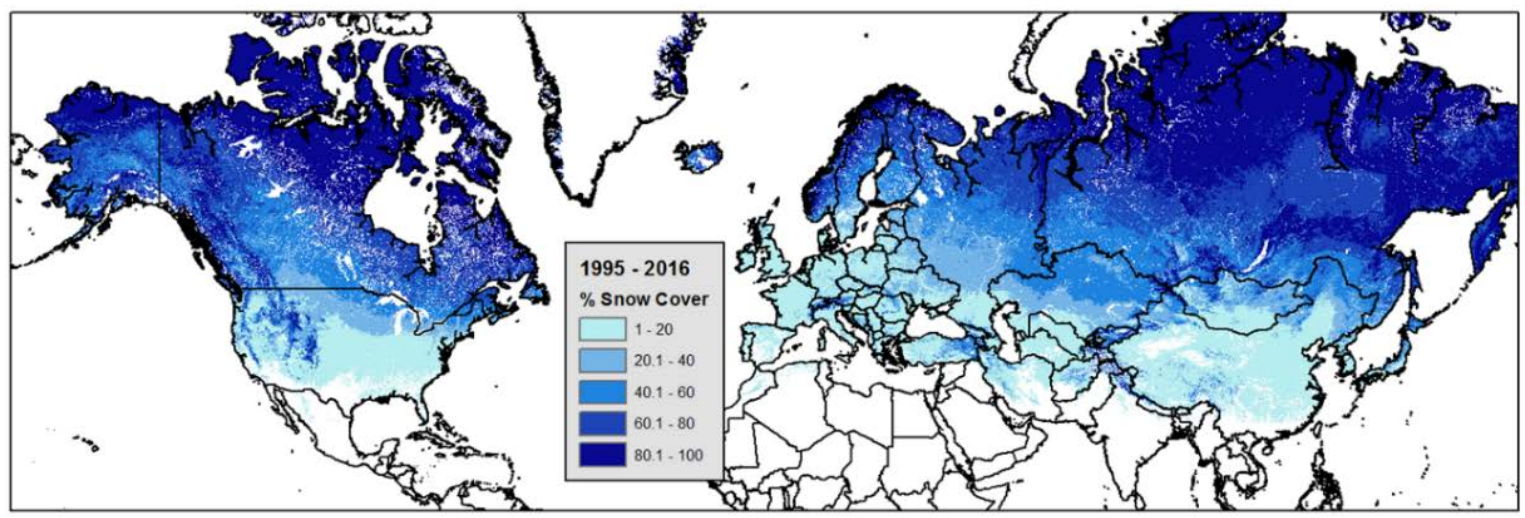

\subsubsection{Snowfall rates}

It is important to distinguish snowfall (precipitation) from snow on the ground, since they can be highly related or decoupled depending on conditions. The rate at which snow is falling during a particular event can impact visibility and sensor performance. Numerous autonomous instruments and techniques are available to monitor precipitation at meteorological stations (Rasmussen et al. 2012) with varying accuracy depending on where those measurements occur, how dense those measurements are spatially, and whether the precipitation is in liquid or solid form. Ground-based precipitation gages are highly susceptible to error due to wind under catch when used to measure snow, and these data often require corrections, especially at higher latitudes and elevations (Yang et al. 2005). At many National Weather Service (NWS) sites, Light Emitting Diode Weather Indicator (LEDWI) systems are used to distinguish rain and snow precipitation, and then a forward scatter visibility sensor is used to estimate intensity (Rasmussen et al. 1999). The accuracy of this method is impacted by variability in snow crystal types and other characteristics. Radar (x-band and millimeter wave) has been used to measure snowfall rates using similar methods to rainfall precipitation (Moran et al. 1998; Sheppard and Joe 2008), however the accuracy of this method can also be affected by crystal types (Boucher and Wieler 1985; Castellani et al. 2015).

Limited unpublished work exploring Light Detection and Ranging (LIDAR)-based snowfall rate estimation has been performed at local study-plot scales, and has the potential to inform ground-based DoD operations. On larger scale, satellite-based techniques (e.g. Global Precipitation Measurements (GPM) and Tropical Rainfall Measuring Mission (TRMM) 
satellites) have evolved into global operational products (albeit coarse resolution, $\sim 25 \mathrm{~km}$ ) through the combination of infrared, multi-channel, dual-polarization passive microwave sensors and active scanning radars (Huffman et al. 2007; Huffman et al. 2018), though their ability to accurately estimate snowfall precipitation is limited.

\subsubsection{Snow-covered area}

SCA, or the spatial extent of snow cover, is one of the most commonly assessed snow variables, and has a long observational remote sensing record (Brown and Robinson 2011; Comiso and Hall 2014; Estilow et al. 2015). Changes in the seasonal snowpack extent can occur over a relatively short time period during snowfall and melt events, dramatically altering the operational environment. Precipitation events and melt rates can be highly variable at a wide range of spatial scales, making observation of the extent critical.

Time-lapse cameras can be used to monitor snow extent at a local scale, but snow covered area is most commonly observed over large areas using satellite observations, specifically electro-optical sensors operating in visible wavelengths. Snow contrasts greatly with most land cover types owing to its high albedo, therefore it can be easily detected at high-resolution using optical sensors. Multispectral sensors (e.g. AVHRR, MODIS, and Landsat) are frequently used to calculate snow cover or snow-covered fraction (SCF). Snow presence or absence is relatively easy to determine. However, accuracy can be greatly impacted by the presence of clouds, density of overlying forest canopy, and existing substrates of similar color (e.g. sea ice, glacial ice); in addition, imagery cannot be collected at night. Nevertheless, optical satellite estimates of SCA on land have been found to be highly accurate over large spatial extents (Gafurov and Bárdossy 2009). Figure 4 depicts SCA across the snow-impacted watersheds of Afghanistan taken from the bi-weekly CRREL and Air Force Weather snow assessment report and is based on a time-filtered daily reflectance product from the VIIRS instrument aboard the NASA/NOAA Suomi-NPP satellite. 
Figure 4. Snow-covered area for the snow-impacted watersheds of Afghanistan estimated from the VIIRS instrument aboard the Suomi-NPP satellite.

Afghanistan Snow Covered Area

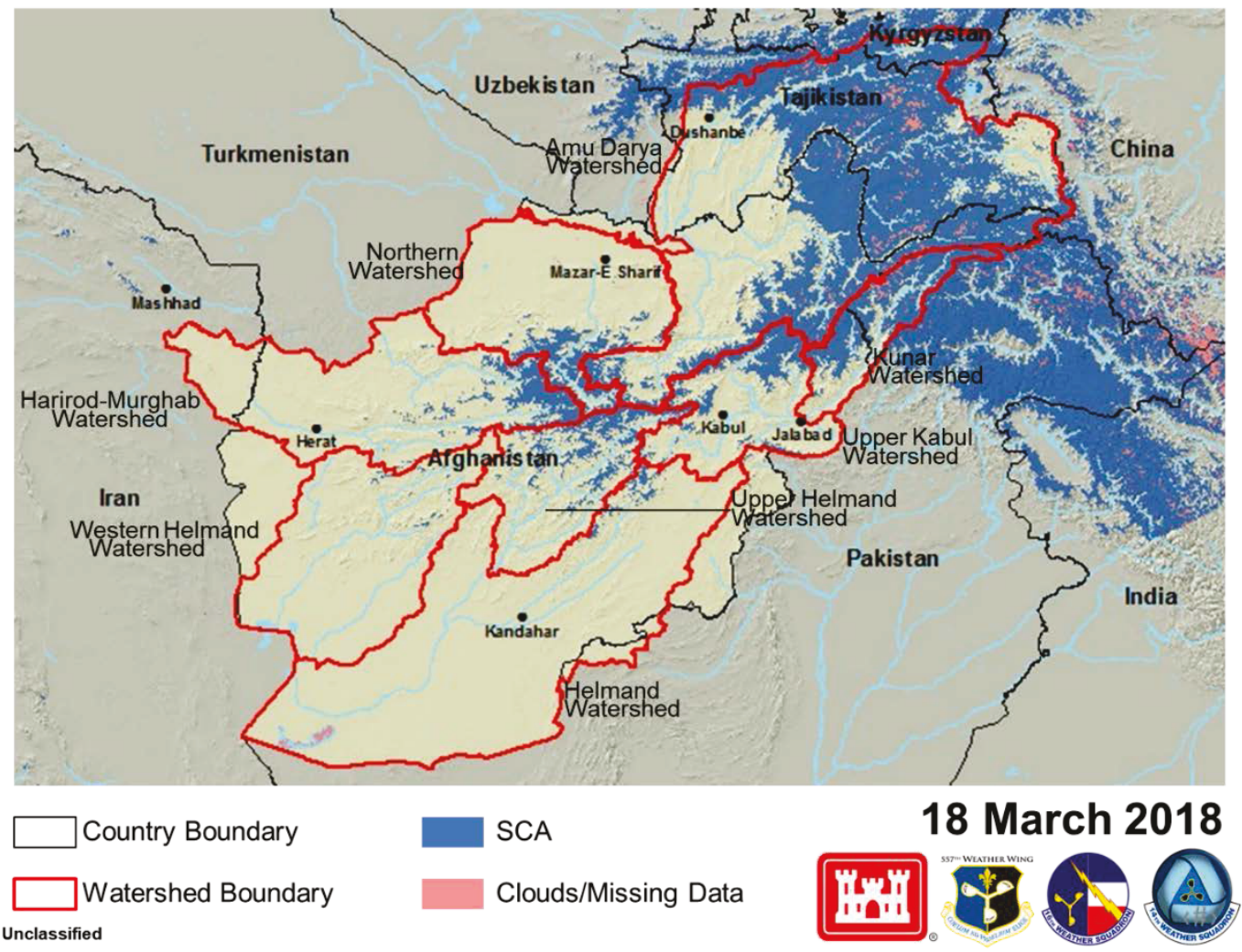

\subsubsection{Snow depth}

Snow depth represents the net accumulation of snow, integrating prior accumulation, transport, settlement, and ablation (sublimation and melt), and is a critical observation for many DoD requirements. Manual groundbased snow depth observations are one of the simplest snow metrics, typically involving insertion of measuring devices into the snowpack at point locations and along snow courses or transects. Measuring devices may be rulers or graduated stakes, but are more frequently incremented metal probes. Automatically recording snow depth probes are commonly employed to collect distributed depth observations in shallow (less than 1.2 m) snowpacks (Sturm 2009). Observations typically fall into categories of routine observation (e.g. Federal and State Agencies, volunteer meso-net), 
or campaign-based studies (e.g., 2002-2004 Cold Lands Processes Experiment (CLPX) (Cline et al. 2003); SnowEx Year 1. ${ }^{*}$ At autonomous stations, acoustic rangefinders are commonly mounted looking downward from above the ground surface and used to track the snow surface level over time. Inexpensive time-lapse cameras are used to take photos of snow stakes to determine depths (Dickerson-Lange et al. 2015). Other stations use the attenuation of GPS satellite signals at ground level to accurately estimate snow depth (Larson et al. 2009) and SWE (McCreight et al. 2014). Frequency-Modulated Continuous-Wave (FMCW) radar has been shown to be effective at observing snow depth and identifying stratigraphic layers (depending on frequency range) through the detection of backscatter differences based on contrasts in dielectric boundaries (air-snow-layeringground). Yet, challenges in reliable interface detection across diverse terrains may limit the operational use of this technique (Holmgren et al. 1998; Marshall and Koh 2008).

Over larger areas, differencing digitally-recorded snow-covered and snowfree terrain surfaces is an increasingly common method for estimating snow depth at fine to intermediate scales (meters to $100 \mathrm{~s}$ of $\mathrm{km}$ ). Terrestrial LIDAR scanning can examine changes in snow accumulation with very high vertical precision (sub-cm) over local scales ( $<1$ to $\left.3 \mathrm{~km}^{2}\right)$ (Deems et al. 2013; Tinkham et al. 2014; Painter et al. 2016; Tennant et al. 2017). Airborne LIDAR can create snow-free and snow covered surfaces over larger domains (up to $100 \mathrm{~km}^{2}$ ), albeit with approximately an order of magnitude larger error (approximately $10 \mathrm{~cm}$ vertical), but still at resolutions that are very high relative to typical snow surface roughness (10's of points per $\mathrm{m}^{2}$ ). Airborne LIDAR-collected surface differencing is used operationally with NASA JPL's Airborne Snow Observatory (ASO) over relatively small basins to observe snow depth (Painter et al. 2016). One advantage of using LIDAR to sense snow depth is that observations can penetrate most canopies, with some fraction of the pulses achieving true ground position even under dense forest canopies. A disadvantage is that LIDAR is challenged in characterizing snow retained in vegetation canopies. Another surface differencing technique, Structure-from-Motion (SfM), employs high-resolution aerial or drone-based photos to create

\footnotetext{
" Hiemstra, C.A., L. Brucker, H.P. Marshall, and K. Elder. "SnowEx 2017 Sampling Strategy: Part 1, Grand Mesa”. (In Preparation) for Water Resources Research SnowEx Special Issue (2018).
} 
snow-free and snow-covered that can be differenced to estimate snow depths (Nolan et al. 2015) with accuracy comparable to LIDAR for a fraction of the cost, but without the same level of vegetation penetration. High resolution satellite imagery can also employ the SfM technique to create snow-covered and snow-free surfaces. The technique has been applied more to land ice and surface mapping (Shean et al. 2016), but shows promise for space-based snow depth estimation within error bounds of several tens of $\mathrm{cm}$ over much larger areas.

\subsubsection{Snow water equivalent}

Snow water equivalent (SWE), the volume of water contained in the snowpack, is a critical parameter for hydrologic applications. In many regions, peak annual SWE is highly correlated to the total volumetric spring runoff, and can be used for forecasting purposes. SWE directly influences flood or drought potential, water resource availability and groundwater recharge. SWE is often estimated as the product of snow depth observations and measurements or models of snow density (Sturm et al. 2010; McCreight and Small 2014). The translation between depth and SWE is common because depth is a more frequently available and easier to measure, with records dating back decades in some locations. However, the estimated density to make the conversion can be a source of uncertainty (Raleigh and Small 2017).

Manual in situ SWE observations can be made by collecting volumetric samples of the snowpack and weighing them, either in individual cores (e.g. using a field-standard Federal Sampler), or using a density cutter to extract snow samples of a known volume from the wall of a snow pit. Autonomous ground-observing stations, such as Snow Telemetry (SNOTEL) or Plate Boundary Observatory water cycle ( $\mathrm{PBO} \mathrm{H} 2 \mathrm{O})$ sites calculate SWE based on weight of snow (SNOTEL) or GPS signal attenuation (PBO H2O) (Lundberg et al. 2010).

SWE can also be estimated remotely by measuring the passive microwave signal naturally emitted from the Earth (Tedesco et al. 2006; Derksen 2008; Kelly 2009; Frei et al. 2012; Vander Jagt et al. 2013). A passive microwave signal at frequencies greater than $\sim 25 \mathrm{GHz}$ is scattered as it passes through the snowpack. Estimation of SWE can be made from this signal attenuation using empirical relationships or microwave emission models. Empirical methods typically rely on statistical relationships be- 
tween experimental observations of SWE, snowmelt and microwave emissions. Alternatively, microwave emission models use physics-based approaches to simulate the effect of a snowpack on attenuation of the microwave radiation (Brucker et al. 2011; Durand and Liu 2012; Kwon et al. 2015). Space-based observations of microwave emission have been available for more than three decades, providing a long historical record. However SWE data produced from the microwave signal are fairly coarse $(25 \mathrm{~km}$ ) and affected by multiple other factors, including deep snow (Dong et al. 2005; Foster et al. 2005), snow metamorphism (Josberger and Mognard 2002; Durand et al. 2011), snow wetting (Walker and Goddison 1993; Ramage et al. 2007) and vegetation (Foster et al. 2005; Derksen et al. 2010), which impact the accuracy of the snow estimation.

Recently efforts to develop higher-resolution (up to $3 \mathrm{~km}$ ) microwave brightness temperatures from the satellite data using image reconstruction techniques (Brodzik et al. 2016) may improve SWE estimation capabilities in regions with high variability. Figure 5 shows an example of the historical (1987 to present) passive microwave SWE record statistics showing the seasonal accumulation and ablation phase of the snowpack as reported in the CRREL and Air Force Weather bi-weekly snow assessment products. The current year trend indicates historically low (based on the period of record) snow volume through 18 March 2018 with likely drought conditions heading into spring. 
Figure 5. Historical (1987 to present) passive microwave satellite assessment of snow water equivalent for the largest snow-impacted watershed in

Afghanistan (Amu Darya). Chart shows the historical max/min, average, and standard deviation across the winter accumulation andspring ablation season.

For perspective, the annual SWE trend for last season (2016-2017) is shown alongside the current year (2017-2018) as of 18 March 2018.

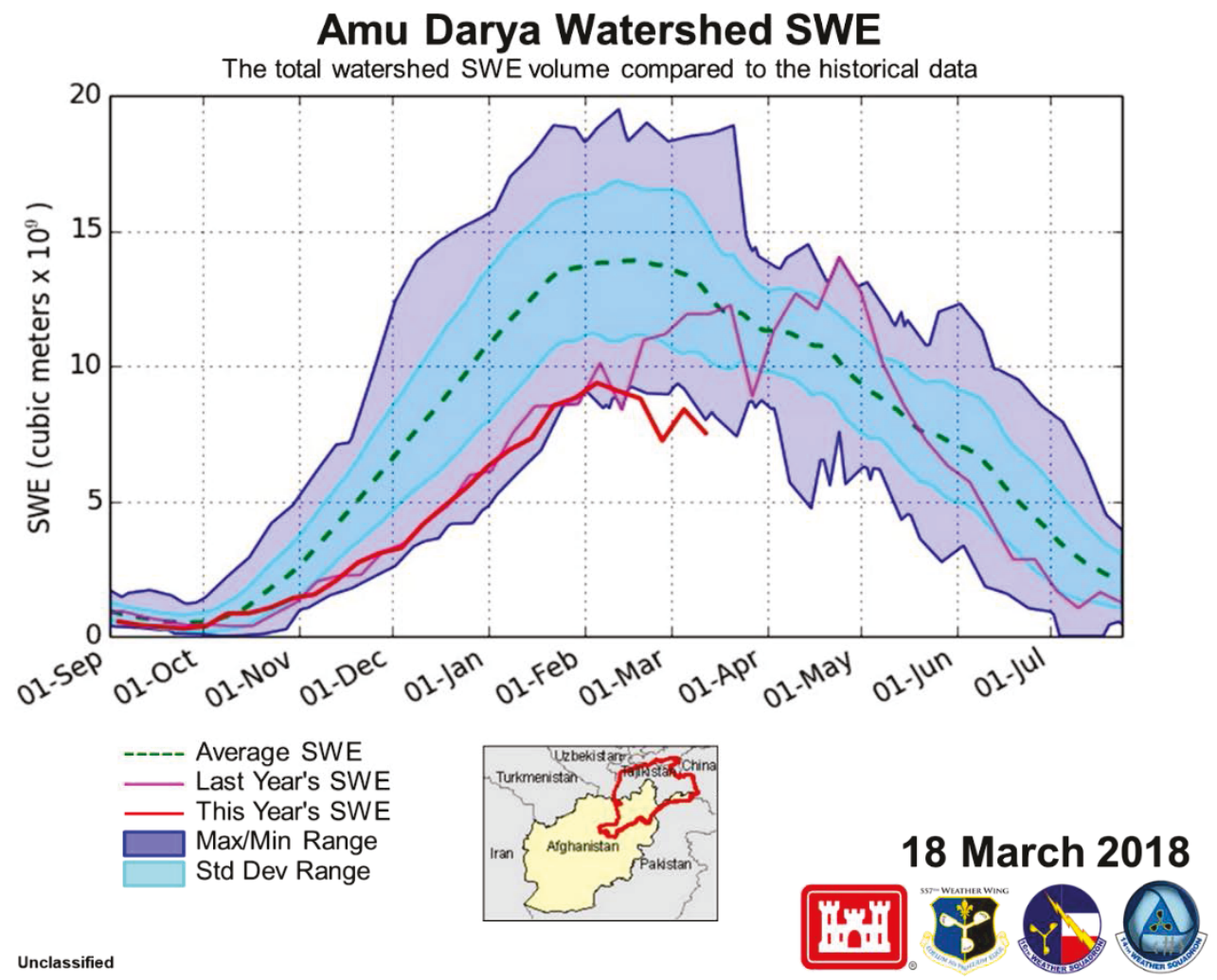

Research evaluating active microwave sensors, or radar, to estimate SWE remotely has shown promise. Using $\mathrm{Ku}$ - and $\mathrm{X}$-band frequencies, backscatter at the snow-air interface and ground-snow interface can be summed to estimate the volume of dry snow (Nolin 2010). L-band synthetic aperture radar (SAR) has been investigated to derive changes in snow depth and density using differential repeat-pass interferometric phase measurements in dry snow (Deeb et al. 2011). Altimetry methods using Ka-band to measure changes in snow depth can also be used to derive SWE. The benefits of using active microwave sensors are a higher resolution and increased depth sensitivity. Two space-borne missions have recently been proposed using these technologies to measure snow, however there are currently no operational satellite platforms in orbit. 


\subsubsection{Snow optical properties (albedo)}

Perhaps one of the most important snow properties, from a global energy balance standpoint, is its albedo, or how reflective the snow is of solar radiation. Snow is highly effective at scattering incident shortwave light, particularly in visible wavelengths, but its reflectivity is sensitive to changes in snow properties, and varies strongly with wavelength (Warren and Wiscombe 1980; Wiscombe and Warren 1980). This impacts the ability to visibly discern targets and develop effective camouflage. Snow albedo also has profound influence over fluxes of energy and mass across the atmosphereland boundary and across atmosphere-ice boundaries over ice sheets and sea ice. The high albedo of snow means that a snow cover reflects tremendous amounts of solar energy, lowering local temperatures and moisture fluxes. Loss of snow results in greater solar absorption, higher temperatures, and further losses of snowpack in a positive feedback (Déry and Brown 2007). The large magnitude of the resulting surface energy balance change, and the sheer spatial coverage of snow on Earth makes this feedback an important factor in weather forecasting and is a leading cause of amplified warming at high latitudes over seasonal and climatological scales (Qu and Hall 2014).

Albedo varies on short timescales and exhibits large spatial variability. Both ground based and remote sensing measurements must be subject to stringent quality and operational control to obtain useful accuracy (Casey et al. 2017; Cook et al. 2017). True albedo, which encompasses the hemispherical reflectance, or the ratio of total reflected irradiance to total incoming irradiance, can be measured using ground-based techniques in broadband, multispectral, and hyperspectral configurations, depending on the degree of spectral resolution required by the application. Remote sensing observations typically provide information on irradiance reflected along only a small finite solid viewing angle - technically a hemisphericaldirectional or hemispherical-conical reflectance (Nicodemus 1970; Nicodemus et al. 1977; Painter and Dozier 2004). These data must be corrected for atmospheric extinction and gathered from multiple look angles for assimilation to produce an estimate of hemispherical surface reflectance that takes reflectance anisotropy into account. This is a complex process with substantial opportunities for introducing errors (e.g. Schaaf et al. 2002; Grenfell et al. 2011).

Multispectral and hyperspectral albedo and reflectance observations can be exploited to determine snow surface properties, the cause of property 
changes, and the degree of vegetation, dust, and soil exposure, with higher spectral resolutions opening more possibilities for remotely discriminating surface characteristics. Multispectral and hyperspectral measurements are collected with a variety of spectroradiometers, which use prisms and diffraction gratings to spectrally divide light onto arrays of silicon (for visible wavelengths) and InGaA or HgCdTe (for Near Infrared (NIR) wavelengths) electro-optical detectors. Ground-based sensors can be fitted with directional or hemispherical collectors. Airborne and space based missions can generally only observe directional or conical reflectance. A wide range of multispectral satellite imaging spectrometer missions operate at low (AVHRR, MODIS, VIIRS), medium (Landsat), and high spatial resolution (WorldView 2-4, GeoEye, Pleiades). Multispectral and hyperspectral imaging spectrometers of a variety of designs are available for characterizing spatial variability in spectral reflectance and are increasingly being deployed on unmanned aerial vehicles (UAVs) (Adão et al. 2017). Only one hyperspectral space-based mission has been launched (Hyperion) and it is no longer operational. Upcoming hyperspectral missions are uncertain, though the most recent Decadal Survey recommends a space-based hyperspectral sensor as one of the foundational observations needed (National Academies 2018). NASA's Hyperspectral Infrared Imager (HyspIRI) visible to short-wavelength infrared (VSWIR) $30 \mathrm{~m}$ resolution spectrometer is delayed until 2022 at the earliest and Japanese Aerospace Exploration Agency's (JAXA's) Advanced Land Observation Satellite-3 (ALOS)-3 mission, carrying Hyperspectral Imager Suite (HISUI), has been delayed until 2019. Proposals to launch hyperspectral cubeSat constellations are active, but currently have uncertain launch dates (Mandl et al. 2016). Aircraftbased hyperspectral imagers, such as the Airborne Visible-Infrared Imaging Spectrometer - Next Generation (AVIRIS-NG) are available for targeted campaigns and produce higher quality data than space-based assets with their higher spatial resolutions and ability to fly below clouds.

\subsubsection{Snow wetness}

Snow wetness, or the amount of liquid water present in a snowpack, can impact snow strength and has applications in snowmelt-onset detection, runoff prediction, and for estimating vehicle speeds and traction. Standard methods for determining in situ snow moisture content are a Denoth meter (Denoth 1994), which is based on the capacitance of snow, and a Finnish snow fork (Sihvola and Tiuri 1986), which is a radiowave sensor, in addition to more conventional calorimetric methods. Other methods utilizing electrical and microwave frequency properties of snow are currently 
under development. In situ measurements of snow wetness are generally labor intensive, destructive, and provide an instantaneous measurement rather than a temporal observation throughout the season.

Space-borne sensors have been used to observe snow wetting due to the sensitivity of microwave wavelength emissions to snow liquid water content (Schmugge et al. 2002). The presence of water within a snowpack increases the emissivity measured at higher frequencies due to an increase in the dielectric constant of the wetted snow (Mätzler 1987; Walker and Goodison 1993). The strong signal response enables periods of snowmelt to be readily identified (Stiles and Ulaby 1980; Kunzi et al. 1982; Drobot and Anderson 2001) because the change in signal response associated with snow wetting overwhelms the impact of other snowpack properties on the microwave signal (Wang et al. 2001). The robust change in this physical property has been shown to be effective for determination of snowmelt onset over large areas using space-based passive microwave sensors (Ramage and Semmens 2012; Semmens et al. 2013).

Active radars can also exploit the large changes in dielectric constant to identify snow wetting and can often do so at much higher resolutions than passive microwave sensors. Ku-band scatterometers, such as NASA Scatterometer (NSCAT) and QuikSCAT, have been used to identify melting snow extent over land, ice sheet, and sea ice surfaces (Howell et al. 2006; Wang et al. 2008, Markus et al. 2009; Nghiem et al. 2012). C-band SAR instruments, such as Seasat and ERS -1/-2 have demonstrated capability for identifying wet snow (Nolin 2010) using change detection algorithms. Thermal band imaging from space based sensors (e.g. MODIS) is commonly used to detect melt extent over ice sheets (e.g. Hall et al. 2009).

\subsubsection{Snow microstructure}

The microstructure of snow ultimately determines the macroscale mechanical, thermal, and optical properties of the snowpack. Snow grain size and shape as well as the bonds between grains impact larger scale properties including snow reflectance, snow strength, density, thermal conductivity, permeability, and dielectric properties. Snow microstructure continually changes due to the fact that snow naturally exists at temperatures close to its melting point and has a significant, temperature-sensitive sublimation vapor pressure. The most commonly observed metric of grain structure is snow specific surface area (SSA) because it is a useful proxy for most radiative transfer properties in snow. 
Perla et al. (1986) used traditional stereology techniques to measure the surface to volume ratio. Methane absorption was used by Legagneux et al. (2002) and Domine et al. (2007) to measure surface to mass ratio. Efforts are maturing to determine SSA in the field using rapid and efficient optical methods including near infrared (NIR) photography (Matzl and Schneebli 2006), contact spectrometry (Painter et al. 2007), and shortwave infrared (SWIR) reflectance (Gallet et al. 2009). Relationships between SSA and interactions with other parts of the electromagnetic spectrum are being exploited to remotely detect surface grain SSA (Nolin and Dozier 2000; Scambos et al. 2007; Painter et al. 2009). In theory, radar backscatter at multiple polarizations and increasingly higher frequencies $(<10 \mathrm{GHz})$ are impacted by snow microstructure which has led to investigations of multiple frequency and multiple polarization radar for SWE estimation (Rott et al. 2008). Ground-based radar systems are also adept at identifying stratigraphic layers (Marshall et al. 2004). However, radar remote sensing to detect internal snow gain structure is still somewhat a basic research activity with the need for additional empirical evidence to determine the efficacy of these techniques.

Detailed observations of snow microstructure can be achieved with microcomputed tomography (micro-CT) (e.g., Heggli et al. 2011) and Scanning Electron Microscope (SEM) (Adams et al. 2001; Rosenthal et al. 2007; Lomonaco et al. 2009). Micro-CT and SEM can be used to measure SSA using 3D renderings of cast snow samples (e.g., Flin et al. 2003; Kaempfer and Schneebeli 2007; Matzl and Schneebli 2010), which provide an accurate representation of the microstructure that can be used to validate other approaches.

\subsubsection{Snow strength and snow density}

Snow strength is currently one of the most uncertain properties of snow and, though substantial research on the subject was undertaken during the Cold War (e.g., Mellor 1974), limited work has been conducted on the subject in recent years. Most in situ tests for strength are based on empirical relationships using density or hardness as measured by a penetrometer (Schneebeli et al. 1999), thin blade penetration resistance (Borstad and McClung 2011), or manual resistance test (Pielmeier and Schneebeli 2003). Direct measurement of snow strength is labor intensive, and typically requires a laboratory set-up (e.g., Upadhyay et al. 2007). Current efforts are underway to validate the empirical field techniques for snow 
strength observation and develop new parameterizations based on electrical (Besic et al. 2012; Leiness et al. 2014; Lum et al. 2017; Sugiyama et al. 2010), optical (Dumont et al. 2010; Räisänen et al. 2015; Langlois et al. 2010; Krol and Lowe 2016; Gergely et al. 2010; Gergely et al. 2014; Wiebe et al. 2013), and acoustic (Capelli et al. 2016; Reiweger et al. 2015; Albert et al. 2015; Datt et al. 2016; Kapil et al. 2014) properties more readily measured in the field.

The density of snow is one indicator related to the strength and stability of the snowpack. Snowpack density changes throughout the season with changes in temperature and liquid water content due to gravitational settling, grain metamorphism, and compaction. Wind can also cause significant densification to the snow by grain rounding and packing during transport and deposition. The current state of the art for snow density estimation includes gamma densiometry (e.g. Wilhelms 1996; Breton et al. 2009), and conventional gravimetric determination through individual cores (e.g. Federal Sampler), or volumetric samples collected from snow pit walls. Efforts are underway to establish neutron probe methods (Morris and Cooper 2003; Hawley and Morris 2006), optical transmission methods (Gergely et al. 2010), and penetrometry methods to parameterize density (Johnson and Schneebeli 1999; Marshall and Johnson 2009). There is no reliable technique for remotely observing snow density, though combinations of methods that detect snow depth (i.e. from LIDAR surface differencing) and SWE, could be employed to derive density.

\subsection{Snow spatial distribution and data merging}

Snow properties vary spatially across a landscape and point snow measurements are often not representative of conditions nearby (Molotch and Bales 2006; Clark et al. 2011). To observe the spatial variability of snow, distributed measurements, dense observation networks, or remote sensing (e.g. airborne or satellite) platforms must be employed. Various techniques for spatially distributing point observations based on landscape characteristics or historical patterns have been investigated. In addition, methods to merge data of different types and resolutions are being developed to produce an integrated estimate. This section describes challenges in understanding the spatial variation in snow characteristics and ongoing research to improve snow estimation over large areas.

The spatial variability in snow accumulation and melt processes plays a critical role in ground moisture conditions and drainage. These processes 
interact with each other through both mass and energy exchanges that impact land surface and atmosphere interactions (Cherkauer and Lettenmaier 2003), and dictate the flow paths of surface runoff or infiltration (Bateni et al. 2015). The complexity of these interactions can be described as a function of scale (i.e. local, watershed, regional), where different processes become more dominant at different scales. The true temporal and spatial variability of snow accumulation and melt processes is likely different than the variability at the scale at which ground or remote observations are made and different at the scale which modeled predictions are needed (Bloschl 1999). This leads to issues in interpolating point observations over large heterogeneous areas, as well as interpreting and disaggregating lower resolution data to relevant scales.

The required scale must be considered in terms of the application (Clark et al. 2011). For global snow estimation, data availability and computational resources are also important factors. The resolution at which data can be produced globally may be coarser than what is required for many DoD applications, such as mobility. Several techniques for downscaling snow data to hillslope scale (1-100 $\mathrm{m}$ ) have been investigated, including sub-grid probability distributions (e.g. Liston 2004). Other methods to downscale coarse resolution estimates include the use of ancillary data, including higher resolution satellite data such as radar, thermal or optical imagery (Scott et al. 2003; Narayan and Lakshmi 2005, 2008), or using indices based on higher-resolution land cover and topography data (Busch et al. 2012). These methods require an understanding of the historical spatial and temporal distribution of snow which can be informed with snow pattern and climatology information.

Long-term patterns of snow residency on landscapes are increasingly used to insinuate snow conditions and longevity (Hall et al. 2015; Macander et al. 2015). Snow patterns, defined as the relative depth distribution (i.e. the spatial location of deep and shallow areas) on a landscape, repeat from one year to the next in a surprisingly consistent way (Sturm and Wagner 2010). The patterns exist because the major controlling factors on snow depth distribution (the interaction of topography, vegetation, and weather patterns) change slowly compared with the seasonal cycle of the snow pack accumulation and melt. This means that while mean snow depth varies from year to year in most landscapes, relative differences remain fixed. Understanding a local snow distribution pattern can enable a point measurement of snow depth to be intelligently extended to describe the snow 
conditions at other locations on a landscape scale (Liston and Sturm 2002). Patchy distributions of snow on meter scale, common in domains where wind is prevalent, cannot be observed by coarse resolution remote sensing, but play a large role in the energy budget in those areas. High resolution tools (e.g. DigitalGlobe's Worldview assets) can significantly add to observation of heterogeneous distributions during melt. These heterogeneous distribution patterns seen during melt can be used to generate predictive high resolution maps of year-specific (Liston 1999) and climatological (Sturm and Wagner 2010) snow distributions in snow-covered landscapes.

The use of snow pattern repeatability for prediction and mapping has so far been extremely limited. The barrier to applying knowledge of repeatable snow patterns to improved snow characterization lies in a lack of fundamental knowledge. There is not yet a quantitative representation of typical snow distribution patterns in most locations or a general assessment of the temporal and spatial variability in the snow depth distribution and morphologies that wind processes create (Liston and Sturm 1998; Sturm et al. 1998; Massom et al. 2001; Sturm et al. 2002; Liston et al. 2007, 2008). Despite historical snow pattern analyses providing useful information of prevailing trends (Sturm and Wagner 2010), these analyses are also vulnerable to errors tied with protruding canopies where snow cover assessments cannot reliably distinguish snow under the canopy (Hall and Riggs 2007). The influence of snow suspended in the canopy remains unaddressed. Figure 6 shows an example of modeled snow depths for Hubbard Brook Experimental Forest (New Hampshire, USA) for simulation years 2000-2013 showing consistent year-to-year elevation and land cover relative snow depth differences and substantial inter-annual variability. 
Figure 6. Simulated 1 March snow depth for Hubbard Brook Experimental Forest (New Hampshire, USA) for years 2000 to 2013.
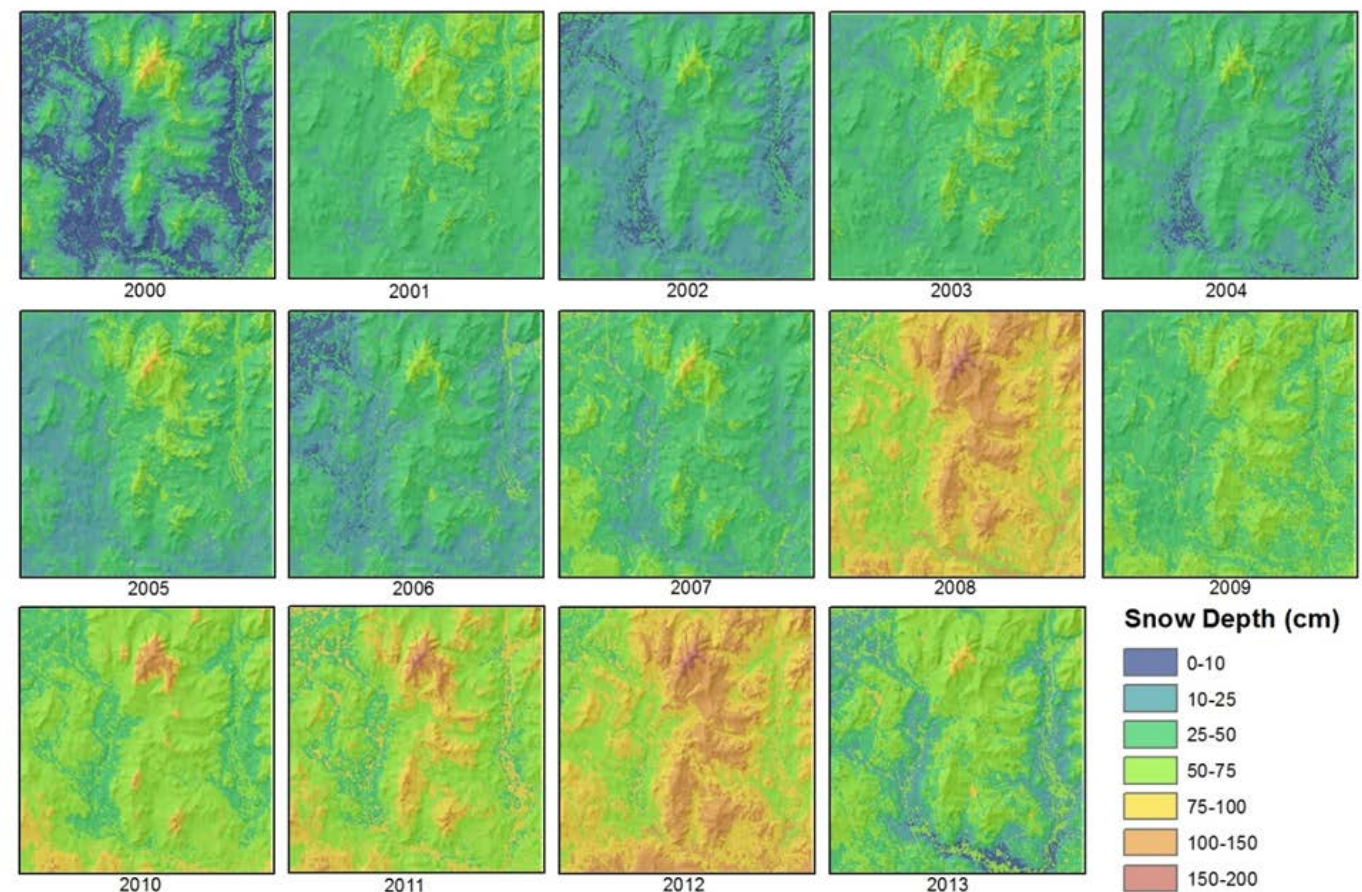

Snow Depth $(\mathrm{cm})$

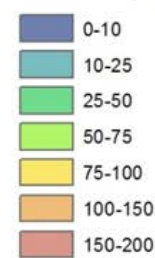

A multi-variable snow climatology can also help inform spatial distribution of snow characteristics based on historical observations and modeled estimates. Several efforts to develop a long-term global snow product have been conducted, though none at the spatial resolution needed to resolve some of the topographic and vegetation influences on snow distribution or at the extent to cover the globe. A global SWE climatology based on passive microwave data was developed from data spanning 1978 through 2007 at a resolution of $25 \mathrm{~km}$ (Armstrong et al. 2005). Several reanalysis products have been developed which provide global SWE and snow depth information, such as Modern Era Retrospective-Analysis (MERRA) (Rienecker et al. 2011), GLDAS (Rodell et al. 2004) and Canadian Meteorological Centre (CMC) (Brown and Brasnett 2010), but at coarse resolutions (> $35 \mathrm{~km}$ ). Liston and Hiemstra (2011) used SnowModel and MERRA reanalysis data to develop a long-term (1979-2009) snow estimate product over the pan-Arctic region at $10 \mathrm{~km}$ resolution. This product used MicroMet to downscale forcing data and account for terrain and vegetation effects. A similar technique applied globally could be used to develop a snow climatology that resolves the spatial variability due to landscape effects. 
To advance spatial characterization and pattern detection, data extraction from a multitude of sources should be employed. Complementary information from different sensors, combined with detailed ground data and processing algorithms, can be used to quantify snow distribution. Machine vision and machine learning are advancing at rapid rates, specifically in developments involving image segmentation and data classification. These techniques have been used to distinguish snow cover from clouds in optical imagery (Srivastava and Stroeve 2003), and for analyzing large data cubes from remote sensing and modeled data to estimate SWE (Bair et al. 2018). As the volume of remotely sensed information from numerous sources increases, a data mining system which evaluates multiple databases and can detect hidden patterns should be investigated for snow.

Multiple sources of spatially distributed snow information can be merged within the modeling framework through data assimilation. Assimilation techniques of varying complexity have been used in operational systems to incorporate snow information (see Section 3.2), from direct insertion to more advanced filtering techniques (Reichle 2008). However, realistic representations of background error uncertainty in all assimilated observations are required. If not, assimilation systems will perform poorly even with good quality observations (Kumar et al. 2017). Limited efforts to date to characterize error in snow data should be expanded (e.g., Dong et al 2005; Foster et al. 2005; Durand et al. 2011).

\subsection{Modeling}

Models are used to represent the physical characteristics of the snowpack and can help in snow estimation spatially and temporally when observations are not available. Models can also be used to downscale coarser-resolution estimates to meet application requirements. Research has been done to develop approaches to numerically simulate the snow characteristics described above as well as snow stratigraphy and temperature. When snow is of interest operationally, the conditions that create and transform it, such as temperature, wind, melt regimes, underlying soil conditions, and vegetation are often also of interest. In this section, various formulations used to simulate snow accumulation and ablation processes are described. We identify a number of physical processes that are now being represented in high resolution local models or global scale reanalysis models which are ripe for transition into improving realism of global scale operational models. 
Physically-based snow models represent snow accumulation and ablation by solving the mass and energy balance equations. Differences between models typical revolve around which processes they choose to represent and how they are parameterized. Processes models typically represent include the ability to simulate snow precipitation; blowing snow redistribution and sublimation; interception, unloading, and sublimation within forest canopies; snow-density evolution; and snowpack ripening and melt. Models can be designed to represent the snowpack as one homogenous layer or multiple layers. Required model inputs include temporally varying meteorological and radiative forcing data within or near the simulation domain, and spatially distributed, time invariant topography and land cover. Several physically-based snowpack evolution models exist, including SNTHERM (Jordan 1991), SNOBAL (Link and Marks 1999; Marks and Winstral 2001; Marks et al. 2002), SnowModel (Liston and Elder 2006; Liston et al. 2007), and CROCUS (Brun 1989; Brun et al. 1992). These types of models are too detailed for a full summary here, but many parameterizations that have been validated at the process-model scale are suitable for near-term transition to operational modeling.

Aspects of physically-based process models currently under development include albedo calculations and snow metamorphism. For example, SnowModel currently uses a simple approach to albedo that initializes new snow albedo at 0.85 , and gradually ages the snowpack's albedo as time passes according to a simple, formula following Douville et al. (1995) and Strack et al. (2004). This calculation omits dust on snow and surface roughness feedbacks. More advanced snow albedo processes models, such as SNICAR (Flanner et al. 2007) are available for incorporation.

Snow metamorphism and microstructure largely determine snow strength, as well as snow optical properties. Traditionally, for the sake of simplicity, snow has been treated as a homogeneous medium made up of uniform spherical particles. Many bulk properties including snow strength, optical properties, and thermal properties are predicted through empirical relationships based on these simplified geometries, and good predictions are often possible if spherical particle size is set correctly. Modeling efforts are underway to relate snow microstructure to macroscale strength properties (Bartelt and Von Moos 2000; Schneebeli 2004; Hagenmuller et al. 2014). 
Model treatment of dry snow metamorphism is more advanced than for wet snow. One current state-of-the-art parameterization uses a microphysical model that takes into account snow temperature, temperature gradient, density, and initial grain size (Flanner and Zender 2006), capturing many expected grain metamorphosis processes. This approach is still too simplistic as it almost always results in greater grain size with higher temperature. Many real world conditions (e.g. kinetic grain growth such as formation of surface hoar) can create complex, high SSA surface grains, and do so preferentially at higher temperatures. Further, though higher temperatures are well-documented on the Greenland ice sheet in recent years (Hall et al. 2013; McGrath et al. 2013), no evidence has been found for appreciable change in dry snow grain size either in remote sensing or surface data (Polashenski et al. 2015). These findings indicate a need for increased model sophistication.

The treatment of wet snow albedo evolution through coupled grain growth and increased moisture content in global scale models is more rudimentary, with almost all current models using parameterizations based on Brun (1989), which does not account sufficiently for the change in SSA brought about by the onset of melting conditions. Brun's work was based on a limited number of seasonal snow samples, and was conducted using digital 2D images to determine grain size. Newer snow imaging technology would allow full $3 \mathrm{D}$ investigations of the evolution of the grain growth, which is important in naturally anisotropic snowpacks. Full 3D analysis also allows for the investigation of secondary microstructure effects (grain shape and orientation) that impact radiative transfer in addition to grain size, wetness, and impurity loading. 
Table 3. Current snow science capabilities: ongoing applied research, TRL 3-5 (green); potential/basic research, TRL 2 (orange); identified research gap,

TRL 1 (red), N/A (gray).

\begin{tabular}{|c|c|c|c|c|c|c|c|c|c|c|}
\hline & Technology & $\begin{array}{c}\text { Spatial } \\
\text { Coverage }\end{array}$ & $\begin{array}{l}\text { Temporal } \\
\text { Resolution }\end{array}$ & $\begin{array}{c}\text { Spatial } \\
\text { Resolution }\end{array}$ & SCA & $\begin{array}{l}\text { SWE/Snow } \\
\text { Depth }\end{array}$ & Optical & Wetness & $\begin{array}{c}\text { Micro- } \\
\text { structure }\end{array}$ & Strength \\
\hline \multirow{4}{*}{ 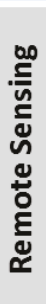 } & $\begin{array}{l}\text { Passive } \\
\text { Microwave }\end{array}$ & Global & Twice daily & $10-25 \mathrm{~km}$ & & & & & & \\
\hline & Radar & Local & Weekly & $1 m-100 m$ & & & & & & \\
\hline & VIS/IR & Global & Daily & $250-500 m$ & & & & & & \\
\hline & LiDAR & Local & $\begin{array}{l}\text { Weekly to } \\
\text { Seasonal }\end{array}$ & $50 \mathrm{~m}$ & & & & & & \\
\hline \multirow{6}{*}{ 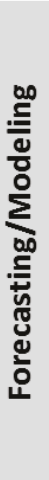 } & $\begin{array}{l}\text { Reconstruction } \\
\text { (Ablation period) }\end{array}$ & Local & Hourly - daily & $1 \mathrm{~m}-1 \mathrm{~km}$ & & & & & & \\
\hline & Energy Balance & $\begin{array}{l}\text { Local to } \\
\text { Regional }\end{array}$ & Hourly - daily & $1 \mathrm{~m}-1 \mathrm{~km}$ & & & & & & \\
\hline & Radiative Transfer & $\begin{array}{l}\text { Local to } \\
\text { Global }\end{array}$ & Hourly - daily & Point $-5 \mathrm{~km}$ & & & & & & \\
\hline & Climate Model & Global & $\begin{array}{l}\text { Daily - } \\
\text { monthly }\end{array}$ & $25-50 \mathrm{~km}$ & & & & & & \\
\hline & Hydrology & Local & Hourly - daily & $100 m-4 \mathrm{~km}$ & & & & & & \\
\hline & $\begin{array}{l}\text { Statistical/ } \\
\text { Machine Learning }\end{array}$ & $\begin{array}{l}\text { Local to } \\
\text { Global }\end{array}$ & Hourly - daily & $1 \mathrm{~m}-1 \mathrm{~km}$ & & & & & & \\
\hline \multirow{4}{*}{ 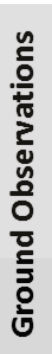 } & $\begin{array}{l}\text { Snow } \\
\text { courses/pillows }\end{array}$ & Point & $\begin{array}{l}\text { Hourly - } \\
\text { weekly }\end{array}$ & Point & & & & & & \\
\hline & Snow Pits & Point & $\begin{array}{l}\text { Weekly - } \\
\text { seasonal }\end{array}$ & Point & & & & & & \\
\hline & $\begin{array}{l}\text { Ground-based PM } \\
\text { Radiometers/ } \\
\text { Radar/LiDAR }\end{array}$ & Point & $\begin{array}{l}\text { Weekly to } \\
\text { seasonal }\end{array}$ & $1 \mathrm{~cm}-1 \mathrm{~m}$ & & & & & & \\
\hline & $\begin{array}{l}\text { Lysimeters / } \\
\text { Discharge Obs }\end{array}$ & Point & $\begin{array}{l}15 \min -1 \\
\text { hour }\end{array}$ & Point-basin & & & & & & \\
\hline
\end{tabular}




\section{Key Gaps in Scientific Knowledge and Capacity}

Gaps in the current scientific understanding of snow processes and our ability to measure snow properties constrain operational product development. The gaps are grouped into four broad categories for discussion: (1) the need for improved remote data collection, enabled by enhanced remote sensing signal processing and algorithm development; (2) the need for improved ground-based data collection, sharing, and archiving; (3) the need to confront data synthesis and scaling issues, and (4) our limited understanding of key processes needed for model development. Often these gaps overlap or require work on multiple fronts in order to be fully addressed.

\subsection{Remote sensing: signal processing and algorithm development}

Key gaps exist in understanding the interactions of electromagnetic signals with snow in the air and on the ground, and more importantly in developing algorithms to exploit the interactions of these signals to produce useful information. Moreover, the complexity of these gaps vary across different snow climates (e.g. spatial) as well as throughout the snow accumulation/ablation season (e.g. temporal). Figure 7 highlights the nature of these complexities in space, time, and across the electromagnetic spectrum. These limitations directly impact the ability to translate snow conditions and sensor performance into tactical decision tools, and impact our ability to effectively exploit the spectrum for remote estimation of snow properties. 
Figure 7. Matrix of the spatial (snow class), temporal (seasonal), and wavelength dependence on the scientific knowledge and research gaps in the remote sensing of snow.

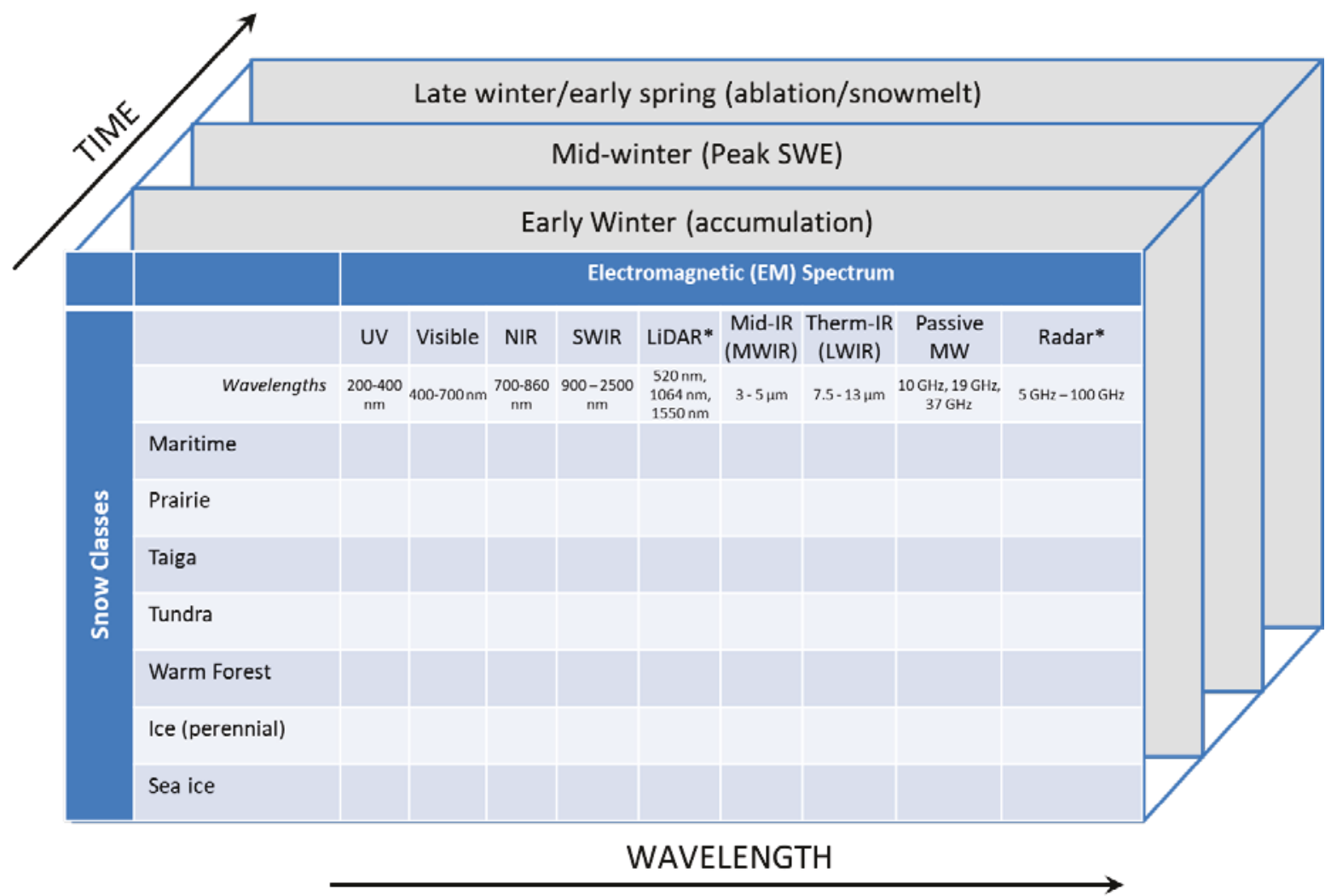

Efforts to quantify SWE, snow depth, albedo, and snowfall rates exist using microwave sensors, space-based radars, and optical imagery, but do not meet the DoD's operational accuracy requirements. Liquid water content, and microstructure observing techniques are all too immature for space-based missions at this time, while some variables, such as snow strength are not currently determined by signal interpretation at all. These must instead be addressed through synthesis of observable data in model frameworks.

Airborne and space-based remote sensing of snow is an area of rapid development. NASA has recognized the need to bring the sensor technology to a new level and is currently sponsoring a multi-year snow campaign (SnowEx) to help develop and validate algorithms for several remote sensing instruments such as active (synthetic aperture radar [SAR]) and passive microwave radiation, visible imagery, and LIDAR. The goal of SnowEx is to help characterize gaps in our understanding of snow remote sensing and to provide the foundation for a NASA satellite mission. This goal is 
well aligned with the goals of this Strategic Plan and provides an opportunity to address many of the same research needs. Here we highlight some of the key gaps in snow remote sensing along with near-term approaches to filling them.

Gap 1.1: Characterization of uncertainty in remotely-sensed signals. Assimilation of remotely sensed observations requires an estimate of uncertainty. Characterization of the uncertainty in various observing techniques is an important area of research as new and existing methods are developed. As an example, passive microwave remote sensing techniques are sensitive to volume scattering of a snowpack and empirical algorithms for microwave sensors have been used for decades to estimate SWE. Accuracy at the level required for operations has remained elusive because the signal is affected by the natural conditioning of the snowpack (Hallikainen et al. 1986; Walker and Goodison 1993), large snow crystals or depth hoar (Hall et al. 1986; Foster et al. 1999; Josberger and Mognard 2002), and vegetation (Derksen et al. 2003, 2005). Empirical methods typically rely on statistical relationships between experimental observations of SWE and microwave emissions. These relationships can break down as the snowpack evolves over the season or with regional vegetation and landscape differences (Vuyovich et al. 2014). Additional research to increase understanding of regional and temporal uncertainty would help increase utility of existing products. Methods to estimate SWE using coupled snow and microwave radiative transfer models (e.g. GlobSnow) have shown improved results over empirical methods (Takala et al. 2011). Research to evaluate and improve microwave radiative transfer models so that brightness temperature data can be assimilated directly should be investigated.

Gap 1.2: High resolution SWE products. Current global SWE observations are available only at coarse spatial resolutions $(>10 \mathrm{~km}$ ) (Frei et al. 2012). Further developments are necessary to estimate SWE at the watershed scale. A newly-available, NASA MEaSUREs Calibrated, EnhancedResolution Brightness Temperature (CETB) Earth System Data Record (ESDR) takes advantage of overlapping satellite observations to produce a higher resolution dataset $(<10 \mathrm{~km})$ over the period of record of microwave observations (1978 - 2017) (Long and Brodzik 2016). These data may help resolve some of the spatial heterogeneity in the SWE signal and increase understanding of snow evolution in varied terrains. The standard deviation of the component data is also captured which may help quantify uncertainty estimates for algorithm development. Empirical algorithms to 
estimate SWE in near real-time using the CETB data may be possible, though it is unclear whether signal noise can be sufficiently reduced from the real-time data. Incorporation of LiDAR and photogrammetry data to measure snow depth can improve the ability to resolve SWE variability, particularly in mountainous terrain, if density data are available or can be estimated. However, substantial questions of accuracy and signal interpretation under forest canopies remain to be resolved.

Gap 1.3: Ability to remotely sense wet snow. The spring ablation period is an important time to monitor snow conditions, but liquid water in the snow impacts many remote sensing techniques for observing snow mass. Ground-based FMCW radar does show some skill in estimating SWE in wet snow (Marshall et al. 2004), though additional research is needed to assess the signal during the transition period, and it is not clear how this technique will translate to a space or airborne platform. Altimetry methods bypass this issue to some degree because they are sensing the physical height of the snow rather than mass, but still need an accurate estimate of density (during a highly transitional time period) to convert those data to SWE.

Active and passive space-borne microwave sensors have shown utility in detecting snowmelt or rain-on-snow events. This sensitivity shows promise in detecting the timing and spatial distribution of melt, but so far are restricted largely to detecting only the binary presence or absence of liquid water. Optical and infrared imagery have been used to estimate snow melt based on albedo and surface temperature observations (Green et al. 2002). There is substantial interest in extracting information about the liquid water content (LWC) of the snowpack. Future research investigating responses to signal polarization may provide the additional information needed to discern LWC. Additionally, techniques to measure SWE even when the snow is wet are needed.

\section{Gap 1.4: Determining snow properties under forest canopies.} Forest canopy cover, in particular, has hindered the ability to measure snow cover and snow water equivalent (SWE) using ground-based observations and remote sensing techniques (Nolin 2010; Hancock et al. 2013). During snow accumulation in all snow-dominated terrestrial environments, snow deposition and movement are shaped by topography and vegetation (Elder et al. 1991; Marks and Winstral 2001; Hiemstra et al. 2002; Hiemstra et al. 2006; Rasmus et al. 2011; Revuelto et al. 2015; Cohen 
2016). The impact of vegetation can be pronounced at scales of meters to kilometers, especially in windy environments where canopy protrudes well above the snowpack. Since canopy height and its spatial distribution in temperate environments is largely correlated with water availability, relatively mesic boreal and montane environments tend to support taller and densely-spaced canopies that obscure ground snow cover. As a result, there is a distinct positive spatial correlation between snow abundance and canopy structure, as well as modulation of energy into and from the snowpack (Link et al. 2004; Lundquist et al. 2013). Interception of falling snow increases with canopy density, often leading to increased snow mass loss by sublimation (Schmidt 1991; Montesi et al. 2004; Gelfan et al. 2004; Musselman et al. 2008; Pomeroy et al. 2012; Moeser et al. 2015). Further, forested environments are increasingly subject to forest structure changes (due to fire, insects, and drought) that can dramatically and rapidly shift canopy-snow interactions.

Satellite, aircraft, or drone-based sensors have difficulty penetrating the canopy in forested areas that are hydrologically critical in middle- and high-latitude environments (Cohen 2016). Effects of the canopy on remotely sensed data are poorly understood. Measurement efforts on the ground are hindered by thick canopy. Dense canopy is often avoided because of time limitations and the desire to sample larger open areas that minimize variability at the remote sensing pixel scale (tens of meters to tens of kilometers), potentially biasing the sample.

Aerial LIDAR (Deems et al. 2013; Painter et al. 2016), airborne and satellite photogrammetry (Nolan et al. 2015; Shean et al. 2016), and InSAR Glacier and Land Ice Surface Topography Interferometer (GLISTIN) (Moller et al. 2017) are used to estimate snow depths for a number of terrestrial environments by differencing a "bare earth" surface with a snowcovered surface. Yet, the accuracy of this approach in forested (and hydrologically vital) environments where aircraft-mounted or drone-based LIDARs are much less likely to penetrate the canopy is under-examined. Current approaches assume that snow depths measured in adjacent gaps translate to areas under the canopy (there are some exceptions to this, e.g. Liston and Hiemstra 2008), and the effectiveness of this approach is specious given that forest-gap transitions experience markedly deeper snows. The approach is likely to be especially false in areas with high wind speeds and larger canopy gaps, where snow can be redistributed into clearings (Hiemstra et al. 2006). Further, these surface-differencing approaches can 
encounter errant "bare earth" observations where, during snow-free data collections, a thick canopy obscures the ground. This is especially true with summer and fall bare-ground data collections when most of the ground is obscured by abundant live or senesced biomass.

At much longer (e.g. microwave) wavelengths, penetration through vegetation is possible, however, accounting for the effect of the vegetation on the signal introduces several more unknown parameters in an already poorly constrained inverse problem. Because of the changes in the snow microstructure under the canopy, as well as wind speed in the canopy, both longwave and shortwave radiation are typically different than in nearby gaps. Current microwave scatterometer approaches and those developed under CoReH2O (Yueh et al. 2009; Du et al. 2010; Xu et al. 2010) require a priori information about snow microstructure, and potentially two parameter microscale correlation length parameters. Additionally, we currently do not know the canopy density threshold for successful remote sensing data retrieval. Methods to estimate SWE that account for the vegetation impact in areas with significant canopy should also be investigated.

\section{Gap 1.5: Determining snow strength from remotely sensed}

quantities. Mobility concerns demand methods to assess snow mechanical properties, but it is unlikely that these properties can be directly or remotely sensed. This gap demands linking snow properties that are measureable to snow strength through a modeling component. Algorithm development will require relationships be developed between in situ observations of snow density and other characteristics and ground-based penetrometry. Remote sensing techniques which detect these properties from airborne and satellite-based data need to be investigated. The ability to remotely sense snow density would have the additional benefit of improving SWE estimates that use snow depth observations by reducing the uncertainty in the snow density estimates.

Gap 1.6: Exploiting high-resolution spectra. Optical imagery is useful in distinguishing snow-covered and snow-free areas, evaluating accumulation and ablation patterns, and informing physically based SWE reconstruction models. Though these data are limited by cloud cover, which often occurs during periods of critical precipitation, a substantial amount of information is available on snow properties from variability in snow's spectral reflectance. Hyperspectral sensors have been used to measure SCA, grain size, near-surface liquid water content, and spectral 
and broadband albedo (Dozier et al. 2009). The lack of a space-based hyperspectral mission is a key gap in capabilities - extending well beyond snow science. Methods to estimate grain size, which has impacts on albedo, from available multispectral space based sensors have shown high uncertainty. Enhancements to the spectral unmixing algorithms and incorporation of ancillary data to improve classification in forested regions should be investigated to advance retrieval methods.

\subsection{Ground observations: improved collection, sharing and archiving}

Reliable in situ data is a critical component of the snow characterization mission, used to validate models and remote sensing observations. Maintaining existing data collection streams and ensuring maximum data availability is a challenge. There is a capacity gap arising from a lack of measurements in many areas, and a need to improve observational capabilities and networks. Some desired measurements are not yet possible with autonomous stations - providing an opportunity to develop new ways of collecting data to increase observation availability in an era of declining monitoring funds and shrinking networks. The synthesis and standardization of data into readily assimilated forms remains a need.

Gap 2.1. Improved operational observation capacity. Ground observations are valuable for providing a long-term record of snow-related conditions and properties, form a critical basis for validating remote sensing techniques, and provide a source of data for assimilation into models. Unfortunately, there are many observational networks in decline, especially in more remote areas where data are already sparse. The degrading capability results in a scarcity of snow observations even where past observations have been collected. In particularly remote environs, such as on sea ice and ice sheets, observations are even sparser. Accumulation of snow on sea ice has been almost entirely neglected, in spite of its importance in ocean ice dynamics, atmospheric interactions, and subsequent snowmelt, and SNODEP estimates of snow depth over Greenland and Antarctica are recognized as poor.

Citizen networks can help fill some ground based observation gaps. Historically citizen networks have been particularly susceptible to incomplete datasets, network attrition, and lack of quality assurance/quality control (QA/QC). Enhanced web-based data gathering and quality assurance tools 
hold promise for greatly improving quantity and quality of this type of collection, and web content scraping techniques (e.g. Facebook post analysis) is opening the possibility to passive collection approaches.

Decreasing costs for autonomous observing equipment, and increasing available bandwidth for data transmission and retrieval, are making distributed autonomous observation networks more feasible than ever before. Autonomous sensor approaches exist and are well developed for snow depth, albedo, and SWE, though costs for quality albedo and SWE sensors remain high. Autonomous sensors for snow density, strength, wetness, and microstructure remain largely non-existent. Coordination, deployment, maintenance, and common data archiving of this type of station would greatly enhance our observational capabilities.

Gap 2.2. Observations of snowfall rates. Errors in meteorological data used to drive snow models can introduce significant error in snow estimation (Nagler et al. 2008). Ground-based precipitation gauges are in decline, particularly where they tend to be ineffective (cold and windy places) and they are hard to maintain. Remote-sensing based precipitation measurements (e.g. NASA's Global Precipitation Measurement Mission; https://www.nasa.gov/mission_pages/GPM/main/) may fill this gap in precipitation data. However, more attention is needed to determine how accurate these estimates are in snow-dominated regions. More importantly, measured snow precipitation is notorious for underestimating actual snowfall and little information is available to relate to the distribution of snow on the landscape.

Gap 2.3 Standardized data archiving. Snow data collected by agencies (e.g. U.S. Department of Agriculture (USDA), U.S. Fish and Wildlife Service (FWS), U.S. National Park Service (NPS), NOAA) and individual funded projects (e.g. NASA, NOAA, National Science Foundation (NSF), Office of Naval Research (ONR), Strategic Environmental Research and Development (SERDP)) in the U.S. are archived across dozens of locations in multiple formats. Campaign-based snow observations remain only partly standardized and the archiving of campaign data remains erratic and incomplete. International data collections are even more complex. The gap is ultimately an interagency and international cooperation but the same emergent software tools that may help with improved citizen science data collection also are likely to extend the utility of scientific observa- 
tions. Operational standardization efforts and increased demands by funding agencies for data to be archived in a highly useful manner are likely to add value to the scientific enterprise.

\subsection{Data assimilation and spatial scaling}

The spatial and temporal distribution of snow is controlled by a number of processes that operate at different scales ranging from weather systems to snow grains. Observational data does not fully capture these scales, and may not represent snow at the scales of interest for operations. There is a research need to quantify the characteristic lengths of both natural processes and sensor data, and bridge the scale differences between them to produce products at a required spatial resolution. A knowledge gap exists because we do not yet have tools to merge and convert observations collected at a full range of resolutions into spatially continuous estimates of snow characteristics at scales and resolutions relevant to operations. Closing this gap, and improving the scaling and synthesis of snow data across spatial scales, ultimately depends on developing and validating improved methods of scaling and interpolating observations, particularly merging datasets of varying nested resolutions.

\section{Gap 3.1. Incorporating snow climatology and pattern infor- mation into models. Numerous field studies on spatial variability} across multiple scales have found that the dominant control on variability of snow accumulation and melt at the watershed scale $(>100 \mathrm{~m})$ is topography, specifically elevation and aspect (Clark et al. 2011). Snowmelt processes and local scale runoff express significant variability at hill slope scales below $1 \mathrm{~km}$, where vegetation and snow redistribution have a significant and complex influence on the energy balance. For regions greater than $1 \mathrm{ha}$, explicit representation of subgrid variability has been found to greatly improve spatially distributed snowpack modeling due to the nonlinearity of snow processes (Luce et al. 1999). However, relatively few observational datasets exist that can provide such distributions and capture their evolution over time, and fewer still are incorporated into modeling tools to improve output.

Historical snow pattern data and snow climatology information can be used to spatially infill sparse observations and downscale coarse resolution data. Development of an updated snow climatology spanning relevant 
length scales (Marshall et al. 2006) and incorporating snow pattern information is a key step to improving global snow estimation and informing operational mobility models.

Gap 3.2. Improved data assimilation methods. Data assimilation methods often incorporate snow datasets that may not be appropriate at certain times of the year, at certain locations (poor in trees, better in treeless areas), or have internal errors. An approach where data are used or discarded during assimilation based on accuracy assessments which account for seasonal or regional error is needed. To do this, comprehensive uncertainty estimates of assimilated data are required by the science community. Operational systems often do not include data assimilation techniques for snow beyond direct insertion and model nudging. More sophisticated data assimilation techniques need to be assessed and employed.

Additionally, a structure needs to be developed to incorporate partial datasets. To date, process and climatological models, as well as reanalysis data, ingest only a small fraction of the available data, generally favoring full planet, low resolution products like passive microwave data, while failing to incorporate isolated, spatially and temporally discontinuous in situ data, which is often of higher certainty and/or resolution. One example is the NASA/Jet Propulsion Laboratory (JPL) Airborne Snow Observatory (ASO) (http://aso.jpl.nasa.gov/), which combines an imaging spectrometer and scanning LIDAR system on an airborne platform to measure snow depth and albedo at very high resolution $(3 \mathrm{~m})$. This platform has the ability to capture mesoscale and microscale distributions, and may make up for a lack of ground observations in the regions it is flown. To the best of our knowledge its outputs are not incorporated into global operational models, nor are models prepared in any way to benefit from limited observations of similar type that could be collected over combat zones. Similarly, if stereo satellite imagery is collected over part of a domain, methods to take advantage of these data without biasing the entire simulation are needed.

Gap 3.3. Methods for handling variability of density. Snow depth measurements are often used with a static density climatology or with limited density observations to estimate SWE. Spatial variability in snow density could impact SWE estimates derived this way where the assumption is that snow density does not change significantly over a landscape. Raleigh 
and Small (2017) found that density was the largest source of uncertainty when estimating SWE from LIDAR in regions with deep $(>60 \mathrm{~cm})$ snowpacks. It is commonly observed that drifted snow is denser than fresh snow, yet this spatial variability on landscapes is unaccounted for in SWE calculations that chiefly rely on snow depths, and it could have large implications for estimates of water equivalent and snow strength. On a global scale, density measurements are rarely available. Improved understanding of the spatial and temporal variability is required to inform modeled estimates (Kelly et al. 2003). Techniques to remotely assess snow density should be investigated.

\subsection{Process studies and model parameterization}

Scaling issues relate directly to the need for process studies. Parameterizations of snow processes form the basis for models that can assimilate multi-scale data within a physics-based framework. Fundamental research into the processes which have a large impact on data scaling, remote sensing, and modeling accuracy are required. Key areas in need of development include snow metamorphism, microstructure, sublimation, strength and thermal properties, and snow-vegetation interactions.

Gap 4.1. Snow grain growth. Snow grain shape and size significantly impact how signals are scattered when passing through snow. Before realistic, complex snow structures can be incorporated into radiative transfer models, the complicated interaction between snow grain size, shape, and microstructure, and the effect of snow properties, must be better understood. Liquid water content, and snow temperature and density influence the snow grain characteristics and growth and must be well quantified to understand the impact on remotely sensed signals.

Current snow microstructural modeling of grain growth is limited to estimations of snow grain size increase over time, with very few models incorporating grain size or multiple modes of growth. Phase field grain growth models have been explored at ERDC-CRREL as one improvement over conventional grain growth models (Kaempfer and Plapp 2009). Microstructural parameters can be determined in part by optical and radiative properties of the snow. However, much remains unknown about the scalability of these relationships, which have been focused on the micro-scale numerical simulations to date, with very few microstructure to macroscale studies. 
Gap 4.2. Radiative transfer modeling in snow. Traditional snow spectral radiative transfer models range from simple exponential decay, to layer doubling, to Monte Carlo, to a detailed discrete ordinate multistream treatment of the equation of radiative transfer (Dunkle and Bevans 1956; Bohren and Barkstrom 1974; Warren and Wiscombe 1980; Wiscombe and Warren 1980; Warren 1982; Stamnes et al. 1988; Leroux et al. 1998; Mishchenko et al. 1999; Aoki et al. 2000; Flanner et al. 2007). For the most part, the models take a continuum approach by assigning bulk optical properties to the medium. The models are usually plane-parallel and have multiple layers; that is, there is vertical variability in optical properties, but layers are uniform in the horizontal direction.

The continuum models do an excellent job in many applications, but are limited in their treatment of scattering and in the geometries they can investigate. Most theoretical work on light scattering in snow has used an idealized snowpack consisting of spheres having the same equivalent diameter and specific surface area as the real snowpack (Grenfell and Warren 1999; Neshyba et al. 2003; Grenfell et al. 2005). Although these spherical approximations have been shown to have reasonably comparable radiative properties to real snow, they do not enable the accurate/explicit handling of snow wetting processes or feedbacks. Cutting edge research models are now exploring photon-tracking radiative transfer in fully resolved microstructure, such as the ERDC-CRREL RT-DEM developed by Kaempfer et al. (2007). The model uses a geometric optics-based approach to follow the paths of individual photons as they travel through and explicitly interact with the porous network formed by the ice matrix.

Several microwave radiative transfer models have been developed by the snow community, including the Snow Microwave Radiative Transfer thermal emission and backscatter model (SMRT; Picard et al. 2018), the Dense Media Radiative Transfer Multi-Layer model (DMRT-ML; Picard et al. 2012), the Microwave Emission Model of Multi-Layer Snow (MEMLS; Wiesmann and Mätzler 1999), and the Helsinki University of Technology multi-layer model (HUT; Pulliainen et al. 1999; Lemmetyinen et al. 2010; Picard et al. 2018). In a comparison of the available models combined with snow evolution models, Sandells et al. (2017) found that the greatest source of uncertainty in these models was the representation of snow microstructure. The next-largest source of uncertainty was biases and errors at different frequencies and polarizations that will require improved understanding of the basic processes. 
Gap 4.3. Snow sublimation. Sublimation has an important role in water budgets because this is a portion of the precipitation that does not contribute to melt. Sublimation is difficult to measure and estimate, yet, sublimation rates are likely changing due to landscape changes (vegetation growth, decline, and fire) or differences in atmospheric circulation patterns. Published rates of snow sublimation range widely; from $3 \%$ to $80 \%$ of total winter precipitation (Liston and Sturm 2004). This variation is due to differences in site conditions, and differences in instrumentation, observation methods, and modeling or analysis approach. Uncertainty in sublimation is severe enough to alter not just the amount of snow modeled in operational tools, but to change the predicted presence or absence of snow cover by durations in excess of 2 months/year in boreal forest and tundra areas. Studies of snow sublimation rates and processes across climates are needed to understand the impact on snowpack water content, local surface energy balance, and heat-moisture fluxes to the atmosphere.

Gap 4.4. Snow mobilization by wind. Limited understanding of snow grain bond and fracture processes currently prevents reliable characterization and prediction of blowing snow events and fluxes. The degree to which snow grains are extracted and mobilized by wind is highly dependent on both wind speed and the morphology of the upper snowpack, particularly inter-grain bonding. Relationships between wind and snow mobilization are relatively well understood for un-bonded fresh snow, as these have direct analogues in sand and dust mobilization. Processes by which snow grains bond together and become resistant to further redistribution, however, are poorly understood and inadequately parameterized in current models, mostly due to limitations in prior efforts and techniques. Increased interest in predictions dependent on snow mobilization (e.g. degraded visual environments in cold domains) are creating new demand for this basic knowledge. New tools (e.g. micro-CT for microstructure imaging) are providing new avenues to pursue the research into intergrain bond formation and strength.

\section{Gap 4.5. Influence of infrastructure and development on snow distribution and properties. The vast majority of snow research is} conducted in natural landscapes where snow distribution and properties are primarily influenced by the natural terrain and vegetation. For snow estimation on a global scale, this is reasonable given the predominate percentage of snow that occurs in undeveloped regions. However, the impact of human development such as structures, surfaces and diversions, on 
snow spatial distribution, evolution, and runoff will influence operational needs. Fundamental research is required to better understand the impact of infrastructure on snow characteristics. 


\section{Strategic Plan}

Characterizing global snow properties and spatial variability at relevant operational scales is difficult. Sizeable investments have been made to install a multitude of point observations, deploy aerial and space-based sensors, and develop snow process models and data assimilation techniques, demonstrating the importance and need for snow information. To meet the nation's snow requirements a comprehensive approach should be utilized to develop a system that can (a) aggregate disparate datasets; (b) assess the accuracy of those datasets; and (c) synthesize those datasets into a realistic and comprehensive analysis of relevant snow conditions. However, before that synthesis product can be developed, the gaps in scientific knowledge identified above need to be addressed. This section describes a plan to systematically improve our understanding of key processes and perform analysis required to support the development of a comprehensive framework for global snow estimation at the wide range of spatial and temporal scales required by the DoD. The plan includes near- to mediumterm tasks with specific goals identified to meet the operational requirements.

The plan was organized with interaction with the LIS framework in mind. The LIS framework provides an opportunity to investigate techniques to improve characterization of snow to meet the snow data needs and requirements of the civil works, military, and intelligence communities. Within the LIS framework there is significant potential to increase data assimilation, embrace more sophisticated data fusion methods for exploiting the information from remotely sensed data, use ensemble modeling to generate estimates of uncertainty and to employ alternate model structures to address battlefield-scale information needs. Over the short term, these will enable smarter processing and assimilation of current observational inputs. Over the longer term there is a need to assimilate new inputs and increase the physical realism of the model. Ultimately these efforts must lead towards output of the variables demanded by DoD requirements identified above, rather than just snow physical properties. Specific research goals to support these efforts are described in the following sections. 


\subsection{Improve current real-time snow characterization (1 - 3 years)}

In the near term there is mature research ready to be transitioned to an operational framework and ongoing research towards helping to improve real-time snow estimation that will immediately improve current capabilities. These efforts include the incorporation of advanced snow model physics and assimilation of available remotely sensed data. Further investigation of signal impacts and the development of a snow climatology to inform spatial distribution and uncertainty will also help in the near- to medium-term. Data flags can be used to indicate when microwave sensing is expected to be very poor (e.g., when the snow is wet). At these times, the snowpack evolved from prior observations by the physics-based model and optical remote sensing data could be alternatively used.

To assimilate remote sensing signals through a forward radiance-based model, an understanding of how the signal is impacted by snow characteristics and the underlying terrain and vegetation is required. A physicsbased snowpack model that realistically evolves grain characteristics and wetness, coupled to a radiative transfer model could appreciably improve the interpretation of remote sensing snow data, and reduce systemic errors in assimilated SWE products. Recent incorporation of the advanced models such as Noah-MP, JULES, and CLM multi-layer snow model with liquid water storage and melt/refreeze capability into LIS, as well as a snow-canopy interception model (Yang and Niu 2003; Niu and Yang 2004) provides some of the physical realism needed to improve modeled microwave radiative transfer.

Efforts to improve remote sensing techniques and model physics rely on in situ observations of key physical snow properties to validate results. Observational networks and field campaigns will provide critical information towards addressing the gaps in snow understanding. Instrumentation which can accurately measure snow characteristics of interest should be supported and advanced. Additionally, standard methods for collecting and archiving ground-based measurements will greatly benefit the entire research community.

Specific near-term goals are

- Algorithm development and uncertainty estimation for remote sensing (i.e. electro-optical/infrared and microwave)

- Development and validation of global snow climatology methodology 
- Explore techniques to remotely sense physical snow properties (i.e. wet snow, density, etc.)

- Explore influence of terrain and vegetation characteristics on remote sensing signals

- Evaluate physics-based snow models for ability to

- Realistically distribute snow properties on the landscape

- Simulate the snowpack stratigraphy and evolution

- Development of downscaling or reconstruction techniques to understand regional snow distribution and improve resolution.

\subsection{Advance data merging and assimilation capabilities (2 - 5 years)}

Large volumes of data currently being collected are not being ingested by the current operational efforts. Simply increasing the number of data sources being assimilated could reduce reliance on imperfect climatology and on empirical algorithms. Success would demand resources for centralizing and standardizing data streams collected by a wide array of agencies, stakeholders, and nations. Data currently not being used in the $557 \mathrm{WW}$ process includes that from in situ sensor networks (e.g. International Arctic Buoy Program data), airborne assets (e.g. ICEBRIDGE, ASO, NRL), and alternate satellite-missions (e.g. AMSR-2, Landsat, MODIS, CRYOSAT). The urgency for incorporating alternate remote sensing data sources is heightened by the concern that there may be a gap in availability of scanning microwave remote sensing data with the remaining DMSP satellites currently operating well beyond their design life. The only other suitable scanning microwave radiometer in operation is the JAXA AMSR-2. With no new launches of similar sensors planned the risk of a data gap is real, bringing urgency to efforts that could assimilate other types of satellite data. Also, the fact that a truly global product is sought (including ice sheets and sea ice) further argues for the need to supplement microwave and optical remote sensing with other means, due to inability of these sensors to provide meaningful information over perennially snow/ice covered areas.

A growing scientific consensus suggests that no single remote sensing tool or spectrum is capable of providing good snow data at all times and in all locations. Instead, particular tools have superior capabilities under certain circumstances. Substantial opportunities already exist for incorporating multi-modal sensing (e.g. Armstrong and Brodzik 2001) that blend multiple remote data streams to increase the fidelity and resolution of snow 
data inputs (e.g. The National Environmental Satellite, Data, and Information Service (NESDIS) Interactive Multi-sensor Snow and Ice Mapping System 4km product (IMS; Helfrich et al. 2007), the Canadian Meteorological Centre Snow Cover product (Brasnett 1999), and the joint U.S. Air Force/NASA blended global snow product (Foster et al. 2011). Efforts underway to improve remote sensing of snow (e.g. NASA SnowEx, ESA CryoSat-2) and bring laser and radar-based altimetry and LIDAR into operational use will soon make multiple source streams at least regionally available.

Many of the snow variables of interest for battlespace environmental awareness are highly heterogeneous over sub-grid scales. Large scale passive microwave remote sensing and large grid snow estimates simply do not meet the needs of the warfighter in these areas. Implementation of higher resolution (on the order of tens of meters to 1 kilometer) downscaling of the passive microwave daily observations should be explored. Tools are available that could be nested within the framework for high resolution (vertical or horizontal) runs over battlespace domains. Such advances may include incorporating a physical-based snow model in such a manner that model physics are permitted to evolve the snowpack stratigraphy, or incorporating a nested higher horizontal resolution model over domains of interest.

Specific medium-term goals are

- Produce global snow climatology based on developed methodology

- Fully incorporate physics-based snow model into LIS

- Develop multi-scale data merging and downscaling techniques

- Investigate real-time high-resolution passive microwave data

- Investigate data assimilation methods for remote sensing and observational data

- Explore machine learning techniques for incorporating multiple data sources

- Develop and validate techniques to sense wet snow mass and melt onset

- Improve background spectral characterization to support implementation of spectral algorithms. 


\subsection{Operational snow characterization framework (more than 5 years)}

An advanced data assimilation system could incorporate multiple inputs intelligently based on a better characterization of snow physics and an understanding of sensor uncertainty. The shared use of LIS in the research and operational communities presents a viable transition pathway for more comprehensive model physics, satellite-based data assimilation techniques, and higher resolution analyses that already exist in the academic realm. A fully operational framework would include the physics-based model and remote sensing data assimilation components. New satellitebased remote sensing capabilities to directly observe/estimate snow properties are expected to emerge and should be explored through coordination with partner agencies.

Improvements to snow capabilities in a data assimilation framework should be evaluated for their impact on applications. Melt regimes, underlying soil conditions and properties, and precipitation type and timing will all affect the ability to estimate terrain conditions and runoff calculations. Energy input and warming at a crucial period of the year when insolation is highest influences snowmelt and infiltration rates. Exploring snow arrival and snowmelt timing in addition to rain-on-snow events and snowcover changes in more detail will improve estimation of snow state and terrain strength for mobility and flood forecasting.

Specific long-term goals are

- Incorporate radiance-based assimilation techniques

- Incorporate uncertainty estimation into assimilation process

- Add wet snow flag to inform onset timing and uncertainty

- Continued improvement of model physics

- Wind redistribution

- Wind redistribution

- Sublimation

- Microstructure

- Explore remote sensing capabilities for other snow characteristics (e.g. density)

- Validate system through hydrologic and climatologic model performance. 


\section{Conclusion}

The technology gaps for snow operational support were grouped into four broad categories for discussion: (1) the need for improved remote data collection, enabled by enhanced remote sensing signal processing and algorithm development; (2) the need for improved ground-based data collection, sharing, and archiving; (3) the need to confront data synthesis and scaling issues, and (4) the limited understanding of key processes needed for model development. Often these gaps overlap or require work on multiple fronts in order to be fully addressed. From these knowledge gaps, we identified short-term through long-term plans to advance remote sensing capabilities, increase data intake and incorporate more comprehensive modeling paradigms.

This plan relies on advancements in snow science on multiple fronts and research activities that span the snow research community from snow process understanding, to sensor and algorithm development, to advanced computational processing and assimilation techniques. This document was developed as a joint effort between CRREL and numerous partner organizations and is expected to be a living document, revised and adjusted as progress is made. It is also anticipated that this plan will further global snow estimation capabilities towards meeting the DoD requirements. 


\section{References}

Adão, T., J. Hruška, L. Pádua, J. Bessa, E. Peres, R. Morais, and J. Sousa. "Hyperspectral imaging: A review on UAV-based sensors, data processing and applications for agriculture and forestry." Remote Sensing 9, no. 11 (2017): 1110.

Adams, E. E., D. A. Miller, and R. L. Brown. "Grain boundary ridge on sintered bonds between ice crystals." Journal of Applied Physics 90, no. 11 (2001): 5782-5785.

Albert, D. G., A. J. Song, and Z. R. Courville. High frequency oblique-angle acoustic reflections from an air-snow interface. The Journal of the Acoustical Society of America 137, no. 4 (2015): 2198-2198.

Aoki, T., T.Aoki, M. Fukabori, A. Hachikubo, Y. Tachibana, and F. Nishio. "Effects of snow physical parameters on spectral albedo and bidirectional reflectance of snow surface." Journal of Geophysical Research: Atmospheres 105, no. D8 (2000): 10219-10236.

Armstrong, R. L., and M. J. Brodzik. "Recent Northern Hemisphere snow extent: A comparison of data derived from visible and microwave satellite sensors." Geophysical Research Letters 28, no. 19 (2001): 3673-3676.

Armstrong, R., M. J. Brodzik, K. Knowles, and M. Savoie. 2005. Global Monthly EASEGrid Snow Water Equivalent Climatology, Version 1. Boulder, CO: National Snow and Ice Data Center Distributed Active Archive Center. doi.org/10.5067/KJVERY3MIBPS.

Bair, E.H., A. A. Calfa, K. Rittger and J. Dozier "Using machine learning for real-time estimates of snow water equivalent in the watersheds of Afghanistan". The Cryosphere 12 (2018): 1579 - 1594.

Bartelt, P., and M. Von Moos. "Triaxial tests to determine a microstructure-based snow viscosity law." Annals of Glaciology 31 (2000): 457-462.

Bateni, S. M., S. Margulis, E. Podest, and K. McDonald "Characterizing snowpack and the freeze-thaw state of underlying soil via assimilation of multifrequency passive/active microwave data: a case study (NASA CLPX 2003)". IEEE Trans. on Geoscience and Remote Sensing (2015) Vol. 53(1), pp. 173 - 189.

Besic, N., G. Vasile, J. Chanussot, S. Stankovic, J.-P. Dedieu, G. d'Urso, D. Boldo, and J.P. Ovarlez. Dry snow backscattering sensitivity on density change for SWE estimation. In Geoscience and Remote Sensing Symposium (IGARSS), IEEE International, pp. 4418-4421. IEEE (2012).

Best, M. J., Pryor, M., Clark, D. B., Rooney, G. G., Essery, R. L. H., Ménard, C. B., Edwards, J. M., Hendry, M. A., Porson, A., Gedney, N., Mercado, L. M., Sitch, S., Blyth, E., Boucher, O., Cox, P. M., Grimmond, C. S. B., and Harding, R. J.: The Joint UK Land Environment Simulator (JULES), model description - Part 1: Energy and water fluxes. Geosci. Model Dev. 4: 677-699. https://doi.org/10.5194/gmd-4-677-2011, 2011. 
Bloschl, G. "Scaling issues in snow hydrology." Hydrological Processes 13 (1999) 2149 2175 .

Bohren, Craig F., and Bruce R. Barkstrom. "Theory of the optical properties of snow." Journal of Geophysical Research 79, no. 30 (1974): 4527-4535.

Borstad, C. P., and D. M. McClung. "Thin-blade penetration resistance and snow strength." Journal of Glaciology 57, no. 202 (2011): 325-336.

Brasnett, B. "A global analysis of snow depth for numerical weather prediction." Journal of Applied Meteorology 38, no. 6 (1999): 726-740.

Breton, D.J., Hamilton, G.S. and Hess, C.T., Design, optimization and calibration of an automated density gauge for firn and ice cores. Journal of Glaciology 55(194), (2009):1092-1100.

Brodzik, M. J., D. G. Long, M. A. Hardman, A. Paget, and R. Armstrong. 2016, updated 2018. MEaSUREs Calibrated Enhanced-Resolution Passive Microwave Daily EASE-Grid 2.o Brightness Temperature ESDR, Version 1. Boulder, Colorado USA. NASA NSIDC DAAC. 10.5067/MEASURES/CRYOSPHERE/NSIDC0630.001.

Brown, R. D. and B. Brasnett. 2010, updated annually. Canadian Meteorological Centre (CMC) Daily Snow Depth Analysis Data, Version 1. Boulder, Colorado USA. NASA National Snow and Ice Data Center Distributed Active Archive Center. doi: https://doi.org/10.5067/W9FOYWHOEQZ3.

Brown, R. D., and D. A. Robinson. "Northern Hemisphere spring snow cover variability and change over 1922-2010 including an assessment of uncertainty." The Cryosphere 5, no. 1 (2011): 219-229.

Brucker, L., A. Royer, G. Picard, A. Langlois, and M. Fily. "Hourly simulations of the microwave brightness temperature of seasonal snow in Quebec, Canada, using a coupled snow evolution-emission model." Remote Sensing of Environment 115, no. 8 (2011): 1966-1977.

Brun, E. "Investigation on wet-snow metamorphism in respect of liquid-water content." Annals of glaciology 13 (1989): 22-26.

Brun, E., P. David, M. Sudul, and G. Brunot. "A numerical model to simulate snow-cover stratigraphy for operational avalanche forecasting." Journal of Glaciology 38, no. 128 (1992): 13-22.

Boucher, Roland J., and James G. Wieler. "Radar determination of snowfall rate and accumulation." Journal of climate and applied meteorology 24, no. 1 (1985): 6873 .

Busch, F. A., J. D. Niemann, and M. Coleman. "Evaluation of an empirical orthogonal function-based method to downscale soil moisture patterns based on topographical attributes." Hydrological Processes 26, no. 18 (2012): 2696-2709. 
Capelli, A., J. C. Kapil, I. Reiweger, D. Or, and J. Schweizer, "Speed and attenuation of acoustic waves in snow: Laboratory experiments and modeling with Biot's theory”. Cold Regions Science and Technology, 125 (2016): 1-11. doi: 10.1016/j.coldregions.2016.01.004

Carroll, T., D. Cline, G. Fall, A. Nilsson, L. Li, and A. Rost. "NOHRSC operations and the simulation of snow cover properties for the coterminous US." In Proceedings of the 69th Western Snow Conference, pp. 16-19. 2001.

Casey, K.A., C. M. Polashenski, J. Chen, and M.Tedesco. "Impact of MODIS sensor calibration updates on Greenland Ice Sheet surface reflectance and albedo trends." The Cryosphere 11, no. 4 (2017): 1781.

Castellani, B.B., Shupe, M.D., Hudak, D.R. and Sheppard, B.E., "The annual cycle of snowfall at Summit, Greenland". Journal of Geophysical Research: Atmospheres, 120(13), (2015) pp.6654-6668.

Cherkauer, K. and D. Lettenmaier "Simulation of spatial variability in snow and frozen soil”. Journal of Geophysical Research: Atmospheres 108 (D22), (2003) doi:10.1029/2003JDoo3575.

Clark, M. P., J. Hendrikx, A. G. Slater, D. Kavetski, B. Anderson, N. J. Cullen, T. Kerr, E. Örn Hreinsson, and R. A. Woods. "Representing spatial variability of snow water equivalent in hydrologic and land-surface models: A review." Water Resources Research 47, no. 7 (2011).

Cline, D., K. Elder, B. Davis, J. Hardy, G. E. Liston, D. Imel, S. H. Yueh, A. Gasiewski, G. Koh, R. Armstrong, M. Parsons. "Overview of the NASA cold land processes field experiment (CLPX-2002)." In Microwave Remote Sensing of the Atmosphere and Environment III, vol. 4894, pp. 361-373. International Society for Optics and Photonics, 2003.

Cohen, J. "An observational analysis: Tropical relative to Arctic influence on midlatitude weather in the era of Arctic amplification." Geophysical Research Letters 43, no. 10 (2016): 5287-5294.

Comiso, J. C., and D. K. Hall. "Climate trends in the Arctic as observed from space." Wiley Interdisciplinary Reviews: Climate Change 5, no. 3 (2014): 389409.

Cook, J. M., A. J. Hodson, A. S. Gardner, M. Flanner, A. J. Tedstone, C. Williamson, T. DL Irvine-Fynn, J. Nilsson, R. Bryant, and M. Tranter. "Quantifying bioalbedo: a new physically based model and discussion of empirical methods for characterizing biological influence on ice and snow albedo." The Cryosphere 11, no. 6 (2017): 2611.

Datt, P., J. C. Kapil, A. Kumar, and P. K. Srivastava. Experimental measurements of acoustical properties of snow and inverse characterization of its geometrical parameters. Applied Acoustics 101 (2016): 15-23.

Deeb, E.J., R.R. Forster and D.L. Kane (2011) Monitoring snowpack evolution using interferometric synthetic aperture radar on the North Slope of Alaska, USA. International Journal of Remote Sensing, 32(14): 39854003, DOI: 10.1080/01431161003801351 
Deems, J., Painter, T., \& Finnegan, D. "Lidar measurement of snow depth: A review". Journal of Glaciology, 59(215) (2013): 467-479. doi:10.3189/2013JoG12J154

Denoth, A. "An electronic device for long-term snow wetness recording." Annals of Glaciology 19 (1994): 104-106.

Derksen, C. "The contribution of AMSR-E 18.7 and 10.7 GHz measurements to improved boreal forest snow water equivalent retrievals." Remote Sensing of

Environment 112, no. 5 (2008): 2701-2710.

Derksen, C., P. Toose, A. Rees, L. Wang, M. English, A. Walker, and M. Sturm. "Development of a tundra-specific snow water equivalent retrieval algorithm for satellite passive microwave data." Remote Sensing of Environment 114, no. 8 (2010): 1699-1709.

Derksen, C., A. Walker, and B. Goodison. "A comparison of 18 winter seasons of in situ and passive microwave-derived snow water equivalent estimates in Western Canada." Remote Sensing of Environment 88:271-282 (2003).

Derksen, C., A. E. Walker, B. E. Goodison, and J. W. Strapp. 2005. "Integrating in situ and multiscale passive microwave data for estimation of subgrid scale snow water equivalent distribution and variability." IEEE Transactions on Geoscience and Remote Sensing 43:960-972.

Déry, S. J., and R. D. Brown. "Recent Northern Hemisphere snow cover extent trends and implications for the snow-albedo feedback." Geophysical Research Letters 34, no. 22 (2007).

Dickerson-Lange, S. E., J. A. Lutz, K. A. Martin, M. S. Raleigh, R. Gersonde, and J. D. Lundquist. "Evaluating observational methods to quantify snow duration under diverse forest canopies." Water Resources Research 51, no. 2 (2015): 1203-1224.

Domine, F., Cincinelli, A., Bonnaud, E., Martellini, T., and Picaud, S. "Adsorption of Phenanthrene on Natural Snow.” Environ. Sci. Technol. 41, 6033-6038, 2007.

Dong, J., J. Walker, and P. Houser, "Factors affecting remotely sensed snow water equivalent uncertainty." Remote Senseing of the Environment 97 (2005): 68 82. doi: 10.1016/j.rse.2005.04.010.

Douville, H., J.-F. Royer, and J.-F. Mahfouf, "A new snow parameterization for the Me' te' o-France climate model. Part I: Validation in stand-alone experiments". Climate Dyn, 12(1995): 21-35.

Dozier, J., R. O. Green, A. W. Nolin, and T. H. Painter. "Interpretation of snow properties from imaging spectrometry." Remote Sensing of Environment 113 (2009): S25S37.

Drobot, S. D., and M. R. Anderson. "An improved method for determining snowmelt onset dates over Arctic sea ice using scanning multichannel microwave radiometer and Special Sensor Microwave/Imager data." Journal of Geophysical Research: Atmospheres 106, no. D20 (2001): 24033-24049. 
Du, J., J. Shi, and H. Rott. "Comparison between a multi-scattering and multi-layer snow scattering model and its parameterized snow backscattering model." Remote Sensing of Environment 114, no. 5 (2010): 1089-1098.

Dumont, M., O. Brissaud, G. Picard, B. Schmitt, J.-C. Gallet, and Y. Arnaud. "Highaccuracy measurements of snow Bidirectional Reflectance Distribution Function at visible and NIR wavelengths-comparison with modelling results". Atmospheric Chemistry and Physics 10, no. 5 (2010): 2507-2520.

Dunkle, R. V., and J. T. Bevans. "An approximate analysis of the solar reflectance and transmittance of a snow cover." Journal of Meteorology 13, no. 2 (1956): 212216.

Durand, M., E.J. Kim, S.A. Margulis, and N.P. Molotch, “A first-order characterization of errors from neglecting stratigraphy in forward and inverse passive microwave modeling of snow." IEEE Transactions of Geoscience and Remote Sensing, 8(4), (2011) 730 - 734, doi: 10.1109/LGRS.2011.2105243.

Durand, M., and D. Liu. "The need for prior information in characterizing snow water equivalent from microwave brightness temperatures." Remote Sensing of Environment 126 (2012): 248-257.

Ek, M. B., K. E. Mitchell, Y. Lin, E. Rogers, P. Grunmann, V. Koren, G. Gayno, and J. D. Tarpley. "Implementation of Noah land surface model advances in the National Centers for Environmental Prediction operational mesoscale Eta model." Journal of Geophysical Research: Atmospheres 108, no. D22 (2003).

Elder, K., J. Dozier, and J. Michaelsen. "Snow accumulation and distribution in an alpine watershed." Water Resources Research 27, no. 7 (1991): 1541-1552.

Estilow, T. W., A. H. Young, and D. A. Robinson. "A long-term Northern Hemisphere snow cover extent data record for climate studies and monitoring." Earth System Science Data 7, no. 1 (2015): 137.

Eylander, J., "Land Information System (LIS) Development Plan, FY13-FY17”. Engineer Research and Development Center/Cold Regions Research and Engineering Laboratory, ERDC/CRREL Technical Note, TN-13-2. October 2013.

Flanner, M. G., and C. S. Zender. "Linking snowpack microphysics and albedo evolution." Journal of Geophysical Research: Atmospheres 111, no. D12 (2006).

Flanner, M. G., C. S. Zender, J. T. Randerson, and P. J. Rasch. "Present-day climate forcing and response from black carbon in snow." Journal of Geophysical Research: Atmospheres 112, no. D11 (2007).

Flin, F., Brzoska, J.-B., Lesaffre, B., Col' eou, C., and Pieritz, R. A., "Full threedimensional modelling of curvature-dependent snow metamorphism: first results and comparison with experimental tomographic data." J. Phys. D. Appl.Phys. 36(2003): 1-6.

Foster, J. L., D. K. Hall, A. T. C. Chang, A. Rango, W. Wergin, and E. Erbe. "Effects of snow crystal shape on the scattering of passive microwave radiation". IEEE Transactions on Geoscience and Remote Sensing 37(1999):1165-1168. 
Foster, J., C. Sun, J. Walker, R. Kelly, A. Chang, J. Dong and H. Powell, “Quantifying the uncertainty in passive microwave snow water equivalent observations", Remote Sensing of the Environment 94 (2005): 187 - 203. doi: 10.1016/j.rse.2004.09.012.

Foster, J. L., D. K. Hall, J. B. Eylander, G. A. Riggs, S. V. Nghiem, M. Tedesco, E. Kim, P. Montesano, R. Kelly, K. Casey and B. Choudhury. "A blended global snow product using visible, passive microwave and scatterometer satellite data." International Journal of Remote Sensing 32, no. 5 (2011): 1371-1395.

Frei, A., M. Tedesco, S. Lee, J. Foster, D. K. Hall, R. Kelly, and D. A. Robinson. "A review of global satellite-derived snow products." Advances in Space Research 50, no. 8 (2012): 1007-1029.

Gafurov, A., and A. Bárdossy. "Snow cover data derived from MODIS for water balance applications." Hydrology and Earth System Sciences Discussions 6, no. 1 (2009).

Gallet, J-C., F. Domine, C. S. Zender, and G. Picard. "Measurement of the specific surface area of snow using infrared reflectance in an integrating sphere at 1310 and 1550 nm." The Cryosphere 3 (2) (2009): 167-182.

Gelfan, A. N., J. W. Pomeroy, and L. S. Kuchment. "Modeling forest cover influences on snow accumulation, sublimation, and melt." Journal of Hydrometeorology 5, no. 5 (2004): 785-803.

Gergely, M., Schneebeli, M., \& Roth, K. "First experiments to determine snow density from diffuse near-infrared transmittance." Cold Regions Science and Technology 64(2), (2010) 81-86.

Gergely, M., F. Wolfsperger, and M. Schneebeli. "Simulation and validation of the infrasnow: An instrument to measure snow optically equivalent grain size." IEEE Transactions on Geoscience and Remote Sensing 52, no. 7 (2014): 4236-4247.

Grayson, R. B., G. Blöschl, A. W. Western, and T. A. McMahon. "Advances in the use of observed spatial patterns of catchment hydrological response." Advances in Water Resources 25, no. 8-12 (2002): 1313-1334.

Green, R. O., Dozier, J., Roberts, D. A., \& Painter, T. H. "Spectral snow reflectance models for grain size and liquid water fraction in melting snow for the solar reflected spectrum.” Annals of Glaciology 34 (2002): 71-73.

Grenfell, T. C., S. J. Doherty, A. D. Clarke, and S. G. Warren. "Light absorption from particulate impurities in snow and ice determined by spectrophotometric analysis of filters." Applied optics 50, no. 14 (2011): 2037-2048.

Grenfell, T. C., and S. G. Warren. "Representation of a nonspherical ice particle by a collection of independent spheres for scattering and absorption of radiation." Journal of Geophysical Research: Atmospheres 104, no. D24 (1999): 31697-31709. 
Grenfell, T. C., S. P. Neshyba, and S. G. Warren. "Representation of a nonspherical ice particle by a collection of independent spheres for scattering and absorption of radiation: 3. Hollow columns and plates." Journal of Geophysical Research: Atmospheres 110, no. D17 (2005).

Hagenmuller, P., T. C. Theile, and M. Schneebeli. "Numerical simulation of microstructural damage and tensile strength of snow." Geophysical Research Letters 41, no. 1 (2014): 86-89.

Hall, D. K., A. T. C. Chang, and J. L. Foster. "Detection of the Depth-Hoar Layer in the Snow-Pack of the Arctic Coastal-Plain of Alaska, USA, Using Satellite Data." Journal of Glaciology 32:87-94 (1986).

Hall, D. K., and G. A. Riggs. "Accuracy assessment of the MODIS snow products." Hydrological processes 21, no. 12 (2007): 1534-1547.

Hall, D. K., Nghiem, S. V., Schaaf, C. B., DiGirolamo, N. E., and Neumann, G. "Evaluation of surface and near-surface melt characteristics on the Greenland ice sheet using MODIS and QuikSCAT data." Journal of Geophysical Research: Earth Surface 114(F4) (2009).

Hall, D., K., J. C. Comiso, N. E. DiGirolamo, C. A. Shuman, J. E. Box, and L. S. Koenig. "Variability in the surface temperature and melt extent of the Greenland ice sheet from MODIS." Geophysical Research Letters 40, no. 10 (2013): 2114-2120.

Hall, D. K., C. J. Crawford, N. E. DiGirolamo, G. A. Riggs, and J. L. Foster. "Detection of earlier snowmelt in the Wind River Range, Wyoming, using Landsat imagery, 1972-2013." Remote Sensing of Environment 162 (2015): 45-54.

Hall, S. J. “AFGWC Snow Analysis Model”. AFGWC/TN-86/o01. Offutt, NE: US Air Force Air Weather Service. February 1986.

Hallikainen, M. T., F. T. Ulaby, and M. Abdelrazik. "Dielectric-Properties of Snow in the 3 to 37 Ghz Range." IEEE Transactions on Antennas and Propagation 34 (1986): 1329-1340.

Hancock, S., R. Baxter, J. Evans, and B. Huntley. "Evaluating global snow water equivalent products for testing land surface models." Remote Sensing of Environment 128 (2013): 107-117.

Hawley, R. L., and E. M. Morris. "Borehole optical stratigraphy and neutron-scattering density measurements at Summit, Greenland." Journal of Glaciology 52, no. 179 (2006): 491-496.

Heggli, M., B. Köchle, M. Matzl, B. R. Pinzer, F. Riche, S. Steiner, D. Steinfeld, and M. Schneebeli. "Measuring snow in 3-D using X-ray tomography: assessment of visualization techniques." Annals of Glaciology 52, no. 58 (2011): 231-236.

Helfrich, S. R., D. McNamara, B. H. Ramsay, T. Baldwin, and T. Kasheta. "Enhancements to, and forthcoming developments in the Interactive Multisensor Snow and Ice Mapping System (IMS)." Hydrological processes 21, no. 12 (2007): 1576-1586. 
Hiemstra, C. A., G. E. Liston, and W. A. Reiners. "Observing, modelling, and validating snow redistribution by wind in a Wyoming upper tree line landscape." Ecological Modelling 197, no. 1-2 (2006): 35-51.

Hiemstra, C.A., G. E. Liston, and W. A. Reiners. "Snow redistribution by wind and interactions with vegetation at upper treeline in the Medicine Bow Mountains, Wyoming, USA." Arctic, Antarctic, and Alpine Research (2002): 262-273.

Huffman, G.J., R.F. Adler, D.T. Bolvin, G. Gu, E.J. Nelkin, K.P. Bowman, Y. Hong, E.F. Stocker, D.B. Wolff, "The TRMM Multi-satellite Precipitation Analysis: QuasiGlobal, Multi-Year, Combined-Sensor Precipitation Estimates at Fine Scale”. J. Hydrometeor 8, 38-55 (2007).

Huffman, G. J., D. T. Bolvin, D. Braithwaite, K. Hsu, R. Joyce, and P. Xie. "NASA Global Precipitation Measurement (GPM) Integrated Multi-satellitE Retrievals for GPM (IMERG)". Algorithm Theoretical Basis Doc., version 5.2. (2018) 30 pp. https://pmm.nasa.gov/sites/default/files/document_files/IMERG_ATBD_V5.2_0.pdf

Holmgren, J., M. Sturm, N. E. Yankielun, and G. Koh. "Extensive measurements of snow depth using FM-CW radar." Cold Regions Science and Technology 27, no. 1 (1998): 17-30.

Howell, S. E., Tivy, A., Yackel, J. J., \& Scharien, R. K. “Application of a SeaWinds/QuikSCAT sea ice melt algorithm for assessing melt dynamics in the Canadian Arctic Archipelago". Journal of Geophysical Research: Oceans, 111(C7) (2006).

Johnson, J. and M. Schneebeli, "Characterizing the microstructural and micromechanical properties of snow”. Cold Regions Science and Technology, Volume 30, Issues 13 (1999): 91-100.

Jordan, R. "A one-dimensional temperature model for a snow cover: Technical documentation for SNTHERM. 89”. CRREL-SR-91-16. Hanover, NH: Cold Regions Research and Engineering Laboratory (1991).

Josberger, E. G., and N. M. Mognard. "A passive microwave snow depth algorithm with a proxy for snow metamorphism”. Hydrological Processes 16 (2002):1557-1568.

Kaempfer T. U. and Schneebeli, M. "Observation of isothermal metamorphism of new snow and interpretation as a sintering process." J. Geophys. Res. 112, D24101, (2008). doi:10.1029/2007JD009047.

Kaempfer, T., and M. Plapp, “Phase-field modeling of dry snow metamorphism.” Physical Review E 79, Issue 3, (2009) doi: 10.1103/PhysRevE.79.031502.

Kaempfer, T.U., M. A. Hopkins, and D. K. Perovich. "A three-dimensional microstructurebased photon-tracking model of radiative transfer in snow." Journal of Geophysical Research: Atmospheres 112, no. D24 (2007).

Kapil, J. C., P. Datt, A. Kumar, K. Singh, V. Kumar, and P. K. "Satyawali. Multi-sensor couplers and waveguides for efficient detection of acoustic emission behavior of snow". Cold Regions Science and Technology 101 (2014): 1-13. 
Kelly, R. "The AMSR-E snow depth algorithm: Description and initial results." Journal of the Remote Sensing Society of Japan 29, no. 1 (2009): 307-317.

Kopp, T. J. and Kiess, R. B. "The air force global weather central snow analysis model" Amer. Meteor. Soc. 15th Conf. on Weather Analysis and Forecasting, Norfolk, VA (1996): pp 220-222.

Koster, R., and Suarez, M. "Energy and Water Balance Calculations in the Mosaic LSM", NASA Tech. Memo. 104606, Vol. 9, 1996.

Koster, R.D., Suarez, M. J., Ducharne, A., Stieglitz, M., and Kumar, P. “A catchmentbased approach to modelling land surface processes in a general circulation model: 1. Model structure.” J. Geophys. Res. 105 (2000): 24809-24822. doi.10.1029/2000JD900327.

Kowalczyk, E., Stevens, L., Law, R., Dix, M., Wang, Y., Harman, I., Haynes, K., Srbinovsky, J., Pak, B. and Ziehn, T. "The land surface model component of ACCESS: Description and impact on the simulated surface climatology." Australian Meteorological and Oceanographic Journal 663, 1, (2013): 65-82.

Krol, Q., and H. Löwe. "Relating optical and microwave grain metrics of snow: the relevance of grain shape." The Cryosphere 10 (2016): 2847-2863.

Kumar, S. V., C. D. Peters-Lidard, Y. Tian, P. R. Houser, J. Geiger, S. Olden, L. Lighty, J. Eastman, B. Doty, P. Dirmeyer, J. Adams, K. Mitchell, E. Wood, J. Sheffield, "Land information system: An interoperable framework for high resolution land surface modeling." Environmental modelling \& software 21, no. 10 (2006): 1402-1415.

Kumar, S.V., R.H. Reichle, C.D. Peters-Lidard, R.D. Koster, X. Zhan, W.T. Crow, J.B. Eylander, and P. R. Houser. "A Land Surface Data Assimilation Framework using the Land Information System: Description and Applications”. Advances in Water Resources 31 (2008): 1419-1432. doi:10.1016/j.adwwatres.2008.01.013

Kumar, S.V., J. Dong, C.D. Peters-Lidard, D.M. Mocko, and B. Gomez, "Role of forcing uncertainty and background model error characterization in snow data assimilation”. Hydrol. Earth Syst. Sci. 21, (2017): 2637-2647. doi:10.5194/hess21-2637-2017.

Kunzi, K. F., S. Patil, and H. Rott. "Snow-cover parameters retrieved from Nimbus-7 scanning multichannel microwave radiometer (SMMR) data." IEEE Transactions on Geoscience and Remote Sensing 4 (1982): 452-467.

Kwon, Y., A. M. Toure, Z. Yang, M. Rodell, and G. Picard. "Error characterization of coupled land surface-radiative transfer models for snow microwave radiance assimilation." IEEE Transactions on Geoscience and Remote Sensing 53, no. 9 (2015): 5247-5268.

Langlois, A., A. Royer, B. Montpetit, G. Picard, L. Brucker, L. Arnaud, P. Harvey-Collard, M. Fily, and K. Goïta. "On the relationship between snow grain morphology and in-situ near infrared calibrated reflectance photographs". Cold Regions Science and Technology 61, no. 1 (2010): 34-42. 
Larson, K. M., E. D. Gutmann, V. U. Zavorotny, J. J. Braun, M. W. Williams, and F. G. Nievinski. "Can we measure snow depth with GPS receivers?" Geophysical Research Letters 36, no. 17 (2009).

Legagneux, L., Cabanes, A., and Domine, F. "Measurement of the Specific Surface Area of 176 Snow Samples Using Methane Adsorption at 77 K." J. Geophys. Res. 107(D17), 4335. doi:10.1029/2001JDoo1016, 2002.

Leinss, S., G. Parrella, and I. Hajnsek. "Snow Height Determination by Polarimetric Phase Differences in X-Band SAR Data." Selected Topics in IEEE Journal of Applied Earth Observations and Remote Sensing 7(9): 3794-3810. (2014).

Lemmetyinen, J., J. Pulliainen, A. Rees, A. Kontu, Y. Qiu, and C. Derksen. "Multiple-layer adaptation of HUT snow emission model: Comparison with experimental data." IEEE Transactions on Geoscience and Remote Sensing 48, no. 7 (2010): 2781-2794.

Leroux, C., J. Deuzé, P. Goloub, C. Sergent, and M. Fily. "Ground measurements of the polarized bidirectional reflectance of snow in the near-infrared spectral domain: Comparisons with model results." Journal of Geophysical Research: Atmospheres 103, no. D16 (1998): 19721-19731.

Li, L., and J. W. Pomeroy. "Estimates of threshold wind speeds for snow transport using meteorological data." Journal of Applied Meteorology 36, no. 3 (1997): 205-213.

Link, T. E., \& Marks, D. "Point simulation of seasonal snow cover dynamics beneath boreal forest canopies." Journal of Geophysical Research 104, (1999): 2784127857 .

Link, T. E., D. Marks, and J. P. Hardy. "A deterministic method to characterize canopy radiative transfer properties." Hydrological processes 18, no. 18 (2004): 35833594 .

Liston, G. E. "Interrelationships among snow distribution, snowmelt, and snow cover depletion: Implications for atmospheric, hydrologic, and ecologic modeling." Journal of applied meteorology 38, no. 10 (1999): 1474-1487.

Liston, G. E., "Representing subgrid snow cover heterogeneities in regional and global models". J. Climate 17(6), (2004): 1381-1397.

Liston, G. E., and K. Elder. "A distributed snow-evolution modeling system (SnowModel)." Journal of Hydrometeorology 7, no. 6 (2006): 1259-1276.

Liston, G. E., and C. A. Hiemstra. "A simple data assimilation system for complex snow distributions (SnowAssim)." Journal of Hydrometeorology 9, no. 5 (2008): 9891004 .

Liston, G. E., and C. A. Hiemstra, "The changing cryosphere: Pan-Arctic snow trends (1979-2009)”. J. Climate 24 (2011): 5691-5712.

Liston, G. E., and M. Sturm. "A snow-transport model for complex terrain." Journal of Glaciology 44, no. 148 (1998): 498-516. 
Liston, G. E., and M. Sturm. "Winter precipitation patterns in arctic Alaska determined from a blowing-snow model and snow-depth observations." Journal of Hydrometeorology 3, no. 6 (2002): 646-659.

Liston, G. E., and M. Sturm. "The role of winter sublimation in the Arctic moisture budget." Hydrology Research 35, no. 4-5 (2004): 325-334.

Liston, G. E., R. B. Haehnel, M. Sturm, C. A. Hiemstra, S. Berezovskaya, and R. D. Tabler. "Simulating complex snow distributions in windy environments using SnowTran3D." Journal of Glaciology 53, no. 181 (2007): 241-256.

Liston, G. E., C. A. Hiemstra, K. Elder, and D. W. Cline, "Mesocell Study Area Snow Distributions for the Cold Land Processes Experiment (CLPX)". $J$ Hydrometeorology 9: (2008): 957-976.

Long, D. G., and M. J. Brodzik. "Optimum image formation for spaceborne microwave radiometer products." IEEE Transactions on Geoscience and Remote Sensing 54, no. 5 (2016): 2763-2779.

Lomonaco, R., Chen, S., \& Baker, I. "Characterization of Porous Snow with SEM and Micro CT”. Microscopy and Microanalysis, 15(S2), (2009): 1110-1111. doi:10.1017/S1431927609093313

Luce, C. H., D. G. Tarboton, and K. R. Cooley. "Sub-grid parameterization of snow distribution for an energy and mass balance snow cover model." Hydrological Processes 13, no. 12 (1999): 1921-1933.

Lum, C.F., H.T. Ewe, F. Xin, L. Jun Jiang, and H. T. Chuah. "An analysis of scattering from snow with relaxed hierarchical equivalent source algorithm.” Geoscience and Remote Sensing Symposium (IGARSS) 2017 IEEE International, (2017): pp. 1434-1437.

Lundberg, A., N. Granlund, and D. Gustafsson. "Towards automated 'Ground truth'snow measurements-A review of operational and new measurement methods for Sweden, Norway, and Finland." Hydrological Processes 24, no. 14 (2010): 19551970.

Lundquist, J. D., S. E. Dickerson-Lange, J.A. Lutz, and N. C. Cristea. "Lower forest density enhances snow retention in regions with warmer winters: A global framework developed from plot-scale observations and modeling." Water Resources Research 49, no. 10 (2013): 6356-6370.

Macander, M. J., C. S. Swingley, K. Joly, and M. K. Raynolds. "Landsat-based snow persistence map for northwest Alaska." Remote Sensing of Environment 163 (2015): 23-31.

Mandl, D., G. Crum, V. Ly, M. Handy, K. F. Huemmrich, L. Ong, B. Holt, and R. Maharaja. "Hyperspectral Cubesat constellation for natural hazard response (follow-on)." $3 \mathrm{O}^{\text {th }}$ Annual AIAA/USU Conference on Small Satellites, vol. SSC16XII-02, (2016).

Marks, D., and A. Winstral. "Comparison of snow deposition, the snow cover energy balance, and snowmelt at two sites in a semiarid mountain basin." Journal of Hydrometeorology 2, no. 3 (2001): 213-227. 
Markus, T., J. C. Stroeve, and J. Miller. "Recent changes in Arctic sea ice melt onset, freezeup, and melt season length." Journal of Geophysical Research: Oceans 114, no. C12 (2009).

Markus, T., D.C. Powell, J.R. Wang, "Sensitivity of passive microwave snow depth retrievals to weather effects and snow evolution." IEEE Transactions on Geoscience and Remote Sensing 44 (1) (2006): 68-77.

Marshall, H., and G. Koh. "FMCW radars for snow research." Cold Regions Science and Technology 52, no. 2 (2008): 118-131.

Marshall, H.P. and J. Johnson, "Accurate inversion of high-resolution snow penetrometer signals for microstructural and micromechanical properties". Journal of Geophysical Research - Earth Surface 114(Fo4016) (2009). doi: 10.1029/2009JFo01269.

Marshall, H. P., Koh, G., and Forster, R. "Ground-based FMCW radar measurements in wet and dry snowpacks, Colorado, U.S.A. - An analysis and summary of the 2002-03 NASA CLPX data”. Hydrologic Processes, 18, (2004): 3609-3622.

Marshall, H., G. Koh, M. Sturm, J. Johnson, M. Demuth, C. Landry, J. Deems, and A. Gleason, "Spatial variability of the snowpack: Experiences with measurements at a wide range of length scales with several different high precision instruments", International Snow Science Workshop Proceedings, Telluride, CO. October 2006.

Massom, R. A., H. Eicken, C. Hass, M. O. Jeffries, M. R. Drinkwater, M. Sturm, A. P. Worby, X. Wu, V. Lytle, S. Ushio, K. Morris, P. Reid, S. Warren, I. Allison. "Snow on Antarctic sea ice." Reviews of Geophysics 39, no. 3 (2001): 413-445.

Matzl, M., and M. Schneebeli. "Measuring specific surface area of snow by near-infrared photography." Journal of Glaciology 52, no. 179 (2006): 558-564.

Matzl, M., and M. Schneebeli. "Stereological measurement of the specific surface area of seasonal snow types: Comparison to other methods, and implications for mmscale vertical profiling." Cold Regions Science and Technology 64, no. 1 (2010): 1-8.

Mätzler, C. "Applications of the interaction of microwaves with the natural snow cover." Remote sensing reviews 2, no. 2 (1987): 259-387.

McCreight, J. L., and E. E. Small. "Modeling bulk density and snow water equivalent using daily snow depth observations." The Cryosphere 8, no. 2 (2014): 521.

McCreight, J. L., E. E. Small, and K. M. Larson. "Snow depth, density, and SWE estimates derived from GPS reflection data: Validation in the western US." Water Resources Research 50, no. 8 (2014): 6892-6909.

McGrath, D., W. Colgan, N. Bayou, A. Muto, and K. Steffen. "Recent warming at Summit, Greenland: Global context and implications." Geophysical Research Letters 40 (10) (2013): 2091-2096.

Mellor, M. A review of basic snow mechanics. US Army Cold Regions Research and Engineering Laboratory, 1974. 
Mishchenko, M. I., J.M. Dlugach, E. G. Yanovitskij, and N. T. Zakharova. "Bidirectional reflectance of flat, optically thick particulate layers: an efficient radiative transfer solution and applications to snow and soil surfaces." Journal of Quantitative Spectroscopy and Radiative Transfer 63, no. 2-6 (1999): 409-432.

Moeser, D., M. Stähli, and T. Jonas. "Improved snow interception modeling using canopy parameters derived from airborne LiDAR data." Water Resources Research 51, no. 7 (2015): 5041-5059.

Moller, D., K. M. Andreadis, K. J. Bormann, S. Hensley, and T. H. Painter. "Mapping Snow Depth from Ka-Band Interferometry: Proof of Concept and Comparison with Scanning Lidar Retrievals." IEEE Geoscience and Remote Sensing Letters 14, no. 6 (2017): 886-890.

Molotch, N. P., and R. C. Bales. "SNOTEL representativeness in the Rio Grande headwaters on the basis of physiographics and remotely sensed snow cover persistence." Hydrological Processes 20, no. 4 (2006): 723-739.

Montesi, J., K. Elder, R. A. Schmidt, and R. E. Davis. "Sublimation of intercepted snow within a subalpine forest canopy at two elevations." Journal of Hydrometeorology 5, no. 5 (2004): 763-773.

Moran, K. P., B. E. Martner, M. J. Post, R. A. Kropfli, D. C. Welsh, and K. B. Widener. "An unattended cloud-profiling radar for use in climate research." Bulletin of the American Meteorological Society 79, no. 3 (1998): 443-455.

Morris, E. M., and J. D. Cooper. "Density measurements in ice boreholes using neutron scattering." Journal of Glaciology 49, no. 167 (2003): 599-604.

Musselman, K. N., N. P. Molotch, and P. D. Brooks. "Effects of vegetation on snow accumulation and ablation in a mid-latitude sub-alpine forest." Hydrological processes 22, no. 15 (2008): 2767-2776.

Nagler, T., H. Rott, P. Malcher, and F. Müller. "Assimilation of meteorological and remote sensing data for snowmelt runoff forecasting." Remote Sensing of Environment 112, no. 4 (2008): 1408-1420.

Narayan, U., and V. Lakshmi. "A simple method for spatial disaggregation of radiometer derived soil moisture using higher resolution radar observations." In Geoscience and Remote Sensing Symposium, IGARSS. Proceedings. IEEE International, vol. $1,(2005)$ pp. 5 .

Narayan, U., and V. Lakshmi. "Characterizing subpixel variability of low resolution radiometer derived soil moisture using high resolution radar data." Water Resources Research 44, no. 6 (2008).

National Academies of Sciences, Engineering, and Medicine. "Thriving on Our Changing Planet: A Decadal Strategy for Earth Observation from Space”. Washington, DC: The National Academies Press. 2018. doi.org/10.17226/24938.

Neshyba, S. P., T. C. Grenfell, and S. G. Warren. "Representation of a nonspherical ice particle by a collection of independent spheres for scattering and absorption of radiation: 2. Hexagonal columns and plates." Journal of Geophysical Research: Atmospheres 108, no. D15 (2003). 
Nghiem, S. V., D. K. Hall, T. L. Mote, M. Tedesco, M. R. Albert, K. Keegan, C. A. Shuman, N. E. DiGirolamo, and G. Neumann. "The extreme melt across the Greenland ice sheet in 2012." Geophysical Research Letters 39, no. 20 (2012).

Nicodemus, F. E. (1970). Reflectance nomenclature and directional reflectance and emissivity. Applied Optics, 9(6), 1474-1475.

Nicodemus, F. E., J. Rchmond, J. Hsia, I. Ginsberg, and T. Limperis. (1977). Geometrical considerations and nomenclature for reflectance (Vol. 160). US Department of Commerce, National Bureau of Standards.

Niu, G., and Z. Yang. "Effects of vegetation canopy processes on snow surface energy and mass balances." Journal of Geophysical Research: Atmospheres 109, no. D23 (2004).

Niu, G., Z. Yang, K. Mitchell, F. Chen, M. Ek, M. Barlage, A. Kumar, K. Manning, D. Niyogi, E. Rosero, M. Tewari, and Y. Xia. "The community Noah land surface model with multiparameterization options (Noah-MP): 1. Model description and evaluation with local-scale measurements.” Journal of Geophysical Research 116 (2011). doi:10.1029/2010JD015139.

Nolan, M., C. F. Larsen, and M. Sturm. "Mapping snow-depth from manned-aircraft on landscape scales at centimeter resolution using Structure-from-Motion photogrammetry." Cryosphere Discussions 9, no. 1 (2015).

Nolin, A. W. "Recent advances in remote sensing of seasonal snow." Journal of Glaciology 56, no. 200 (2010): 1141-1150.

Nolin, A. W., and J. Dozier. "A hyperspectral method for remotely sensing the grain size of snow." Remote sensing of Environment 74, no. 2 (2000): 207-216.

Oleson, K. W., D.M. Lawrence, B. Gordon, M.G. Flanner, E. Kluzek, J. Peter, S. Levis, S. Swenson, P. Thorton, et al. "Technical description of version 4.0 of the Community Land Model (CLM)." NCAR Technical Note, NCAR/TN-478+STR (2010).

Painter, T. H., N. P. Molotch, M. Cassidy, M. Flanner, and K. Steffen. "Contact spectroscopy for determination of stratigraphy of snow optical grain size." Journal of Glaciology 53, no. 180 (2007): 121-127.

Painter, T. H., \& Dozier, J. "Measurements of the hemispherical-directional reflectance of snow at fine spectral and angular resolution”. Journal of Geophysical Research: Atmospheres, 109(D18) (2004).

Painter, T. H., D. F. Berisford, J. W. Boardman, K. J. Bormann, J. S. Deems, F. Gehrke, A. Hedrick, M. Joyce, R. Laidlaw, D. Marks, C. Mattmann, B. McGurk, P. Ramirez, M. Richardson, S. M. Skiles, F. Seidel, A. Winstral. "The Airborne Snow Observatory: Fusion of scanning lidar, imaging spectrometer, and physicallybased modeling for mapping snow water equivalent and snow albedo." Remote Sensing of Environment 184 (2016): 139-152.

Painter, T. H., K. Rittger, C. McKenzie, P. Slaughter, R. E. Davis, and J. Dozier. "Retrieval of subpixel snow covered area, grain size, and albedo from MODIS." Remote Sensing of Environment 113, no. 4 (2009): 868-879. 
Perla, R., J. Dozier, and R. E. Davis. "Preparation of serial sections in dry snow specimens." Journal of Microscopy 142, no. 1 (1986): 111-114.

Peters-Lidard, C. D., P. R. Houser, Y. Tian, S. V. Kumar, J. Geiger, S. Olden, L. Lighty, B. Doty, P. Dirmeyer, J. Adams, K. Mitchell, E. Wood, J. Sheffield. "Highperformance Earth system modeling with NASA/GSFC's Land Information System." Innovations in Systems and Software Engineering 3, no. 3 (2007): 157165.

Picard, G., L. Brucker, A. Roy, F. Dupont, M. Fily, and A. Royer. "Simulation of the microwave emission of multi-layered snowpacks using the dense media radiative transfer theory: the DMRT-ML model." Geosci. Model Dev. Discuss 5 (2012): 3647-3694.

Picard, G., M. Sandells, and and H. Loewe. "SMRT: An active / passive microwave radiative transfer model for snow with multiple microstructure and scattering formulations (v1.o)." Geosci. Model Dev. Discuss. https://doi.org/10.5194/gmd2017-314, (2018).

Pielmeier, C., and M. Schneebeli. "Stratigraphy and changes in hardness of snow measured by hand, ramsonde and snow micro penetrometer: a comparison with planar sections." Cold Regions Science and Technology 37, no. 3 (2003): 393405 .

Polashenski, C. M., J. E. Dibb, M. G. Flanner, J. Y. Chen, Z. R. Courville, A. M. Lai, J. J. Schauer, M. M. Shafer, and M. Bergin. "Neither dust nor black carbon causing apparent albedo decline in Greenland's dry snow zone: Implications for MODIS C5 surface reflectance." Geophysical Research Letters 42, no. 21 (2015): 93199327.

Pomeroy, J., X. Fang, and C. Ellis. "Sensitivity of snowmelt hydrology in Marmot Creek, Alberta, to forest cover disturbance." Hydrological Processes 26, no. 12 (2012): 1891-1904.

Pulliainen, J. T., J. Grandell, and M. T. Hallikainen. "HUT snow emission model and its applicability to snow water equivalent retrieval." IEEE Transactions on Geoscience and Remote Sensing 37, no. 3 (1999): 1378-1390.

Qu, X., and A. Hall. "On the persistent spread in snow-albedo feedback." Climate Dynamics 42, no. 1-2 (2014): 69-81.

Räisänen, P., A. Kokhanovsky, G. Guyot, O. Jourdan, and T. Nousiainen. "Parameterization of single-scattering properties of snow". The Cryosphere 9, 3 (2015): 1277-1301.

Raleigh, M. S., and E. E. Small. "Snowpack density modeling is the primary source of uncertainty when mapping basin-wide SWE with lidar." Geophysical Research Letters 44, no. 8 (2017): 3700-3709.

Ramage, J., and K. A. Semmens. "SWEHydro Model and AMSR-E observations: an effective tool to reconstruct snowmelt runoff timing and magnitude." IAHS-AISH publication (2012): 367-370. 
Ramage, J. M., J. D. Apgar, R. A. McKenney, and W. Hanna. "Spatial variability of snowmelt timing from AMSR-E and SSM/I passive microwave sensors, Pelly River, Yukon Territory, Canada." Hydrological Processes 21, no. 12 (2007): 15481560 .

Rasmus, S., R. Lundell, and T. Saarinen. "Interactions between snow, canopy, and vegetation in a boreal coniferous forest." Plant Ecology \& Diversity 4, no. 1 (2011): 55-65.

Rasmussen, R. M., J. Vivekanandan, J. Cole, B. Myers, and C. Masters. "The estimation of snowfall rate using visibility." Journal of Applied Meteorology 38, no. 10 (1999): 1542-1563.

Rasmussen, R., B. Baker, J. Kochendorfer, T. Meyers, S. Landolt, A. P. Fischer, J. Black, J. Theriault, P. Kucera, D. Gochis, C. Smith, R. Nitu, M. Hall, K. Ikeda and E. Gutmann. "How well are we measuring snow: The NOAA/FAA/NCAR winter precipitation test bed." Bulletin of the American Meteorological Society 93, no. 6 (2012): 811-829.

Reichle, R. "Data Assimilation methods in Earth Sciences", Adv. Water Resour. 31, 14111418. doi.org/10.1016/j.advwatres.2008.01.001, 2008.

Reiweger, I., Mayer, K., Steiner, K., Dual, J., Schweizer, J., "Measuring and localizing acoustic emission events in snow prior to fracture". Cold Reg. Sci. Technol. 110 (2015): 160-169. doi:10.1016/j.coldregions.2014.12.002.

Rienecker, M., M. Suarez, R. Gelaro, R. Todling, J. Bacmeister, E. Liu, M. Bosilovich, S. Schubert, L. Takacs, G. Kim, S. Bloom, J. Chen, D. Collins, A. Conaty, A. Da Silva, W. Gu, J. Joiner, R. Koster, R. Lucchesi, A. Molod, T. Owens, S. Pawson, P. Pegion, C. Redder, R. Reichle, F, Robertson, A. Ruddick, M. Sienkiewicz, and J. Woollen. "MERRA: NASA's Modern-Era Retrospective Analysis for Research and Applications.” Journal of Climate 24 (2011): $3624-3648$.

Revuelto, J., J. I. López-Moreno, C. Azorin-Molina, and S. M. Vicente-Serrano. "Canopy influence on snow depth distribution in a pine stand determined from terrestrial laser data." Water Resources Research 51, no. 5 (2015): 3476-3489.

Rodell, M., P. R. Houser, U. E. A. Jambor, J. Gottschalck, K. Mitchell, C. J. Meng, K. Arsenault, B. Cosgrove, J. Radakovich, M. Bosilovich, J. Entin, J. Walker, D. Lohmann, and D. Toll. "The global land data assimilation system." Bulletin of the American Meteorological Society 85, no. 3 (2004): 381-394.

Rosenthal, W., J. Saleta, and J. Dozier. "Scanning electron microscopy of impurity structures in snow." Cold regions science and technology 47, no. 1-2 (2007): 8089 .

Rott, H., Cline, D., Duguay, C., Essery, R., Haas, C., Macelloni, G., Malnes, E., Pulliainen, J., Rebhan, H., \& Yueh, S. "CoReH2O - A Ku- and X-Band SAR mission for snow and ice monitoring." EUSAR 2008 Proceedings, Paper 5.2.2. 7th European Conference on Synthetic Aperture Radar, June 2-5, 2008. Friedrichshafen, Germany. 
Sandells, M., R. Essery, N. Rutter, L. Wake, L. Leppänen, and J. Lemmetyinen. "Microstructure representation of snow in coupled snowpack and microwave emission models." The Cryosphere 11, no. 1 (2017): 229.

Semmens, K. A., J. Ramage, A. Bartsch, and G. E. Liston. "Early snowmelt events: detection, distribution, and significance in a major sub-arctic watershed." Environmental Research Letters 8, no. 1 (2013): 014020.

Scambos, T. A., T. M. Haran, M. A. Fahnestock, T. H. Painter, and J. Bohlander. "MODISbased Mosaic of Antarctica (MOA) data sets: Continent-wide surface morphology and snow grain size." Remote Sensing of Environment 111, no. 2-3 (2007): 242257.

Schaaf, C. B, Gao, F, Strahler, A. H, Lucht, W, Li, X. W, Tsang, T, Strugnell, N. C, Zhang, X. Y, Jin, Y. F, Muller, J. P, Lewis, P, Barnsley, M, Hobson, P, Disney, M, Roberts, G, Dunderdale, M, Doll, C, D'entremont, R. P, Hu, B. X, Liang, S. L, Privette, J. L and Roy, D. "First operational BRDF, albedo nadir reflectance products from MODIS”. Remote Sensing of Environment, 83 (2002): 135-148.

Schmidt, R. A. "Sublimation of snow intercepted by an artificial conifer." Agricultural and Forest Meteorology 54, no. 1 (1991): 1-27.

Schmugge, T.J., W. P. Kustas, J. C. Ritchie, T. J. Jackson, and A. Rango. "Remote sensing in hydrology". Advances in water resources 25 (2002), no. 8-12: 1367-1385.

Schneebeli, M., Pielmeier, C., and Johnson, J. B. "Measuring snow microstructure and hardness using a high resolution penetrometer". Cold Regions Science and Technology, 30(1), (1999): 101-114.

Schneebeli, M., "Numerical simulation of elastic stress in the microstructure of snow". Annals of Glaciology 38, (2004): 339-342.

Scott, C.A., Bastiaanssen, W.G., Ahmad, M.D., "Mapping root zone soil moisture using remotely sensed optical imagery." Journal of Irrigation and Drainage Engineering 129(5) (2003): 326-335.

Shean, D. E., O. Alexandrov, Z. M. Moratto, B. E. Smith, I. R. Joughin, C. Porter, and P. Morin. "An automated, open-source pipeline for mass production of digital elevation models (DEMs) from very-high-resolution commercial stereo satellite imagery." ISPRS Journal of Photogrammetry and Remote Sensing 116 (2016): 101-117.

Sheppard, B. E., and P. I. Joe. "Performance of the precipitation occurrence sensor system as a precipitation gauge." Journal of Atmospheric and Oceanic Technology 25, no. 2 (2008): 196-212.

Sihvola, A. and M. Tiuri, "Snow Fork for Field Determination of the Density and Wetness Profiles of a Snow Pack," IEEE Transactions on Geoscience and Remote Sensing, GE-24 (5) (1986): 717-721. doi: 10.1109/TGRS.1986.289619

Slater, A. G., T. J. Bohn, J. L.McCreight, M. C. Serreze, and D. P. Lettenmaier, “A multimodel simulation of pan-Arctic hydrology” J.Geophys. Res. 112 (2007). doi:10.1029/2006JGoo0303. 
Srivastava, A. and J. Stroeve, "Onboard detection of snow, ice, clouds and other geophysical processes using kernel methods," in Proc. 12th Int. Conf. Machine Learning: Machine Learning Technologies for Autonomous Space Applications Workshop, Washington, DC. 21-24 August 2003.

Stamnes, K., S. Tsay, W. Wiscombe, and K. Jayaweera. "Numerically stable algorithm for discrete-ordinate-method radiative transfer in multiple scattering and emitting layered media." Applied Optics 27, no. 12 (1988): 2502-2509.

Stiles, W. H., and F. T. Ulaby. "Microwave remote sensing of snowpacks." National Aeronautics and Space Administration, Scientific and Technical Information Office. Vol. 3263 (1980).

Strack, J. E., G. E. Liston, and R. A. Pielke, Sr., "Modeling snow depth for improved simulation of snow-vegetation-atmosphere interactions". J. Hydrometeorology 5 (2004): 723-734.

Sturm, M. "Field techniques for snow observations on sea ice." Field Techniques for Sea Ice Research, pp. 25-47. Fairbanks: University of Alaska Press, 2009.

Sturm, M., K. Morris, and R. Massom. "The winter snow cover of the West Antarctic pack ice: its spatial and temporal variability”. Antarctic Sea Ice: Physical Processes, Interactions and Variability, American Geophysical Union, 1998.

Sturm, M., D. K. Perovich, and J. Holmgren. "Thermal conductivity and heat transfer through the snow on the ice of the Beaufort Sea." Journal of Geophysical Research: Oceans 107, no. C10 (2002).

Sturm, M., B. Taras, G.E. Liston, C. Derksen, T. Jonas, and J. Lea. "Estimating snow water equivalent using snow depth data and climate classes." Journal of Hydrometeorology 11, no. 6 (2010): 1380-1394.

Sturm, M., and A. M. Wagner, "Using repeated patterns in snow distribution modeling: An Arctic example", Water Resources Research 46, W12549, (2010). doi:10.1029/2010WRoo9434.

Sugiyama, S., H. Enomoto, S. Fujita, K. Fukui, F. Nakazawa, and P. Holmlund. "Dielectric permittivity of snow measured along the route traversed in the JapaneseSwedish Antarctic Expedition 2007/08”. Annals of Glaciology 51, no. 55 (2010): 9-15.

Takala, M., K. Luojus, J. Pulliainen, C. Derksen, J. Lemmetyinen, J. Kärnä, J. Koskinen, and B. Bojkov. "Estimating northern hemisphere snow water equivalent for climate research through assimilation of space-borne radiometer data and ground-based measurements." Remote Sensing of Environment 115, no. 12 (2011): 3517-3529.

Tedesco, M., E. J. Kim, D. Cline, T. Graf, T. Koike, R. Armstrong, M.J. Brodzik, and J. Hardy. "Comparison of local scale measured and modelled brightness temperatures and snow parameters from the CLPX 2003 by means of a dense medium radiative transfer theory model." Hydrological Processes 20, no. 4 (2006): 657-672. 
Tennant, C. J., A. A. Harpold, K. A. Lohse, S. E. Godsey, B. T. Crosby, L. G. Larsen, P. D. Brooks, R. W. Van Kirk, and N. F. Glenn. "Regional sensitivities of seasonal snowpack to elevation, aspect, and vegetation cover in western North America." Water Resources Research 53 (2017): 6908-6926. doi:10.1002/2016WR019374 .

Tinkham, W. T., A. MS Smith, H.P.Marshall, T. E. Link, M. J. Falkowski, and A. H. Winstral. "Quantifying spatial distribution of snow depth errors from LiDAR using Random Forest." Remote sensing of environment 141 (2014): 105-115.

U.S. Army. "Unified Land Operations." Army Doctrine Publication, ADP 3-0. Department of the Army. October 2011.

U.S. Army, "Combined Army Countermobility Operations. Army Technical Publication, ATP 3-90.8. Headquarters, Department of the Army. September 2014.

U.S. Army, "Intelligence Preparation of the Battlefield/Battlespace”, Army Technical Publication, ATP 2-01.3, Headquarters, Department of the Army. November 2014.

U.S. Army. "General Engineering”, Army Technical Publication, ATP 3-34.40, Headquarters, Department of the Army. February 2015.

U.S. Army. "Brigade Combat Team Intelligence Techniques", Army Technical Publication, ATP 2-19.4, Headquarters, Department of the Army. February 2015.

U.S. Army. "Field Artillery Target Acquisition”, Army Technical Publication, ATP 3-09.12, Headquarters, Department of the Army. July 2015.

U.S. Army. "Distributed Common Ground System - Army increment 2 (DCGS-A Inc 2)" Technical Report, U.S. Aberdeen Proving Ground, March 2016.

U.S. Army. "Mountain Warfare and Cold Weather Operations", Army Technical Publication, ATP 3-90.97, Headquarters, Department of the Army. April 2016.

U.S. Army. "Prevention of Heat and Cold Casualties", Training and Doctrine Command (TRADOC) Regulation 350-29, Headquarters, Department of Army. July 2016.

U.S. Army. "Army Weather Functional Activities”, Army Regulation, AR 5-25, Headquarters, Department of the Army, October 2016.

U.S. Army. "Geospatial Engineering”, Army Technical Publication, ATP 3-34.80, Headquarters, Department of the Army. February 2017.

U.S. Army. "Weather Support and Services for the U.S. Army", Army Regulation, AR 11510, Headquarters, Department of the Army, March 2017.

U.S. Army Corps of Engineers. “Flood-Runoff Analysis”, Engineer Manual 1110-2-1417, USACE Headquarters, Aug 1994. Accessed at https://www.publications.usace.army.mil/Portals/76/Publications/EngineerManuals/e $\underline{\text { m_1110-2-1417.pdf }}$ 
U.S. Army Corps of Engineers. "Runoff from Snowmelt”, Engineer Manual 1110-2-1406, USACE Headquarters, Mar 1998. Accessed at http://www.dtic.mil/dtic/tr/fulltext/u2/a402482.pdf

U.S. Army Corps of Engineers. "Sustainable Solutions to America's Water Resource Needs, Civil Works Strategic Plan 2014-2018”, USACE Headquarters, February 2015. Accessed at https://www.usace.army.mil/Portals/2/docs/civilworks/news/201418 cw_stratplan.pdf

U.S. Army Corps of Engineers. “FY18-22 USACE Campaign Plan”, USACE HQ, June 2017. Accessed at https://www.usace.army.mil/Portals/2/docs/FY18_22\%20UCP_171031.pdf

Upadhyay, A., S. K. Joshi, and C. Chandel. "Tensile strength of snow using centrifugal technique." Defense Science Journal 57, no. 6 (2007): 787.

Vander Jagt, B. J., M. T. Durand, S. A. Margulis, E. J. Kim, and N. P. Molotch. "The effect of spatial variability on the sensitivity of passive microwave measurements to snow water equivalent." Remote sensing of environment 136 (2013): 163-179.

Vuyovich, C. M., J. M. Jacobs, and S. F. Daly. "Comparison of passive microwave and modeled estimates of total watershed SWE in the continental United States." Water Resources Research 50, no. 11 (2014): 9088-9102.

Walker, A. E., and B. E. Goodison. "Discrimination of a wet snow cover using passive microwave satellite data." Annals of Glaciology 17 (1993): 307-311.

Wang, L., C. Derksen, and R. Brown. "Detection of pan-Arctic terrestrial snowmelt from QuikSCAT, 2000-2005." Remote Sensing of Environment 112, no. 10 (2008): 3794-3805.

Wang, J., Z. Chang, B. Jin, X. Zhang, and Y. Niu. "Investigation on Distribution Rule of Snowpack in Qilian Mountains Forest Region." Journal of Northwest Forestry University S1 (2001): 14-16.

Warren, S. G., and W. J. Wiscombe. "A model for the spectral albedo of snow. II: Snow containing atmospheric aerosols." Journal of the Atmospheric Sciences 37, no. 12 (1980): 2734-2745.

Warren, S. G. "Optical properties of snow." Reviews of Geophysics 20, no. 1 (1982): 6789.

Wiebe, H., G. Heygster, E. Zege, T. Aoki, and M. Hori. "Snow grain size retrieval SGSP from optical satellite data: Validation with ground measurements and detection of snow fall events". Remote sensing of environment 128 (2013): 11-20.

Wiesmann, A., and C. Mätzler. "Microwave emission model of layered snowpacks." Remote Sensing of Environment 70, no. 3 (1999): 307-316.

Wilhelms, F. "Measuring the conductivity and density of ice cores." Ber. Polarforsch 191 (1996): 1-224. 
Wiscombe, W. J., and S. G. Warren. "A model for the spectral albedo of snow. I: Pure snow." Journal of the Atmospheric Sciences 37, no. 12 (1980): 2712-2733.

Wrzesien, M., M. Durand, T. Pavelsky, I. Howat, S. Margulis and L. Huning. "Comparison of methods to estimate snow water equivalent at the mountain range scale: a case study of the California Sierra Nevada." Journal of Hydrometeorology 18 (2017): 1101-1119.

Xu, X., D. Liang, L. Tsang, K. M. Andreadis, E. G. Josberger, D. P. Lettenmaier, D. W. Cline, and S. H. Yueh. "Active remote sensing of snow using NMM3D/DMRT and comparison with CLPX II airborne data." IEEE Journal of selected topics in applied earth observations and remote sensing 3, no. 4 (2010): 689-697.

Yang, D., D. Kane, Z. Zhang, D. Legates, and B. Goodison. "Bias corrections of long-term (1973-2004) daily precipitation data over the northern regions." Geophysical Research Letters 32, no. 19 (2005).

Yang, Z., and G.Niu. "The versatile integrator of surface and atmosphere processes: Part 1. Model description." Global and Planetary Change 38, no. 1-2 (2003): 175-189.

Yueh, S. H., S. J. Dinardo, A. Akgiray, R. West, D. W. Cline, and K. Elder. "Airborne Kuband polarimetric radar remote sensing of terrestrial snow cover." IEEE Transactions on Geoscience and Remote Sensing 47, no. 10 (2009): 3347-3364. 


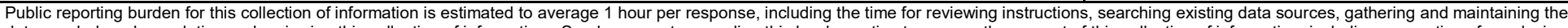

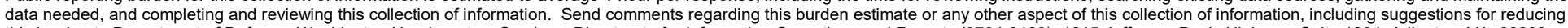

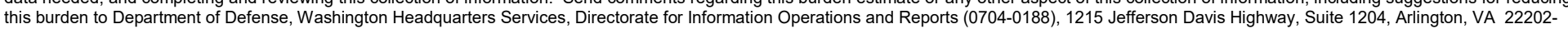

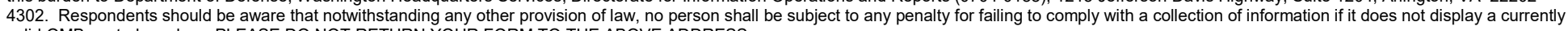
valid OMB control number. PLEASE DO NOT RETURN YOUR FORM TO THE ABOVE ADDRESS.
1. REPORT DATE (DD-MM-YYYY)
September 2018
2. REPORT TYPE
Final

4. TITLE AND SUBTITLE

3. DATES COVERED (From - To)

5a. CONTRACT NUMBER

Snow Strategic Science Plan

5b. GRANT NUMBER

5c. PROGRAM ELEMENT NUMBER

0603734A

6. AUTHOR(S)

5d. PROJECT NUMBER

Carrie M. Vuyovich, Elias J. Deeb, Christopher Polashenski, Zoe R. Courville,

Christopher A. Hiemstra, Anna M. Wagner, John B. Eylander, and Robert E. Davis

5e. TASK NUMBER

5f. WORK UNIT NUMBER

7. PERFORMING ORGANIZATION NAME(S) AND ADDRESS(ES)

8. PERFORMING ORGANIZATION REPORT NUMBER

Cold Regions Research and Engineering Laboratory

U.S. Army Engineer Research and Development Center

ERDC/CRREL TR-18-17

72 Lyme Road

Hanover, NH 03755

\section{SPONSORING / MONITORING AGENCY NAME(S) AND ADDRESS(ES)}

Headquarters, U.S. Army Corps of Engineers

441 G Street NW

Washington DC 20314-1000

10. SPONSOR/MONITOR'S ACRONYM(S)

HQUSACE

11. SPONSOR/MONITOR'S REPORT NUMBER(S)

\section{DISTRIBUTION / AVAILABILITY STATEMENT}

Approved for public release. Distribution is unlimited.

\section{SUPPLEMENTARY NOTES}

\section{ABSTRACT}

The U.S. Department of Defense (DoD) requires global terrestrial, atmospheric, and environmental awareness to support civil works and warfighting functions. Snow is a critical component of environmental awareness that can change rapidly and impacts DoD operations. Domestically, the U.S. Army Corps of Engineers (USACE), requires information on snow to develop accurate, timely hydrologic forecasts for water resource allocation, infrastructure design and construction, and flood forecasting. Abroad, DoD requires snow information for mission planning and operations.

The purpose of this document is to outline a plan for future research designed to improve snow characterization capabilities and meet identified data needs. A primary goal is to bring snow characterization efforts together in a system-based approach that will result in highly accurate global snow estimation.

The intent is to identify specific development pathways which can provide application-oriented information to take full advantage of the existing state of the science, and push the limits of research.

The technology gaps for snow operational support were placed into four broad categories for discussion. Short- through long-term plans for improvement were identified and specific goals towards this plan were set.

\section{SUBJECT TERMS}

Snow-Research, Research_-Planning, Cold regions

16. SECURITY CLASSIFICATION OF:

a. REPORT Unclassified

\section{b. ABSTRACT} Unclassified c. THIS PAGE

Unclassified

17

OFIMITATION
OF ABSTRACT
UU

18. NUMBER OF PAGES

91 19a. NAME OF RESPONSIBLE PERSON

19b. TELEPHONE NUMBER (include area code) 